\title{
Dual allegiance in organizational teams; A dual identification perspective
}

Citation for published version (APA):

Cuijpers, M. P. J. (2011). Dual allegiance in organizational teams; $A$ dual identification perspective. [Doctoral Thesis, Maastricht University]. Universitaire Pers Maastricht. https://doi.org/10.26481/dis.20111219mc

Document status and date:

Published: 01/01/2011

DOI:

10.26481/dis.20111219mc

Document Version:

Publisher's PDF, also known as Version of record

\section{Please check the document version of this publication:}

- A submitted manuscript is the version of the article upon submission and before peer-review. There can be important differences between the submitted version and the official published version of record.

People interested in the research are advised to contact the author for the final version of the publication, or visit the DOI to the publisher's website.

- The final author version and the galley proof are versions of the publication after peer review.

- The final published version features the final layout of the paper including the volume, issue and page numbers.

Link to publication

\footnotetext{
General rights rights.

- You may freely distribute the URL identifying the publication in the public portal. please follow below link for the End User Agreement:

www.umlib.nl/taverne-license

Take down policy

If you believe that this document breaches copyright please contact us at:

repository@maastrichtuniversity.nl

providing details and we will investigate your claim.
}

Copyright and moral rights for the publications made accessible in the public portal are retained by the authors and/or other copyright owners and it is a condition of accessing publications that users recognise and abide by the legal requirements associated with these

- Users may download and print one copy of any publication from the public portal for the purpose of private study or research.

- You may not further distribute the material or use it for any profit-making activity or commercial gain

If the publication is distributed under the terms of Article $25 \mathrm{fa}$ of the Dutch Copyright Act, indicated by the "Taverne" license above, 
DUAL ALLEGIANCE IN ORGANIZATIONAL TEAMS

A DUAL IDENTIFICATION PERSPECTIVE 
(C) Maarten Cuijpers, Maastricht 2011

ISBN 9789461591012

Omslagontwerp: Lonneke en Andy Bik

Druk: Datawyse |Universitaire Pers Maastricht 


\section{DUAL ALLEGIANCE IN ORGANIZATIONAL TEAMS}

A DUAL IDENTIFICATION PERSPECTIVE

\section{PROEFSCHRIFT}

Ter verkrijging van de graad van doctor aan de Universiteit Maastricht, op gezag van de Rector Magnificus, Prof. mr. G. P. M. F. Mols, volgens het besluit van het College van Decanen, in het openbaar te verdedigen op maandag 19 december 2011 om 16:00 uur door

Maarten Petrus Johannes Cuijpers

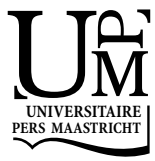


Promotor:

Prof. dr. M. G. Heijltjes

Copromotor:

Dr. U. Glunk

Beoordelingscommissie:

Prof. dr. R. A. Roe (Voorzitter)

Prof. dr. W. Gijselaers

Prof. dr. C. P. M. Wilderom (Universiteit Twente) 


\section{TABLE OF CONTENTS}

Chapter 1 Setting the Scene ............................................................................................... 7

Chapter 2 The Influence of Dual Allegiance on Management Team Conflict and Behavioral Integration.

Chapter 3 Management Team Members' Individual Perception of Dual Allegiance: An

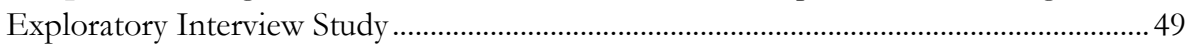

Chapter 4 Experiencing and Enacting Dual Allegiance in the Management Team .....69

Chapter 5 Effects of Dual Identification and Conflict Development on Multi-Team System Performance.

Chapter 6 Discussion and Conclusion........................................................................... 119

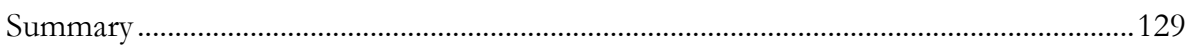

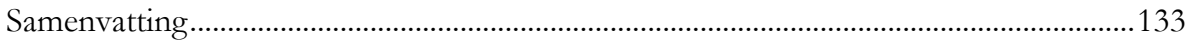

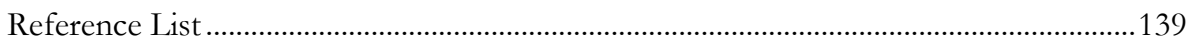

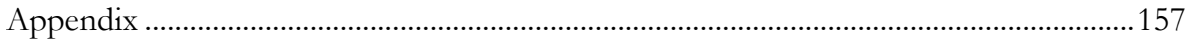

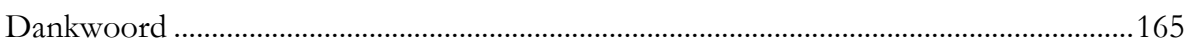

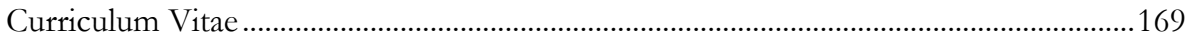





\section{Chapter 1}

Setting the Scene ${ }^{1}$

${ }^{1}$ Unless indicated otherwise, in this dissertation, the use of "we" refers to Maarten Cuijpers, Mariëlle Heijltjes and Ursula Glunk. 


\section{INTRODUCTION}

We often define ourselves in terms of group membership. We see ourselves as being of a specific nationality, race or gender, and we also feel part of a sports team or organization. Tajfel (1982) has labeled our sense of belongingness and emotional and value attachment to a group social identification. He posited that when we identify with collectives, we are inclined to favor the group we are a member of over others. This socalled in-group favoring behavior manifests itself in many forms. For example, we assert one country to be better than other countries. We start wearing shirts in the colors of our favorite football team and engage in behavior to reflect our perceived supremacy.

While the examples above are descriptions of regular informal activities, organizational researchers have argued that the same types of mechanisms are also present at work within and between organizations (e.g. Abrams \& Hogg, 2004; Ashforth \& Mael, 1989; Haslam, 2001; Hogg, 2001). We attach value to our organizational membership and within these organizations we tend to feel closely connected to the department or division we work in or the project or work group we are a member of (e.g. Van Dick, Wagner, Stellmacher, Christ, 2004; van Knippenberg \& Schie, 2000). Identification with a collective proves to be an important factor in our organizational life. Research has shown that, for example, identification with the organization positively influences employees' work attitudes and behaviors (e.g. Ashforth and Mael, 1989; Dutton, Dukerich and, Harquail, 1994; Bergami \& Bagozzi, 2000; Christ, Wagner, Stellmacher \& Van Dick, 2003; Van Dick et al., 2004). In a recent meta-analysis, Riketta (2005) demonstrates how identification with the organization decreases absenteeism or intent to leave and increases employees' in-role and extra-role behavior, job involvement and satisfaction.

Not only does identification with the organization positively influence a person's attitudes and behaviors, studies have also shown that a person's identification with his/her organizational team or work group increases team effectiveness (Christ et al., 2003; Han \& Harms, 2010; Hinds \& Mortenson, 2005; Hobman \& Bordia, 2006; O’Reilly \& Chatman, 1986; Van Der Vegt \& Bunderson, 2005). People who identify with their organizational team are said to internalize their team's goals and to act in accordance with those goals. As such, Van Der Vegt and Bunderson (2005) showed social identification to have a significant positive effect on group learning and performance.

Yet, most studies take an intra-team perspective (see for an overview Mathieu, Maynard, Rapp, Gilson, 2008) and focus on how intra-team composition is related to intra-team processes and organizational outcomes (Mathieu et al., 2008; Williams \& O'Reilly, 1989). Contemporary organizational developments, however, show organizational structures to become increasingly complex (e.g. Marrone, 2010; Mathieu, Marks \& Zaccaro, 2001). That is, within organizations, people are generally members of multiple organizational groups (i.e. teams, departments, divisions) and while being member of one group they simultaneously act as delegate of another group. This 
implies that the extant perception of organizational teams as isolated entities (e.g. Li \& Hambrick, 2005) needs reconsideration. In organizations, people do not only come to the team as an agent of themselves or the job position they fulfill, but are also compliant to the organizational group they represent.

We perceive this phenomenon as a structural property in the makeup of organizational teams and label this dual allegiance; embedded in the job role of organizational team members is their membership to one organizational group (i.e. teams, departments, divisions) while simultaneously representing another organizational group (Marrone, 2010; Marrone et al., 2007; Vora \& Kostova, 2007). For example, a management team (MT) member who is also responsible for the marketing division brings, besides his social identity as MT member, also his identity as marketer to the MT and with that the interests and goals of the marketing division. This implies that on the one hand the interests and goals of the higher-order MT, and on the other hand the interests and goals of the lower-order marketing division need to be accommodated.

Despite the acknowledgement by some scholars, the organizational team literature has only afforded scant attention to this organizational phenomenon and we find only little about the complications and consequences that dual allegiance may entail. (e.g. Mathieu, Maynard, Rapp \& Gilson, 2008). However, to truly understand organizational teams, we should consider the impact of multiple organizational group membership on organizational team dynamics. This is important because the duality in responsibilities and organizational expectations may potentially be problematic. It may cause friction, not only within, but also among organizational team members and hamper organizational team processes and subsequently team performance (Johnson, 1999; Li, Xin \& Pillutla, 2002).

Therefore, in this dissertation our primary focus will be to explore the role of dual allegiance in organizational teams. We define organizational teams as a set of bounded persons who depend on each other to reach a common goal. Persons are members of organizational teams when they acknowledge each other as such and share the responsibilities and consequences (i.e. rewards or punishment) for the results (Hackman \& Wageman, 2005). Given the fact that dual allegiance is a structural organizational team characteristic, we examine how organizational team members experience and enact on dual allegiance and how this influences organizational team processes.

We mainly use social identity theory (SIT) (Tajfel, 1975; Turner, 1982) to understand how organizational team members experience dual allegiance. The theory specifies the motivation and assumptions behind the attitudes and behaviors of team members that lead to organizational team processes. Since we are interested in what happens within modern-day organizational teams and in the consequences of the broader inter-team (i.e. divisional or departmental) complexities on team processes, we apply a dual identification perspective. The perspective is rooted in SIT and posits that people need to attach a cognitive and emotional value to a higher-order and lowerorder organizational groups simultaneously for optimal well-being and positive organizational team processes (Ashforth \& Johnson, 2001; Hogg \& Terry, 2000; Hornsey \& Hogg, 2000). Based on reasons of conceptual simplicity, we will focus on 
the identification of organizational team members with one higher-order and one lower-order organizational group. We will elaborate on this decision later in the dissertation. SIT allows making predictions at the individual as well as team level of analysis and is used in chapter 2, 3, 4, and 5 .

By means of boundary theory (Ashforth, Kreiner \& Fugate, 2000; Kreiner, Hollensbee \& Sheep, 2006) we illustrate what cognitively happens if organizational team members structurally commute between the fulfillment of higher-order and lowerorder organizational group goals and responsibilities, adding a dynamic component to understanding how team members experience dual allegiance. The theory further explicates how organizational team members who constantly "change hats" (Ashforth \& Johnson, 2001) may activate intra-, but also interpersonal conflict situations (Ashforth et al., 2000; Kreiner et al., 2006; Li et al., 2002). The theory thus also affords making assumptions at the individual as well as team level of analysis. We refer to boundary theory in chapter 2 and 4, mainly.

Lastly, we use role theory (Biddle, 1979, Blau, 1964) to derive what it is for individual organizational team members to fulfill two different organizational roles at the same time. The theory primarily focuses on what happens within the person if the expectations of different roles are not compliant to each other. It allows us to make predictions in terms of dual allegiance at the individual level. We deal with this specifically in chapter 3 .

By means of these theories we aim to better understand the consequences of difference in how organizational team members may experience dual allegiance for team processes. We investigate the effects of dual allegiance on task and relationship conflict (Jehn, 1995); in the literature defined as disagreements regarding the tasks that have to be executed and interpersonal animosity, respectively, but we will also examine behavioral integration; the cohesive interaction among organizational team members (Hambrick, 1994).

In this introduction, we will first elaborate in more detail on why it is important to reflect on the role of dual allegiance in organizational team processes. We do this by giving a short overview of the team diversity and boundary spanning research and emphasize how the examination of the role of dual allegiance adds to the exploration of organizational team processes. We will then describe the three theories (i.e. social identity, boundary, and role theory) that we consider core to the understanding of dual allegiance enactment by organizational members. We conclude this chapter by indicating the research gaps in the current organizational team literature and we will introduce the empirical studies by means of which we aim to address these research gaps.

\section{WHY STUDY DUAL ALLEGIANCE IN ORGANIZATIONAL TEAMS}

For long, management and organizational behavior scholars have been interested in explaining the functioning of organizational teams; how do teams make decisions, why do conflicts occur, why is it so difficult to work together in a team? To find answers to these questions the input-process-outcome framework has served as an imperative 
guide for team researchers (Cohen \& Bailey, 1997; Jackson, Joshi \& Erhardt, 2003; Mathieu et al., 2008). Inputs being considered as important antecedents of team processes, team processes to be assumed vital for understanding how inputs are transformed into outcomes and outcomes being the result of team processes (Mc Grath, 1964).

In accordance with this framework, team researchers have mainly considered the organizational team as isolated from the rest of the organization. Team research has therefore mainly focused on inputs from within the team (McGrath, Arrow \& Berdahl, 2000; Ilgen, Hollenbeck, Johnson \& Jundt, 2005). However, in modern organizations, team members fulfill a bridging role in which they have to represent the goals, expectations and interests of two or more organizational groups at the same time (Friedman \& Podolny, 1992). Today's challenges in organizations are very much related to the efficient and effective coordination of the diverse interests of interdependent organizational teams (Marrone, 2010; Smith, Caroll \& Ashford, 1995). This implies that aspects external to the team become increasingly important for internal team functioning (Choi, 2002).

Below, we shortly describe the fields of team composition and boundary spanning research. We do this, because researchers in both fields slowly start to acknowledge the influence that such a bridging role may have on team processes and exploring the consequences of dual allegiance, may advance knowledge regarding team processes in both these fields. We describe team composition research, because this field, until today, dominates our thinking regarding team processes and team performance (van Knippenberg \& Schippers, 2007). Yet, the field produces inconsistent research results in terms of linking team composition (aspects inside the team) to team processes and outcomes. We portray the advancement in boundary spanning literature as this type of research does consider the importance of the external team environment, but devotes only scant attention to how external activities influence internal team processes and rather focuses on team outcome effects (Ancona \& Caldwell, 1992).

\section{Team Composition Research}

Diversity is, in general, characterized as the 'differences between individuals on any attribute that may lead to the perception that another person is different from self (van Knippenberg \& Schippers, p. 517). In team composition research, the personality characteristics or demographics has been considered proxies for deeper psychological differences among team members (Hambrick \& Mason, 1984; Harrison, Price, \& Bell, 1998; Williams \& O’Reilly, 1998). For long, team composition researchers have considered the examination of the relationship between team compositional diversity (i.e. demographic, functional or educational background diversity) and team processes and outcomes most critical in scrutinizing the consequences of team compositional complexities (van Knippenberg \& Schippers, 2007). Hereby, researchers have implicitly assumed diversity between teams to reside within the organizational team.

To explain the emergence of intra-group processes (e.g. Marks, Mathieu \& Zaccaro, 2001), such as conflict, team cohesion or social integration (e.g. De Dreu \& 
Weingart, 2003; Michalisin, Karau \& Tangpong, 2004; Simons \& Peterson, 2000; Tekleab, Quigley \& Tesluk, 2004), team composition studies have drawn extensively from two perspectives. First, the information and decision making perspective assumes that high diversity among team members increases team members' access to a diverse set of information and knowledge that helps in higher quality decision making processes (e.g. Brodbeck, Kerschreiter, Mojzisch \& Schulz-Hardt, 2007; van Knippenberg, De Dreu \& Homan, 2004). As such, researchers have found more diverse organizational teams to be more creative and innovative than less diverse teams (Webber \& Donahue, 2001; Williams \& O'Reilly, 1998). Second, the social identification perspective (e.g. Tajfel, 1975; Turner, 1982) argues that diversity creates subgroups within teams which, in turn, emerge into relational conflicts. Depending on the type of conflict (i.e. task or relationship conflict), diversity may then have beneficial or detrimental effects on team performance (e.g. Jehn, 1995; 1997; Jehn \& Mannix, 2001).

To date, however, no consistency exists regarding the relationship between team diversity, processes and performance (e.g. De Dreu \& Weingart, 2003; Jackson et al. 2003, Williams \& O'Reilly, 1998) and an increasing number of studies concedes that the benefit of diverse teams is a function of more complex relationships between team diversity and moderator variables (Jackson, Joshi \& Erhardt, 2003; Webber \& Donahue, 2001; Homan et al., 2008). As such, the type of diversity within teams (i.e. faultline or cross categorization) has shown to interact differentially with team reward structures, team type (i.e. higher or lower level organizational team) and personality characteristics (e.g. Homan et al., 2008; Webber \& Donahue, 2001). In addition, researchers acknowledge that many more dimensions (e.g. shared mental models, social identification) than merely demographic or informational diversity influence group processes and outcomes and that these dimensions should therefore deserve more research attention (e.g. Cannon \& Edmondson, 2001; Lovelace, Shapiro \& Weingart, 2001).

In particular, researchers have urged for more empirical research in which team functioning is more thoroughly analyzed by means of, for example, social identification processes (Hogg, Abrams, Otten, Hinkle, 2004; van Knippenberg \& Schippers, 2007). More specifically, researchers argue that when examining the larger organizational system in which teams are embedded (i.e. dual allegiance), research should highlight the mechanisms behind intergroup relations that find their origin not only within, but also across teams (e.g. DeChurch \& Zaccaro, 2010; Li \& Hambrick, 2005; Li, Xin \& Pillutla, 2002). Yet, there still exists a dearth of organizational team studies that do this (see Chattopadyay, George, Lawrence, 2004; Hobman \& Bordia, 2006). This thesis may thus add value by taking a dual allegiance lens and by exploring the relationship between the experience of dual allegiance and organizational team processes.

\section{Team Boundary Spanning Research}

The phenomenon that organizational team functioning depends as much on linkages within as across teams has been mainly examined in boundary spanning research (e.g. 
Ancona \& Caldwell, 1992). Whereas team diversity research has primarily taken an intra-team perspective, boundary spanning literature acknowledges that organizations are comprised of sub-systems of interconnected organizational teams (e.g. Choi, 2002; Joshi, Pandey \& Han, 2009; Marrone, 2010). Boundary spanning is commonly referred to as the act of coordinating and managing the interaction among disconnected parties (Ancona \& Caldwell, 1992; Marrone, Tesluk \& Carsson, 2007). The boundary spanning act can entail, amongst others, information gathering behavior or external representational functions to other organizational teams (Marrone, 2010). Please note that, though related, boundary spanning is different from boundary theory, a concept prominently used in this thesis. Whereas boundary theory is primarily cognitive in nature, boundary spanning theory has behavioral roots and refers to the behavioral activity of crossing boundaries.

In the tradition of Ancona and Caldwell's (1992) seminal work, boundary spanning research has dominantly focused on 'how team member's efforts to persuade other parties of team decisions or the distribution of resources influences team performance' (Marrone, 2010, p. 914). In this research, organizational team's external directed activities have been primarily associated with team outcome variables (e.g. Ancona \& Caldwell, 1992; Marrone, 2010; Joshi, 2006). Boundary spanning research has thus contributed significantly to understanding the importance of boundary spanning activities for organizational and team performance (Marrone, 2010), but gaps remain concerning our knowledge how boundary spanning impacts internal team processes (e.g. Choi, 2002; Marrone, 2010).

It is fascinating that boundary spanning research has conceptually been differentiated from research that focuses on internal team processes, whereas studies have predominantly taken an intra-team perspective to explain the effects of outward directed behavior of single persons (e.g. Faraj \& Yan, 2009; Joshi, Pandey \& Han, 2009). Internally and externally oriented processes are suggested to be inherently different (Gladstein, 1984; Marks et al., 2001). Processes that cross boundaries are more complex and often characterized by multiple competing influences, originating from interdependence and competing group identifications (Glynn, Kazanjian \& Drazin, 2010; Hogg \& Terry, 2000). Recently, DeChurch and Marks (2006) have provided experimental support for the suggestion that the management within and across team boundaries is, indeed, different. They demonstrated leadership interventions, focused on within team processes, to only impact within team performance, whereas interventions on inter-team processes positively influenced inter-team functioning. These results thus indicate that more research attention is warranted to better understand the functioning of modern-day organizational teams that are increasingly common in a wide range of contexts.

Scholars acknowledge that a person's external representational function may significantly change the interaction processes within the team (e.g. Choi, 2002; Marrone, 2010; Joshi, Pandey, Han, 2009). The interests and values an organizational team member brings to the team, as an external team representative, may change organizational team dynamics beyond what we currently know about intra- team functioning. However, only few studies have actually focused on how external team 
representations influence intra- team functioning (see Joshi, 2006; Joshi \& Roh, 2009; Li \& Hambrick, 2005). So far, research has only started to explore how external team delegations can be managed to optimally capitalize upon its resources and to not harm the teams' processes (Keller, 2001, Marrone, Tesluk, Carson, 2007). Exploring the role of dual allegiance may be a logical next step.

\section{UNDERSTANDING DUAL ALLEGIANCE}

In the introduction we mentioned that our focus would be on the allegiance between a higher-order and lower-order organizational group. The assumption that organizational team members experience dual allegiance as a structurally grounded trade-off between higher-order and lower-order organizational responsibilities suggests that team members are continuously confronted with a distributive challenge. This proposition is based on the assumption that different organizational groups have varying and competing organizational responsibilities (Albert \& Whetten, 1985) and that, therefore, team members need to constantly balance conflicting goals and interests. Below, we will describe on what conceptual premises we built this assumption and we elaborate on the mechanisms and consequences of dual allegiance for organizational team members. We do this by using social identity theory, role theory and boundary theory as guiding frameworks.

\section{Social Identity Theory}

In this dissertation the dominant theoretical lens is SIT and, in essence, the theory explains why organizational members come to see themselves as members of an organizational group and how this influences attitudes and behaviors (Hogg \& Terry, 2000). Social identity researchers argue that organizational members routinely search for affiliations with collectives to define "who they are" in the organization (e.g. Hogg \& Abrams, 1988). The strength of the affiliation determines their willingness to devote increased efforts to the benefit of the group(s) they feel affiliated with (Ashforth et al., 2008; Christ et al., 2003). As such the theory allows making predictions regarding the effects of dual allegiance on both an individual and team level.

By taking a social identity perspective, we can define organizations as constellations of structurally embedded allegiances. Namely, the partitioning of organizations in organizational groups such as organizational teams, departments or business units greatly facilitates people's identification processes (Ashforth \& Johnson, 2001; Corley, 2003). In the language of SIT, the design of organizations enables organizational group members to fulfill innate needs of belonging and distinctiveness (Ashforth \& Mael, 1989; Tajfel, 1975; Turner, 1982). Being an organizational group member means that members can share common goals and values (Stets \& Burke, 2000). Since every business team, division or department is usually responsible for one specific aspect of the organization (i.e. sales, $R \& D, H R$ ), the goals and interests of each organizational group is unique and different. So aside from the opportunity to share commonalities, the organization also provides its members with means to create unique 
cognitive and emotional attachments with organizational groups and, as such, create organizational group identities they can relate to. For example, when employees from an organizational sales department feel and see themselves as sales department members and organizational members define themselves in terms of this sales department membership, an organizational sub-identity is created.

Most often, organizational groups are nested-one organizational group is hierarchically embedded within another organizational group (e.g. Ashforth \& Johnson, 2001; Brewer, 1991; Hornsey \& Hogg, 2000). For example, an organizational business unit is hierarchically entrenched within the higher-order organization. This implies that the dual allegiance of organizational members is also hierarchically structured and that people thus may identify with a higher-order as well as a lower-order organizational group. In SIT, this is called dual identification (Hogg \& Terry, 2000) and it is this mechanism that, we believe, plays a vital role in organizational team members' experience of dual allegiance in organizational teams.

Conflict of Interests. The duality in allegiances between lower-order and higher-order organizational groups should, in principle, not cause any frictions as lower-order (i.e. business unit) organizational goals are generally set in place to serve higher-order (i.e. organization) organizational interests. Thus, generally, there exists considerable overlap between the lower-order and higher-order interests. However, research has shown that the size and structure of many modern organizations is generally so complex that lower and higher-order responsibilities are often deviating (Ashforth \& Johnson, 2001; Brown, 1969; Greene, 1978; Rotondi, 1975). Organizational members are thus confronted with a continuous dilemma of what interests need to be prioritized; the goals of the higher-order or lower-order group. This inconsistency and conflict of interest are further emphasized by organizational reward structures and resource allocation mechanisms that are in place (Ashforth \& Mael, 1989; Ashforth \& Johnson, 2001). In many instances, organizational measures motivate behavior in the best interest of the lower-order organizational group instead of the higher-order organization (Glynn, 2000).

Moreover, membership to organizational groups is not voluntary. We mean by this that organizational members are generally assigned to organizational groups, based on their job function. This implies that while the job function establishes the formal compliance of organizational members, the level of identification determines the willingness to comply with all responsibilities (Ashforth et al., 2008; Corley, 2004). In other words, organizational members' dual identification strength (with a higher and lower-order organizational group) determines the motivation people are willing to exert to accomplish job tasks (Van Dick et al., 2005; van der Vegt, van de Vliert \& Oosterhof, 2003) and influences how dual allegiance is experienced. An important task for organizations is thus to aptly manage members' identification strengths.

According to SIT, the variability in the strength of dual identification influences organizational team processes (Hornsey \& Hogg, 2000; Richter et al., 2006). Two main perspectives can be distinguished in the literature. First, some researchers opt that conflicts of interests can best be mitigated by emphasizing team members' identification with the higher-order organizational group as it buffers against all other 
conflicting goals and allegiances (Brewer, 2000; Dovidio et al., 1998; Gonzalez \& Brown, 2003, 2006). In this way, every single group member would internalize the goals and interests of the group and invest maximum efforts to accomplish the higher-order organizational goals, whilst all other goals and interests are eliminated (e.g. Gaertner, Dovidio, Anastasio, Bachman \& Rust, 1994).

Nonetheless, as seen above, the increasing size and world-wide propensity of contemporary organizations combined with increasing amounts of job discretion enable organizational group members to create and maintain strong lower-order identities (O’Leary \& Mortenson, 2010; O’Leary, Mortenson \& Woolley, 2011). Neglecting people's identification with these identities would, according to optimal distinctiveness theory (e.g. Brewer, 1991; Hogg \& Terry, 2000), motivate differentiating behavior and interpersonal animosity, because organizational members' self concept would be threatened. Researchers in this field argue that people derive pride and status from their affiliation with an organizational group and when this affiliation is not acknowledged, their sense of uniqueness is challenged and people will start engaging in behavior that reinstates their sense of uniqueness. This involves acts that primarily benefit their lower-order organizational group interests, resulting in counterproductive interpersonal processes. Therefore, scholars opt for triggering dual identification amongst organizational team members. Organizational team processes are then expected to be most harmonious and productive as members feel "optimally distinct" (Brewer, 1991); affiliated with the higher-order organizational group such as a MT and distinct because their lower-order group membership is sufficiently respected (Hogg \& Terry, 2000, Richter et al., 2006). Hence, SIT literature demonstrates divergent perspectives on how duality in responsibilities is managed best.

\section{Role Theory}

Interestingly, studies on how organizational members cope with duality of interests are not completely lacking. For example, role theory predicts that when (job) role expectations are incompatible or different, people will experience role conflict and ambiguity that may negatively influence a person's well-being and consequently affect a person's organizational behavior (Biddle, 1997; Blau, 1964; Katz \& Kahn, 1978). Whereas both role theory and SIT reason from a reflexive self that can categorize and see him/herself as an object, the theories are also different.

Role theory focuses on how differences in expectation, at the individual level, impact a person's state (i.e. well being, role conflict) and actions (Stets \& Burke, 2000). SIT emphasizes how homogeneity in expectations and actions amongst group members influence subsequent group favoring behavior. SIT may thus add to our understanding of why organizational members may experience a conflict of role expectations. Recent research by Li et al. (2002) suggests that organizational members' experience of role conflict is strongest when they identify with both the higher and lower-order organizational group. This happens due to an increased willingness to satisfy (irreconcilable) expectations of the groups involved (Ashforth et al., 2008). Role conflict would be solved if organizational members would only feel an affiliation with either one of the organizational groups. Yet, empirical evidence for this suggestion is 
lacking. To conclude, dual allegiance may not only elicit frictions and tensions at an organizational group level, but also at the individual level.

\section{Boundary Theory}

SIT and role theory may explain why organizational members experience intra- and inter-personal tensions, the theories say little about how people commute between the identities and what tactics they employ to differentiate or integrate their identities (Kreiner Hollensbe \& Sheep, 2006). For this purpose we use boundary theory. Boundary theory has been applied in numerous disciplines to indicate where a phenomenon begins and ends. Boundaries can be physical, temporal, emotional or cognitive depending on the phenomenon under study (Ashforth et al., 2000; Kreiner et al., 2006). Organizational group boundaries are physical to the extent that membership comprises different organizational activities that fit the role that needs to be fulfilled. Boundaries are also cognitive as they help to separate organizational groups and to specify how job roles are related or separate from one another (Ashforth et al., 2000; Fiol, 1989).

The cognitive boundaries function as a lens through which team members perceive the environment around them and help to make sense of what is expected. In others words, the cognitive boundaries help to define an organizational member's selfconcept and to delineate the responsibilities that need to be fulfilled (Dutton, Dukerich, Harquail, 1994; Festinger, 1957; Kreiner et al., 2006). Boundaries are fixed to the extent that people identify themselves with their organizational groups and enact upon the group's responsibilities (Weick, 1995). When group membership is less clearly defined or job responsibilities are vague, boundaries are more flexible.

Several researchers have emphasized the importance of boundary theory in understanding the management of interactions among organizational members (Ashforth et al., 2000; Fiol, 1989; Kreiner et al., 2006; Pratt \& Foreman, 2000). In this dissertation, we were inspired by the framework of Kreiner and colleagues (2006) and we will use their terminology to clarify the complexities that organizational members are confronted with in their daily work. In Figure 1, we visualized the nature of these organizational identity dynamics.

As seen above, in a situation where identities are nested it is especially important that higher-order and lower-order organizational groups have clearly defined responsibilities and job expectations. The success of higher-order goals substantially depends on the completion of lower-order ones. Given the fact that higher and lower order responsibilities often diverge it is important for organizational group members to seek agreement on what responsibilities deserve preference and what expectations need to be met. Boundary theory explains when looking for these commonalities and consensus is more or less problematic.

According to boundary theorists, agreements are reached easiest when organizational group identities are analogous and complementary (Kreiner et al., 2006). Recent research suggests that such a situation occurs if people strongly identify with both higher and lower-order organizational groups (Van Dick, van Knippenberg, Kerschreiter, Hertel \& Wieseke, 2008; Vora \& Kostova, 2007). Boundaries between 
groups are then said to be permeable. In the language of boundary theory, team members are able to balance their organizational identifications to such an extent that they are the same and different at the same time (Kreiner et al., 2006). That is, organizational members are aware of the benefits that multiple perspectives can bring, and work attitude and behavior will positively benefit both organizational groups (van Knippenberg, van Knippenberg, DeCremer \& Hogg, 2004). Pratt and Foreman (2000) defined this situation as 'identity synergy'. Under these circumstances, the alignment of identification makes organizational teams optimally integrated, with minimum experienced conflict, and complementary performance results (Ashforth et al., 2000; Kreiner et al., 2006).

\section{Figure 1: The Nature of Organizational Group Identity Boundaries (Adapted from Kreiner et al., 2006).}

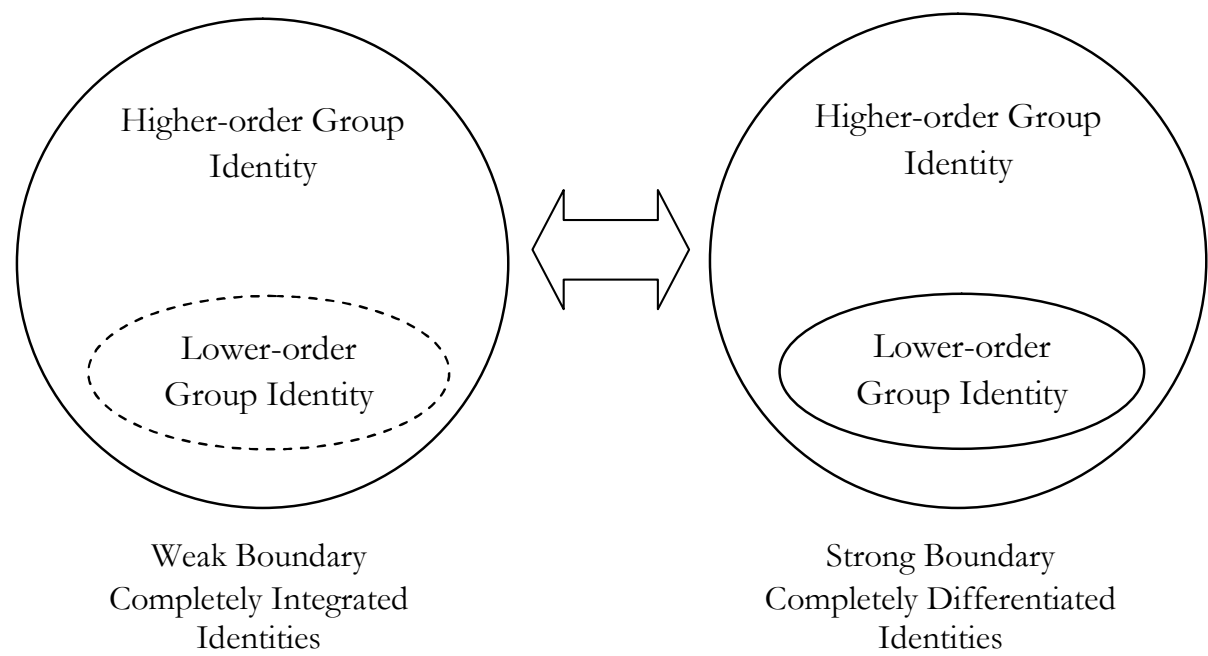

Note: each of the identity's boundaries can vary in strength, depending on the team member's perception. The objects depicted here are snapshots in time.

The situation is different when organizational members experience an unaligned identification with organizational groups; for example, when identification with lower-order identities is strong while identification with higher-order identities is weak. In such a situation, organizational group identities are disparate and conflictual (Kreiner et al. 2006). That is, organizational team members perceive a cognitive inconsistency and experience a strong, impermeable, boundary between organizational group identities. Team members experience a lot of difficulties finding agreement and consensus regarding the job tasks to be executed (van Knippenberg et al., 2004; Kreiner et al., 2006).

Above, we only described two extreme situations. Team members can move between these two extremes depending on the strength of the dual identification. These, so-called, boundary dynamics take place at the interface of the organizational 
group identities and have implications for team member's attitudes and behavior (Kreiner et al., 2006). For example, in the situation of an asymmetrical dual identification, as described in the previous paragraph, organizational members will become aware of the fact that they are member of an organizational group they actually do not identify with (van Dick et al., 2008). In order to solve this perceived inconsistency, organizational members will engage in behavior that solves this inconsistency. Consequently, this behavior will affect interpersonal relations (Brewer, Manzi \& Shaw, 1993). Hence, boundary theory helps to explain what happens, at the intra- and inter-individual level of analysis, when organizational members commute between organizational group identities.

\section{RESEARCH CONTEXT}

We primarily use the (top) management team (MT) context to investigate dual allegiance dynamics. From a social identity perspective, the saliency of both higherorder organizational interests as well as lower-order organizational responsibilities makes the MT an appropriate context to examine the impact of dual allegiance dynamics on team functioning (Ashforth \& Mael, 1989; Ashforth \& Johnson, 2001). Primarily, the functioning of (top) managers in the MT can be explained by the manner organizations are structured. Their organizational position, generally gives them high discretionary decision making power. Additionally, the status and power in their job function makes MT members act as semi-autonomous barons (Hambrick, 1994). The separation of organizations into divisions or departments supports an MT manager's intrinsic need for distinctiveness and uniqueness. Given this assumption, social identity theory underlines that the existence of these structurally created subgroups is a source of competition and conflict, threatening intergroup harmony (Ashforth \& Mael, 1989; Ashforth \& Johnson, 2001; Tajfel, 1982). This is especially the case when the goals and interests of the higher-order organization do not match and are irreconcilable with the goals and interests of the team member's other organizational unit (Ashforth \& Mael, 1998; Smith \& Tushman, 2005; Walsh, 1988). The role of the MT, herein, is to offer MT members "a locale" (see Silva \& Sias, 2010) in which differing ideas and perspectives are aligned and balanced in the best interest of the higher-order organization (Bunderson \& Sutcliffe, 2002; Joshi, et al., 2009).

Additionally, we use multi-team systems (MTSs) to investigate dual allegiance dynamics. MTSs are constellations of interdependent teams who need to coordinate their activities and align their individual team goals in order to accomplish a higherorder system goal (Mathieu, Marks \& Zaccaro, 2001). Similar to MTs, MTSs also have a salient dual allegiance design. The nested identity configuration of MTs and MTS are homologous. To be successful, the accomplishment of lower-order team goals needs to be in function of the completion of higher-order MTS goals (Mathieu et al., 2001). Hence, from a social identity and boundary perspective, MTS members are to cope with related dual allegiance dynamics and predicaments as MT members. 


\section{RESEARCH GAPS AND THESIS OUTLINE}

The effects of dual allegiance on organizational team processes have only been scarcely touched upon in the organizational team literature. Whereas extant literature has focused on the emergence of dual allegiance tensions in organizational mergers (e.g. Bartels, Pruyn, de Jong, 2009; van Knippenberg, van Knippenberg, Monden, de Lima, 2002; Terry \& Amiot, 2008), we are not aware of studies examining the effects of dual allegiance in organizational teams, such as MTs or MTSs. In addition, only few studies have elaborated on the effects of dual allegiance on team processes per se (see Johnson, 1999; Li \& Hambrick, 2005; Li, Xin \& Pillutla, 2002). Organizational team literature may thus benefit from a more thorough examination of the effects of dual allegiance on team processes.

We operationalize MT members' experience of dual allegiance by their social identification with a higher-order and lower order organizational group. Interestingly, studies that examine dual allegiance have all used social identity theory to build theoretical arguments regarding the effects on team processes, but actually fail to measure this relationship. Moreover, the creation of a higher-order common identity is often considered a sufficient means for smoothening team interaction processes (cf. Bartels et al., 2009; van Knippenberg et al., 2002). As seen above however, based on the optimal distinctiveness theory (Brewer, 1991), interpersonal relations are more complex.

Especially when organizational units nested, identification with both a higherorder and lower-order organizational group are a assumed to play a significant role in the emergence of interpersonal processes (e.g. Ashforth \& Mael, 1989; Hornsey \& Hogg, 2000). This dissertation thus explores the dual allegiance mechanism by primarily taking social identification approach and examining the phenomenon by means of four studies. We have visualized the intended proceeding in Figure 2.

In Chapter 2, we introduce a conceptual framework to model the impact of dual allegiance on MT conflict and behavioral integration processes. More specifically, driven by the principles of social identity theory and boundary theory, we first explain how the experience of dual allegiance at the individual level depends on MT members' dual identification (identification with the higher-order MT and lower-order sub-unit). Second, we propose a theoretical model at the team level of analysis in which we investigate how MT members' dual identification relates to MT conflict (i.e. task and relationship) and behavioral integration.

In Chapter 3 we start to explore how MT members experience dual allegiance and when dual allegiance emerges into role conflict. The reason for examining this research question is that, to our knowledge, literature has not yet investigated if and how organizational team members in managerial positions deal with potential conflicts. Existing literature is inconclusive about the experience of role conflict by MT members. Past studies, like for example Shenkar and Zeira (1992), suggest that managers at the top of organizations perceive role conflict as less intense than other organizational team members. More recent studies, however, point out that dual allegiance may negatively influence MT interaction via role conflict (Li et al., 2002; Vora \& Kostova, 2007). In 
short we thus must conclude that we only know little about the consequences of dual allegiance for individual MT members (see for exception Vora, Kostova \& Roth, 2007).

Figure 2: Structure of Dissertation

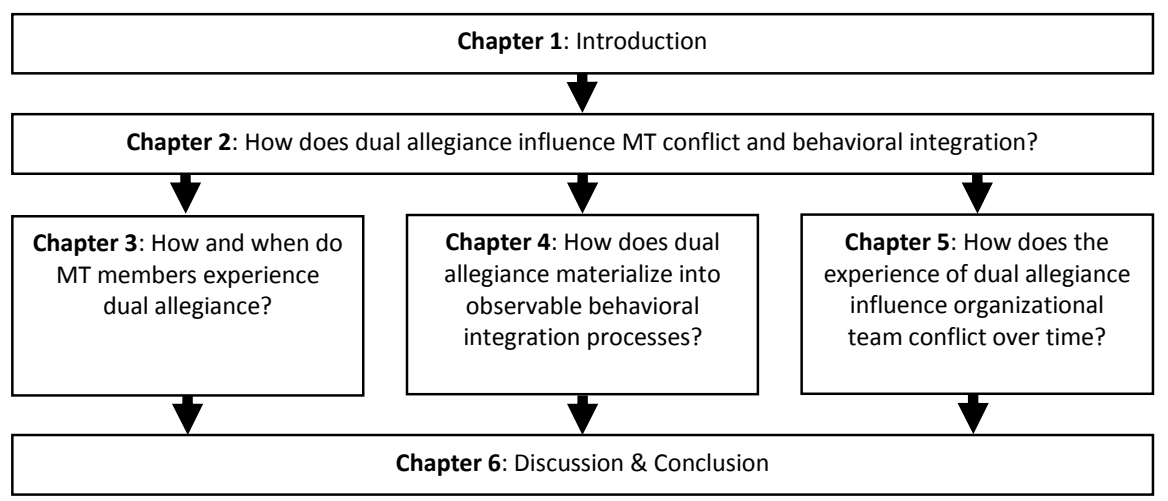

Whilst role theory may add to our understanding of how discrepancies in role expectations may cause inter-role conflicts, the theory is less informative in answering questions about how and why MT members experience conflict. For this reason, we have explored MT members' individual experience of dual allegiance by means of 11 semi-structured interviews with managers in boundary spanning positions. In this study, we start from role theory, but combine role theory with social identity theory to recognize the mechanisms behind the potential incongruence in expectations.

To shed more light on what is actually happening within teams in terms of dual allegiance, we video-observed the biweekly meetings of an MT and zoom in on observable behavioral integration processes across 5 MT meetings. Additionally, we conducted personal interviews with the MT members. The majority of team and MT researchers concentrate on statistically validated measures and fail to examine the why and how of team functioning (Jarzabkowski \& Spee, 2009). Extant research has therefore called for more qualitative studies to more carefully examine how specific team interaction patterns emerge (Carpenter, Geletkanycz \& Sanders; Priem, Lyon \& Dess, 1999). More specifically, researchers increasingly call to bring back the role of emotions, motivations and actions in the exploration of organizational team functioning (DeChurch \& Zaccaro, 2010; Jarzabkowski \& Spee, 2009; Johnson, Melin \& Whittington, 2003). In Chapter 4, we answer this call by documenting the findings of a mixed-method study. We take a team level perspective and primarily draw from social identity theory.

Research on social identification has been primarily cross-sectional in nature (see for exceptions, Han \& Harms, 2010; Gleibs, Noack \& Mummendey, 2010). This is surprising since social identity theory, as suggested by Tajfel (1982) assumes the social identification of people to be relatively dynamic as it depends on the context and interaction among people (Haslam, Powell, Turner 2000; Haslam \& Reicher, 2006). In Chapter 5, we therefore focus on longitudinal effects of nested identities on team 
conflict and performance. Because of the dearth of longitudinal studies on social identification as well as the absence of examinations of the effects of nested identities on team processes, we decided to conduct an experimental study. We have created a multi-team system (e.g. Mathieu, Marks and Zaccaro, 2001) where subjects are asked to take part in a command and control computer simulation. Mathieu, Marks and Zaccaro (2001) distinguish multi-team structures from common organizational designs, but further argue that the team structure of MTs is comparable to multi-team designs.

Although we acknowledge that a multi-team system is certainly not similar to a MT, the dual allegiance structures are comparable. Notwithstanding the differences in task content, in both situations, organizational team members are confronted with a nested identity structure. In addition, the characteristics of the task are, to a certain degree homologous. In both situations, team representatives are responsible for other organizational sub-unit members. The team task is uncertain since subjects do not know where and when problems will arise. The task is complex because participants need to coordinate their actions both with a fellow unit member and another unit. Additionally, the task requires strategic and operational skills since subjects need to anticipate on where and when problems will arise and resources need to be organized collectively to successfully accomplish the task. Recent research by Martin (2011) and Martin and Eisenhardt (2010), who urge to perceive MTs as a platform where crossunit activities eventually lead to accomplishment of common goals, provide additional support for the notion that MT structures may be comparable with MTS' structures.

Finally, in Chapter 6, we summarize the most important research findings and discuss the theoretical and practical implications of the studies. Suggestions for future research are discussed. Please note that chapter 2, 3, 4, and 5 are fully self-contained and can be read as separate studies. The various chapters therefore contain overlap in terms of the theoretical framework introduced. 


\section{Chapter 2}

\section{The Influence of Dual Allegiance on Management Team Conflict and Behavioral \\ Integration $^{2}$}

2 An earlier version of this chapter was presented at the Academy of Management Conference in Montreal, Canada, August 6 -10, 2010. We are thankful to Frances Milliken for her excellent comments and suggestions on an earlier version of this paper. We also thank the participants of the Discussion Paper Session at the Academy of Management Conference. 
Chapter 2

\begin{abstract}
Management team members' work is characterized by dual allegiance. They need to be loyal to the organization as a whole and at the same time protect the interests of specific units within the organization. To investigate the influence of dual allegiance on management team conflict and behavioral integration, we draw from social identity theory and boundary theory to argue that management team members engage in boundary crossing activities that are embedded in the work of management team members. Our framework describes how team members' identification with the higherorder management team as well as lower-order organizational sub-unit determines the experience of dual allegiance. We propose that MT members' dual identification at the team level of analysis influences management team conflict and behavioral integration.
\end{abstract}




\section{INTRODUCTION}

The study of management teams (MT) has become a significant strand of research with a well-developed body of theoretical and empirical knowledge. Especially the relationship between management team composition, processes and performance has recently received considerable attention (Li \& Hambrick, 2005; Jackson, Joshi, \& Erhardt, 2003; Williams \& O’Reilly, 1998). MTs are settings in which managers engage in strategic decision making by integrating divergent interests and goals of interdependent organizational groups (Cohen \& Bailey, 1997; Li \& Hambrick, 2005; Srivastava, Bartol, \& Locke, 2002). In practice, the MT is thus characterized by a dual allegiance of its members; on the one hand members need to be loyal to the organization as a whole and on the other hand they are supposed to protect the interests of a sub-unit within the organization.

MT members are expected to work collaboratively and coordinate and integrate a variety of complex tasks, while they are at the same time confronted with a dual allegiance and need to balance diverging goals and interests from various organizational echelons (Hambrick, 1994; 2007). A critical aspect and challenge of MT work is thus MT members' continuous confrontation with the choice to enact upon the goals and interests of the MT and/or of the organizational sub-unit. (c.f. Ancona \& Caldwell, 1992; Hambrick, 1994; Smith \& Tushman, 2005). These consequences have only been scarcely analyzed in upper echelon team research and most MT studies have focused on the (diversity) effects of personal identities on MT processes and performance. For instance, upper echelon research has investigated how personal characteristics such as knowledge, experiences and values impact MT levels of conflict, behavioral integration and team outcomes (Amason, 1996; Knight et al., 1999; Olsen, Parayitam, Bao, 2007). Yet, only few studies have focused on the role of external allegiances on these MT processes (see for exceptions Johnson, 1999; Li \& Hambrick, 2005; Li, Xin, Pilutla, 2002).

We argue this is because MT scholars have implicitly considered MTs as isolated entities (Joshi \& Roh, 2009; Li \& Hambrick, 2005) and they failed to consider the work of MT members to go beyond representing individual team member's goals and interests. As a result, variation in MT processes and performance have been mainly linked to intra-team differences (e.g. Bunderson \& Sutcliffe, 2002; Cohen \& Bailey, 1997; Simsek, Veiga, Lubatkin \& Dino, 2005). This is surprising as the representative role of MT members is inherent to the make-up of MTs (Ancona \& Caldwell, 1992; Cohen \& Bailey, 1997; Li \& Hambrick, 2005) and critical to understand MT processes.

We thus posit that MT processes are not only influenced by MT membership per se, but also by the membership to other organizational groups. Given the fact that knowledge on the true nature of MT processes is slow to accumulate (Barrick, Bradley \& Colbert, 2010; Carmeli \& Shteigman, 2010), a focus on understanding when and how MT members' dual allegiance influences MT processes would be useful. Therefore, we formulated the following research question: How does dual allegiance influence MT processes? 
We answer this research question theoretically and propose a team level framework in which we link the experience of MT members' dual allegiance to MT processes. In specific, we focus on three MT processes that prior literature has shown can have pervasive effects on MT performance: task conflict, relationship conflict and behavioral integration (e.g. Amason, 1996; Boone \& Hendriks, 2009; Knight et al., 1999; Simsek et al., 2005). The framework is guided by social identity theory and boundary theory, which are particularly useful because these theories allow for predictions about how MT members' perceptions of organizational group membership are related to intentions and interpersonal behavior (Ashforth, Kreiner \& Fugate, 2000; Hornsey \& Hogg, 2000; Kreiner, Hollensbe \& Sheep, 2006a; Tajfel, 1982; Turner, 1975). We use social identity theory to draw inferences about how MT members define themselves (i.e. self-concept) and behave in terms of dual allegiance. In doing so, we take a dual identification perspective. More specifically, we use optimal distinctiveness theory (e.g. Brewer 1991) to propose that MT members, as member of the MT and organizational sub-unit, continuously search for an optimal balance between a sense of belonging and feeling unique (i.e. identification) (Brewer, 1991; Hogg \& Terry, 2000; Vora \& Kostova, 2007). Boundary theory (Ashforth et al., 2000; Kreiner et al., 2006a) serves to illustrate that MT members psychologically and, where relevant, physically commute between MT and organizational sub-unit responsibilities and that this commuting influences MT members' behavior and subsequently MT processes.

We argue that dual allegiance influences MT processes via the experience of MT members about the dual allegiance. This experience depends on the strength and alignment of MT members' dual identification (with MT or organizational sub-unit). The decision of MT members "which hat to wear" is a function of their personal observation of how many goals, interests and values they have in common with the MT and/or organizational sub-unit (i.e. identification strength) and how many opportunities they see to combine or integrate MT and organizational sub-unit goals (i.e. alignment of identification). The strength of identification is related to the efforts MT members want to invest in accomplishing specific goals; the stronger the identification, the higher the efforts. The alignment of dual identification determines the fluency with which organizational group goals can be integrated. The more aligned MT members' dual identification, the easier the group goals can be merged.

We believe we make several key contributions whilst answering our research question. First, we show how dual organizational group membership can influence MT processes and herewith we add value to the understanding of the managerial "blackbox" (Lawrence, 1997) and the consequences of dual allegiance on MT functioning. Most MT research has focused on processes as they occur in, what we refer to as "isolated", teams. In this type of research, the impact of individual MT member characteristics on MT processes is acknowledged, but the impact of MT members' representative role is often forgotten. Second, we emphasize the role of social identification as a lens to understand MT processes. While MT studies recognize the role of (social) identification mechanisms in MT processes (e.g. Li \& Hambrick), only scant attention is devoted to how such cognitive and psycho-social factors influence MT processes (see for exception Carmeli \& Shteigman, 2011). In this paper, we 
explicitly outline the function of MT members' twofold attachment to organizational groups.

In the sections that follow, we will first outline the importance of the role of dual allegiance in MT functioning. We then review social identity and boundary theory literature in order to understand the mechanisms behind MT members' individual experience of dual allegiance. Concurrently, we introduce our dual identification framework at the team level of analysis, develop research propositions and discuss the implications of this research.

\section{MANAGEMENT TEAM STRUCTURE}

In this section we explain the structure of MTs in more detail and argue the structural differences between the work of MTs and non-managerial teams to be important for why dual allegiance is vital for MT processes. MT structure is considered more complex and ambiguous than work in other organizational teams, because of the function MTs have in terms of strategic decision making and organizational outcomes (Ancona 1989; Bantel \& Jackson, 1989; Carpenter \& Frederickson, 2001; Hambrick, 1994; O’Toole, Galbraith \& Lawler, 2002). These characteristics, which are considered typical for MTs, are assumed to influence MT processes in a specific way and have deserved special research attention over the years (Carpenter et al., 2004; Certo et al., 2006).

MT research has been primarily driven by Hambrick and Mason's (1984) upper echelon theory. The theory builds on the premise of bounded rationality and argues that managers cannot objectively understand complex and uncertain situations. To interpret the environment, managers enact on their personal biases and dispositions. To understand why organizations perform the way they do, we need to examine executives' personal experiences, values and personalities.

Hambrick and Mason's (1984) call to use personal characteristics as proxy for manager's biases and dispositions has generated plenty of research, relating demographic profiles to organizational performance. Yet, the evidence for these relationships is contestable (Carpenter et al., 2004; Priem et al., 1999; Certo et al., 2006). Certo and colleagues (2006), for example, demonstrate that the suggested relationship between MT composition and organizational performance is only partially supported; they show a modest positive relationship for functional and executive tenure diversity and no relationship at all for educational and organizational tenure diversity.

Consequently, researchers have investigated the "black-box" by examining how psychological and social processes mediate the link between MT composition and organizational performance outcomes (Amason, 1996; Simons, Pelled, Smith, 1999; Smith et al, 1994). Studies that have examined MT processes reveal the criticality of MT process variables such as information sharing, conflict and behavioral integration on strategic choice and performance (Boone \& Hendriks, 2009; O'Reilly, Snyder, and Boothe, 1993; Smith et al., 1994). Yet, despite evidence of the important role of social processes for organizational performance outcomes, we still know very little about the antecedents of MT processes. Studying compositional diversity factors has thus far yielded ambiguous results (Priem et al., 1999). Hence, refinements have been called for 
to increase the predictive value of MT research (Carpenter et al., 2004; Hambrick, 2007).

\section{Power and status differences}

One of the most commonly addressed refinements in MT research is the influence of power and status difference on MT processes. Experiences and perspectives of the most powerful and dominant team members heavily influence MT strategic decision making (e.g. Finkelstein, 1992; Mathieu et al., 2008). Scholars show that the most powerful team members also have the highest impact on strategic decision making processes (Bunderson, 2003; Finkelstein, 1992; Finkelstein \& Hambrick, 1996). MTs' power inequalities have been suggested to hamper the coherence and the willingness to collaborate among MT members (Amason, 1996; Hambrick, 1994; Srivastava et al., 2002).

In line with this research, Hambrick (1994) posited that not only the hierarchical power and status differences within teams influence the strategic decision making process, but that MT members' perceived importance of themselves is also a factor. According to Hambrick (1994), MTs not necessarily act as teams, but as semiautonomous barons or officers because of the amount of decision making discretion and independence they experience in their work. However, since team-like properties are critical for MT success, Hambrick (1994) introduced the behavioral integration construct - the degree to which MT members mutually and collectively interact. MTs that are behaviorally integrated capitalize more effectively on diverging perspectives and generate higher qualitative strategic decisions (Boone \& Hendriks, 2009; Carmeli \& Schaubroeck, 2006).

Unfortunately, while studying MT performance, MT research has primarily focused on the specification of compositional and process contingencies (c.f. Bantel \& Jackson, 1989; Boone \& Hendriks, 2009; Bunderson, 2003; Knight et al., 1999). That is, MT scholars have only been giving scant attention to contextual and structural determinants (e.g. Carpenter et al., 2004; Jackson, Joshi, Erhardt, 2003; Joshi \& Roh, 2009). For example, MT studies scarcely describe the process of aligning and balancing the divergent goals and objectives of organizational sub-units, despite its critical role in the functioning of MTs.

\section{Dual allegiance}

Dual allegiance has only been given scant attention in the literature and we believe this is because MT researchers have implicitly preserved the assumption that MTs are isolated units (Abrams \& Hogg, 2004; Haslam, Powell, Turner, 2000; Li \& Hambrick, 2005) where individual team member characteristics influence team processes (e.g. Carpenter et al., 2004; Certo et al., 2006; Jackson et al. 2003). MT members, however, emanate from different echelons or organizational units and represent these different entities while pursuing their jobs (Cohen \& Bailey, 1997; O’Toole, Galbraith \& Lawler, 2002). Not only do MT members derive a sense of status, pride and accountability from this "representative role", it also implies that they continuously need to balance their 
organizational and sub-unit responsibilities (Bunderson \& Sutcliffe, 2002; Lewis, 2000; Srivastava et al., 2002).

According to Hambrick (1994; 2007), MT members are generally not motivated to share interest in the concerns of fellow members, because of the manner in which organizations are structured. Reward systems are, for instance, primarily focused on sub-unit or personal performance indicators, de-emphasizing organizational interests (Friedkin \& Simpson, 1985; Homan et al., 2008). Their job role, however, expects them to also be concerned with organizational interests (Bunderson \& Sutcliffe, 2002; Cohen \& Bailey, 1997). MT scholars acknowledge this structural factor to negatively influence intra-team dynamics and to create a more competitive atmosphere than is commonly the case for other organizational teams (e.g. Hambrick, Li, Xin, Tsui, 2001; Katzenbach, 1998; Li \& Hambrick. 2005). So, MT members' conflicts of interests do not only reside in personal characteristics, but also in the structural design of organizations (Joshi \& Roh, 2009). Only a limited set of studies paid attention to explore how friction between collective interests impacts MT processes (see for exceptions Li \& Hambrick, 2005; Li, Xin \& Pillutla, 2002).

\section{CONSEQUENCES OF DUAL ALLEGIANCE AT THE INDIVIDUAL LEVEL}

In this section we elaborate on the pivotal role of dual allegiance for the individual MT member and argue that social identity and boundary theory are appropriate lenses to understand how MT members experience this phenomenon. Social identity theory explains the importance MT members attach to the accomplishment of organizational group goals, while boundary theory contributes to the understanding of goal alignment.

\section{Social Identity Theory}

The core assumption of social identity theory is that people's self-concept is for a substantial part determined by the collectives they are part of, because people have an innate need to belong to groups and be distinct from others at the same time (Tajfel, 1974; Turner, 1975). The structuring of organizations in organizational groups (i.e. units, divisions, departments) fulfills this need of employees within the context of the overall organization (Ashforth \& Mael, 1989). According to social identity theorists, the partitioning of organizations into organizational groups affords perceiving organizations as a constellation of organizational sub-identities and as an important source of intra-organizational conflict (Albert \& Whetten, 1985; Ashforth \& Mael, 1989; Dukerich, Golden, Howell, 2002). This is, because organizations are designed in such a way that organizational groups are continuously competing for limited resources and often this competition is strengthened by the manner in which reward systems encourage the achievement of individual group goals (Ashforth \& Johnson, 2001). From a social identity perspective, the MT is thus a setting in which various competing organizational sub-identities come together and need to be aligned in the best interest of the MT. 
Further, social identity theorists suggest that identifying with a lower-order organizational group enables MT members to easier fulfill their need of uniqueness than identifying with a more inclusive higher-order group as the MT. Sub-identities are generally more exclusive and their goals are more tangible and concrete than higherorder organizational identities (such as a MT). Actions and activities in the sub-unit are more direct and visible in comparison to those in the MT which are most often indirect and delayed (Ashforth \& Johnson, 2001; van Knippenberg \& Schie, 2000). For example, because interaction of MT members with organizational team members in the sub-unit is far more frequent and proximal, goal accomplishments are much more visible than in the MT. This makes it easier for MT members to develop fine distinctions in their work and demarcate areas of expertise from which they can derive uniqueness and distinctiveness (Ashforth \& Mael, 1989; Dukerich et al., 2002). MT goals are more abstract, which means that, when identifying with the MT, it is more difficult for MT members to create a sense of distinctiveness. Thus the discussion above underlines the importance of MT members' identification with lower-order organizational groups as it is critical for the creation of their organizational selfconcept. It allows MT members to feel distinct, while being part of the larger organization (Ashforth \& Johnson, 2001; van Knippenberg \& Schie, 2000).

Vital for our understanding of dual allegiance is that organizational subidentities are generally nested within higher-order MT identities. This implies that the activities and actions of organizational groups are the means by which higher-order goals are put into practice (Brown, 1969; Albert \& Whetten, 1985). The nested characteristic thus implies that overlap exists among higher-order and lower-order organizational group goals (Ashforth \& Mael, 1989; Hornsey \& Hogg, 2000). In holographic organizations (Albert \& Whetten, 1985)—where the overarching organizational identity is dominant in all organizational sub-identities-researchers thus assume that it is unlikely that conflicts of interest emerge between higher-order and lower-order entities.

However, the increasing complexity and size of modern organizations makes that organizations are increasingly becoming ideographic in nature which means that organizational sub-identities are often (partially) deviating from higher-order organizational identities (e.g. Ashforth \& Mael, 1989; Dukerich et al., 2002). For example, overall long-term organizational goals can be in conflict with more short-term oriented sub-unit goals. Or, alternatively, tensions may exist between divisional or departmental interests; while marketing puts its emphasis on expanding sales, the production department considers efficiency in the production processes more important (Polzer et al., 1999). Research evidence also confirms this assertion that goals of organizational sub-identities may be in conflict with higher-order organizational goals (Brown, 1969; Glynn, 2000; Polzer, Steward \& Simmons, 1999; Rotondi, 1975).

We acknowledge that, in reality, MT members often participate in more than two organizational groups, but based on the social identity saliency principle (Tajfel, 1975; Turner, 1986) we infer that, within the MT context, it is most likely that two nested organizational group identities are especially salient, the MT and the organizational sub-unit respectively. Salience is defined as 'the probability that a social 
identity is invoked' (Ashforth \& Johnson, 2001, p. 32). The saliency of an identity is highly context dependent and is a function of the subjective importance and situational relevance of the identity to the person (Ashforth \& Johnson, 2001). For example, it is unlikely that a MT member will identify with his/her identity as orchestral musician when being in a business meeting. Although the identity as orchestral musician may be subjectively important to the manager, the context is not very likely to trigger this association. In other words, the situational relevance determines the saliency of organizational group membership. Given how organizations are structured-the MT as higher-order organizational "locale" in which lower-order sub-unit identities should be integrated and aligned (Silva \& Sias, 2010)-we assume that, within the context of the MT, MT members' identification with the MT and organizational sub-unit are most likely to be invoked (i.e. dual identification).

\section{Boundary Theory}

Social identity theory describes why and what value MT members ascribe to organizational groups. The theory fails to explain what happens if MT members need to commute between higher-order and lower-order organizational responsibilities. By means of boundary theory we are able to explain what happens when MT members need to align different organizational responsibilities and how MT members' dual identification impacts the commuting across identity boundaries.

According to boundary theory, people construct psychological or physical boundaries to simplify and order the environment (Kreiner et al., 2006a; Weick, 1995). When organizational actors create boundaries to simplify the distinction between their organizational responsibilities, this also complicates the act of switching between organizational responsibilities. The thicker or more impermeable the perceived boundary between organizational social groups becomes, the more difficult the alignment and balancing of deviating goals and interests (Ashforth et al., 2000; Kreiner et al., 2006a). For example, an MT member who perceives impermeable boundaries between his MT and sub-unit appreciates a strong differentiation between being a MT member and sub-unit representative and would not integrate aspects of sub-unit representativeness into MT membership. Someone who perceives the boundaries to be more permeable would allow aspects of his/her role as sub-unit representative to influence his/her MT membership. The permeability of boundaries thus determines whether organizational features are integrated with or differentiated from other organizational features (Pratt \& Foreman, 2002).

The permeability and location of the boundaries are socially constructed and subject to change (Weick, 1995; Kreiner et al., 2006a). This means that MT members are able to re- negotiate the boundaries, depending on how they perceive the existing boundary between aspects. For example, MT members may experience confusion when the boundary of an organizational group is too permeable and, as a consequence, they perceive MT goals to be overrepresented relative to their sub-unit goals (Ashforth et al., 2006). In this case, the permeable boundary tolerates too many MT responsibilities to integrate with sub-unit responsibilities and this leads to blurred expectations regarding MT members' job roles (Katz \& Kahn, 1978). In order to restore expectations, MT 
members may choose to strengthen the boundary to more clearly demarcate different job domains (MT and sub-unit). For example, MT members may choose to oppose specific MT policies, because these do not enough acknowledge the interests of the organizational sub-unit.

\section{Experience of Dual Allegiance}

What can we learn from combining social identity theory and boundary theory for our understanding of MT members' individual experience of dual allegiance ${ }^{3}$ ? To start, we should note that in the language of boundary theory, the MT and organizational subunit identity are cross-cutting and thus partially integrated domains (Kreiner, Hollensbe \& Sheep, 2009). As Figure 1 illustrates, there is a unique area for the MT identity, a unique area for the sub-unit identity and an area in which MT and sub-unit identity overlap. The degree to which MT members perceive the higher-order MT and/or lower-order sub-unit identity to be a significant part of their self-concept (i.e. identification) influences their experience of dual allegiance and this has consequences for the ease with which MT members can psychologically transit from MT responsibilities to organizational sub-unit responsibilities and vice versa (Ashforth et al., 2000).

Following Ashforth and colleagues (2000), identification does not only determine the psychological lens through which MT members make sense of the world around them, but it also establishes the strength of the psychological boundaries around organizational group identities. In other words, if MT members strongly identify with the MT, they primarily interpret organizational events from a MT member perspective and will experience difficulties interpreting events from the perspective of the organizational sub-unit. The stronger the MT identification is, the more important

MT members perceive MT responsibilities to be and the more difficult a switch towards the fulfillment of sub-unit responsibilities becomes.

We visualized this in Figure 1A. The solid line around the management team identity indicates an impermeable MT identity boundary, while the dashed line indicates a permeable boundary around the sub-unit identity. This implies that the sub-unit identity is considered subordinate to and embedded in the MT identity. MT members who experience a "MT oriented" dual allegiance consider others that also classify as MT members as in-group members, while those who do not classify are out-groupers (Tajfel, 1982). Of course, the MT orientation is facilitated by the non-alignment in identification strength; when identification with the MT is stronger than with the sub-

\footnotetext{
3 Scant research attention has been devoted to the consequences of dual allegiance for individual MT members and MT processes. Using a role theory perspective, Li and colleagues (2002) argued that the differences in responsibilities would cause MT members to experience role conflict. They suggested that when MT members would identify strongly with both the higher-order MT identity and lower-order sub-unit identity people would get torn between organizational demands which would eventually harm MT processes. Since role theory goes beyond the scope of this chapter, we kindly refer to Chapter 3 of the dissertation for further inquiry. In this chapter, we limit ourselves to explaining the basic mechanisms of dual identification that are necessary to understand how individual MT members experience dual allegiance.
} 
unit. The bigger the difference in strength of identification between the MT and subunit, the more impermeable the perceived MT identity boundary will be and the more difficult it is to represent the 'weaker' sub-unit identity as a separate entity in the selfconcept. Along the same line of reasoning, and depicted in Figure 1B, MT members may also consider their sub-unit responsibilities to prevail over MT responsibilities (Sub-Unit orientation) and experience difficulties to include the MT identity as a significant part of their self-concept. The more oriented the MT member is toward one of the organizational group identities, the less flexible the MT member will be in accepting responsibilities or perspectives which are different from his dominant identification perspective (Roccas \& Brewer, 2002).

\section{Figure 1: Visualization of Identity Boundary Situations between MT and Sub-} Unit identities

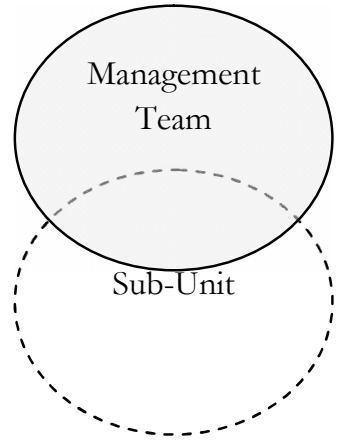

$1 \mathrm{~A}$

MT orientation

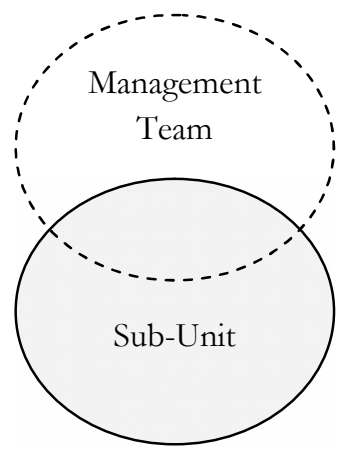

$1 \mathrm{~B}$

Sub-Unit orientation

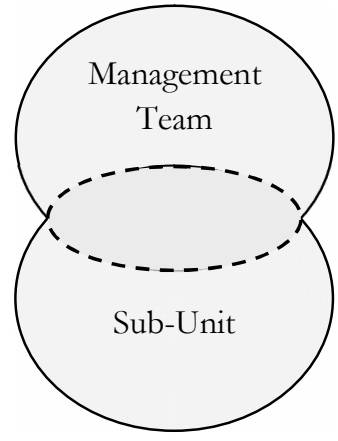

$1 \mathrm{C}$

Identity Synergy

Note: Solid lines indicate impermeable boundaries; Dashed lines indicate permeable boundaries

Since organizational sub-unit identities are organizationally nested in the MT, substantial overlap may exist between MT and sub-unit responsibilities. In terms of the accomplishment of responsibilities or acceptance of perspectives, a dominant MT members' identification may not cause much friction when the responsibilities are located in the overlapping areas of the MT and sub-unit identity. In figure $1 \mathrm{~A}$ and $1 \mathrm{~B}$ this would be the overlap between the solid and dashed circle. Fulfilling sub-unit responsibilities automatically means fulfilling those of the MT. However, as discussed before, the nested lower-order organizational responsibilities may often be incongruent with the higher-order ones. In Figure $1 \mathrm{~A}$ and $1 \mathrm{~B}$ these responsibilities would reside in the unique areas of the MT and sub-unit identity. This implies that not all responsibilities can be sufficiently fulfilled.

Drawing from optimal distinctiveness theory (e.g. Brewer, 1991) there are limits to the degree that a person's identification can overrun another identification, as this would violate MT members' perception of distinctiveness, inclusion and self- 
concept consistency. The violation would foster confusion and anxiety about what responsibilities need preference (Kreiner et al., 2006b; 2009). Therefore, researchers argue that to solve and avoid these self-concept inconsistencies, people are continuously in search of a balance between identifications that provides an optimal fit between inclusiveness, uniqueness and self-concept consistency (Brewer, 1991; Kreiner et al., 2006a; 2006b).

To achieve this balance, it is necessary that the MT and sub-unit identifications are strong and closely aligned (Brewer, 1991; Richter, West, van Dick \& Dawson, 2006; Vora \& Kostova, 2007). Recent research by van Dick and colleagues (2008) shows that optimal outcomes are reached if people strongly identify with higherorder and lower-order organizational groups. When MT members strongly identify with both organizational groups, the boundary interface between the identities is permeable enough to allow for an optimal fit between inclusiveness and uniqueness (Kreiner et al. 2006a). This situation of identity synergy, as depicted in Figure 1C, affords the "facilitation of an appreciated exchange in which a person's self-concept is perceived as neither too unique nor too inclusive in relation to the other organizational group identity" (Kreiner et al. 2006a ; p.1331). Thus, when MT members identify with both their higher-order MT and lower-order organizational sub-unit they are able to recognize and embrace the non-convergent responsibilities of both organizational entities, without this emerging into within person role conflict.

\section{CONSEQUENCES OF DUAL ALLEGIANCE AT THE TEAM LEVEL}

Regarding our research question, and given the different ways in which individual MT members experience dual allegiance, how does dual allegiance influence processes at the team level of analysis? For this purpose, we have developed a theoretical framework and we argue that the average levels of dual identification strength and alignment influences MT task conflict, MT relationship conflict and MT behavioral integration. To ease interpretation, we follow Klein and Kozlowski (2000) and consider dual identification a shared team property; originating at the individual level but held in common by all members of the MT. Put differently, we consider the MT to consist solely of MT oriented members, Sub-unit oriented members and members who identify with both the higher-order MT and lower-order sub-unit (alignment of dual identification). However, we are aware of the complexities and challenges that aggregating to the team level entails and by no means have the ambition to neglect any possible configural properties (see Klein \& Kozlowski, 2000) of MT members' dual identification. Yet, for conceptual robustness we focus on homogenous MTs in terms of dual identification levels.

\section{A Dual Identification Framework at the MT Level}

Based on the existing literature we have reviewed, dual identification influences MT processes via two main forces. First, MT processes are influenced by dual identification strength. MT members may identify stronger or weaker with their MT and sub-unit, 
depending on the extent their basic needs such as belonging and distinctiveness are met (Brewer, 1999)). Second, MT processes are influenced by the relative alignment of MT members' dual identification strength. Aligned levels of dual identification influence MT processes differently than non-aligned levels of dual identification (i.e. a persons' identification with one organizational group is stronger than with another).

The combination of these two forces results in a 4-cell matrix that helps to understand how MT members' dual identification influences MT conflict and behavioral integration. The matrix is visualized in Figure 2. As described above, alignment of dual identification results in cognitive consistency and permeability of the perceived boundaries between MT and organizational sub-unit (Festinger, 1975; van Knippenberg et al., 2004; Kreiner et al., 2006). We expect more positive outcomes regarding MT conflict and behavioral integration when dual identification strength is aligned. Along this line of reasoning, we build on research of van Dick and colleagues (2008) who found proof for their assumption that stronger levels of aligned dual identification yielded more positive outcomes than weaker levels of aligned dual identification.

Unaligned levels of dual identification imply that MT members are either more MT or sub-unit oriented and that a difference in identification strength exists (van Dick et al., 2008; Ashforth et al., 2000). The direction and difference in non-alignment (MT versus sub-unit orientation) determine the impermeability of the boundary between MT and sub-unit and the difficulties MT members experience when they want to switch between organizational groups. For instance, stronger MT identification will result in a stronger compliance with organizational responsibilities and dissociation from sub-unit responsibilities, while stronger sub-unit identification will have the reverse effect. In sum, we expect the strength and alignment of MT members' dual identification to affect MT conflict and behavioral integration.

\section{Dual Identification Regarding Task Conflict}

Previous literature consistently defines task conflict as disagreement regarding the task being executed; that includes differences in opinion, viewpoints or ideas (Jehn, 1995). A long line of research has regarded task conflict to have positive outcomes, especially when the tasks to be performed are complex and ambiguous, such as in an MT (e.g. Jehn, 1995; Jehn \& Mannix, 2001; Olsen, Parayitam \& Bao, 2007). Task conflict is deemed cognition based and considered beneficial for MT functioning when it is addressed constructively (Gibson, 2001; Marks et al., 2001). When MTs are unified enough to allow for coordination and diffused enough to maximize information flows (e.g. De Dreu \& Weingart, 2003; Gibson, 2001; Gladstein, 1984), constructive task conflict prompts substantive and issue-related disagreements. MT scholars argue that this results in the better integration and combination of knowledge (Amason, 1996; Eisenhardt \& Bourgeois, 1988; Amason \& Mooney, 1999). Since task conflict is believed to be an inherent and naturally occurring phenomenon in properly functioning MTs (e.g. Amason, 1996; Amason \& Mooney, 1999), we refer to constructive levels of task conflict when using the task conflict construct. We expect a polynomial 
Figure 2: 4-Cell Matrix for MT Level Dual Identification

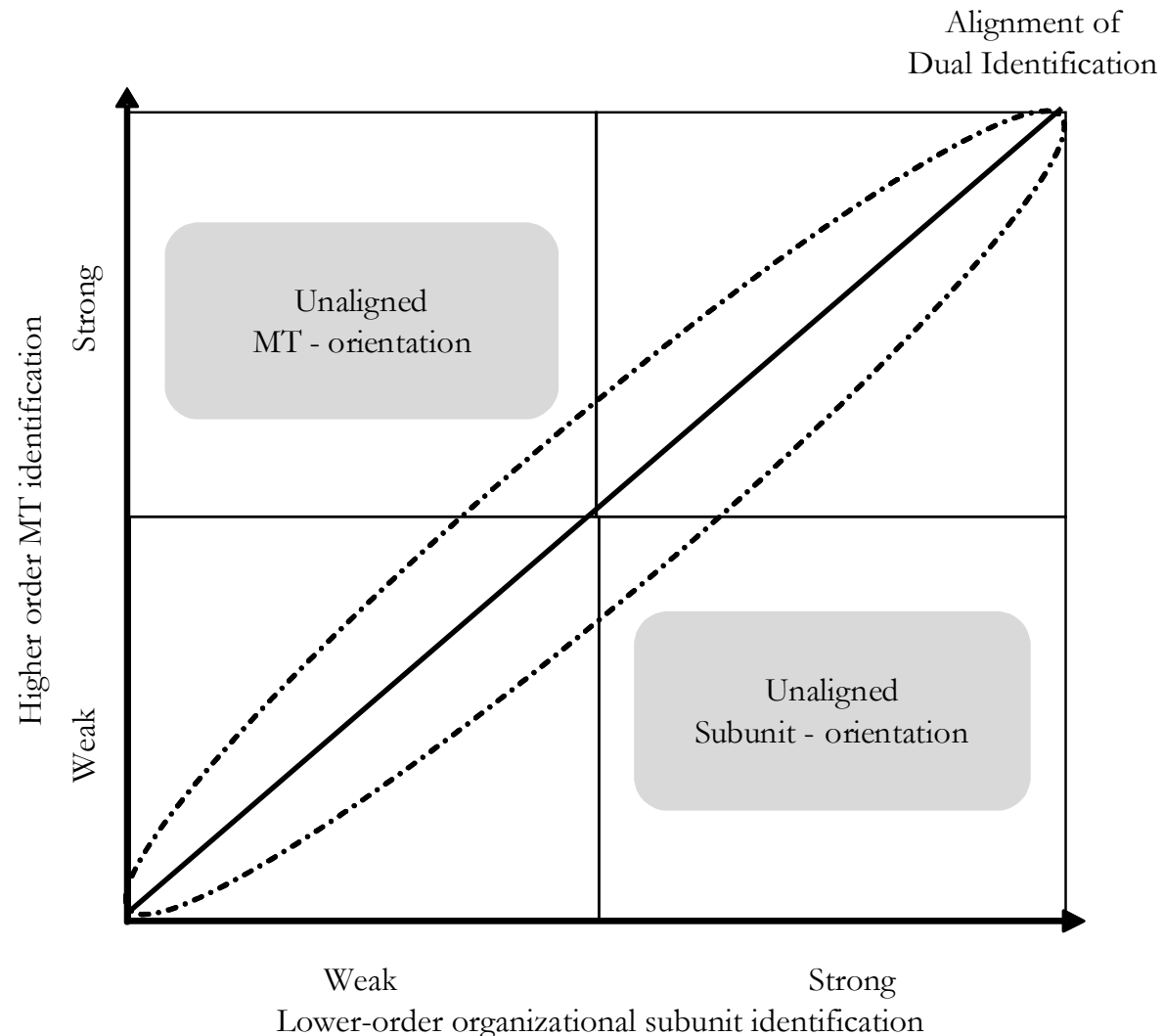

relationship between MT members' dual identification and task conflict and will explain this further in the remainder of this section.

Literature argues that when MT members identify with the MT, constructive levels of task conflict are guaranteed (Ashforth \& Mael, 1989; van der Vegt et al., 2003; Tajfel, 1982). Empirically, however, research results seem to suggest that MT identification alone is not enough for constructive levels of task conflict (Brodbeck, et al., 2007; Hollenbeck et al., 2005). Despite some evidence that MT identification adds more to MT functioning than no MT identification (e.g. van der Vegt \& Bunderson, 2003), research fails to indicate that MTs, by means of developing MT identification among its members, are capable to exploit the team's full knowledge potential (e.g. Brodbeck et al., 2007; Han \& Harms, 2010; Harrison \& Klein, 2007).

Unaligned MT orientation. A too strong internalization of MT goals and interests can lead to closed-mindedness, biased decision making and groupthink (e.g. Brodbeck et al., 2007; Janis, 1982; Schulz-Hardt, Frey, Lüthgens, Moscovici, 2000). When MT members experience dual allegiance as more MT-oriented-strong MT identification relative to sub-unit identification (as depicted in the upper-left corner of Figure 2)-a situation occurs in which the organizational sub-unit is considered of minor 
importance in comparison to the encompassing MT (Hogg \& Terry, 2000). In the language of boundary theory, the strong MT identification integrates all diverging subunit identifications into an overarching MT identity which is shared by all MT members (Ashforth et al., 2001). Additionally, the strong MT identification creates an impermeable boundary for MT members to "enter" or "exit" their MT member role. In other words, they are stuck in interpreting events via the MT identity lens and are more inclined to hold back personal ideas or viewpoints because it is not in the best interest of the MT or because they do simply not consider sub-unit or personal information relevant as this is psychologically located in a separate domain. As a result, under these circumstances, levels of pronounced and constructive task disagreements will be low.

Unaligned sub-unit orientation. Vora and Kostova (2007) pronounced that MT members' organizational sub-unit identification is key for capitalizing on the full knowledge potential among MT members. When MT members identify strongly with their sub-unit they are more inclined to defend their goals and interests within the MT and in this manner sub-unit identification is critical in the emergence of constructive task conflict. However, when this strong sub-unit identification is not counterbalanced by MT identification, a non-alignment emerges in which MT members experience dual allegiance as more sub-unit oriented-identification with sub-unit is stronger than with MT (a situation depicted in the lower-right corner of Figure 2). When MT members identify more strongly with their organizational sub-unit, higher value is attached to the responsibilities of the sub-unit (e.g. van Knippenberg \& Schie, 2000; Vora \& Kostova, 2007). The sub-unit orientation then increases the contrast between the perceived importance of MT and sub-unit responsibilities (Louis, 1980). In terms of boundary theory, the interface between the MT and sub-unit becomes more impermeable and thicker, segmenting the organizational identities. This "mental fence" (Ashforth et al., 2000 , p. 476) makes the integration of perspectives or ideas difficult. Glynn (2000) has illustrated how such a mental fence may result in social identity conflicts in the MT of an Australian orchestra when musicians and managers disagreed on how to proceed with the orchestra after a re-organization. Here, disagreements emerged because the parties concerned were too much involved in defending their own goods, while losing sight of the bigger picture; the interests of the orchestra. Hence, differences regarding too much sub-unit orientation are thus likely to result in substantive, but unconstructive task disparities.

Alignment of dual identification. Ashforth, Rogers and Corley (2010) suggest that in such situations a higher-order identity, such as the MT, may function as foil to reconcile the sub-unit identity conflicts. Based on the dual identification perspective we derive that when MT members exhibit a strong level of identification with both the MT and organizational sub-unit, its members are better able to understand the importance of the goals and interests of the overarching organization and sub-unit (cf. Reade, 2001; Vora \& Kostova, 2007). When dually identified, MT members not only pursue the interests of the lower-order organizational sub-unit, but also give way to the overarching organizational goals. The alignment decreases the perceived contrast between identities and adapts the perceived permeability of the interface to such an extent that an optimal transition across boundaries is possible 
(Ashforth et al., 2000; Kreiner et al., 2006). That is, in MTs where its members identify as strongly with the MT as with the sub-unit, persons are capable of looking for a common ground (i.e. MT identification) to keep all members involved, while at the same time being aware of the responsibilities they have as sub-unit representative (i.e. sub-unit identification). In other words, MT members who identify with the MT as well as their sub-unit distribute diverse viewpoints and differences of opinion more constructively among MT members than members with an unaligned dual identification structure (MT or Subunit orientation) (e.g. DeDreu \& Weingart, 2003; Gibson, 2001). Earlier we referred to this condition as identity synergy; the combined result of both alignment and strength of dual identification.

The stronger the aligned identification of MT members with MT and organizational sub-unit will be, the more constructive the task conflict as it will get easier for MT members to create a common ground with which task conflict can be soothed. We base our assumption on Vora and Kostova's (2007) work who posit that stronger dual identification increases the basis for understanding different organizational responsibilities. We believe that stronger dual identification levels among MT members strengthen the base for collective understanding within the MT. Consequently, when dual identification weakens, constructive task conflict decreases as MT members become less concerned with the various organizational responsibilities. We assume that, in such a situation, MT members are primarily personal career oriented and will engage in the minimum job necessities only. As a consequence, levels of task conflict are low and non-constructive. The following propositions reflect these ideas.

Proposition 1a: (Constructive) task conflict will be higher when MT members' dual identification is aligned and strong rather than aligned and weak.

Proposition 1b: (Constructive) task conflict will be lower when MT members' dual identification is more unaligned and MT or sub-unit oriented rather than more aligned and weak.

\section{Dual Identification Regarding Relationship Conflict}

Relationship conflict is defined as interpersonal struggles, annoyances or disagreements among team members (Jehn, 1995). In essence, relationship conflict is detrimental to MT performance, regarding productivity, consensus building and satisfaction (Amason, 1996; Jehn, 1995; Pelled et al., 1999). Relationship conflict hampers effective team processes as it consumes cognitive processing capability, time and energy that MT members otherwise could have used for task-related work. It makes team members less receptive to other people's ideas especially of those they do not like (Jehn, 1995).

Unaligned MT orientation. Social identification protagonists infer that strong identification with the MT will distract attention away from the differences between subgroups and transform MT members' perception from "them" and "us" thinking into "we" thinking. According to the common in-group identity model intergroup biases and stereotypical attributions decrease and interpersonal liking increases when everyone identifies with the MT (Gaertner et al., 1994). Boundary 
theorists explain this via the complete overlap that exists between aspects that define MT identification and sub-unit identification. Differences between sub-units are overwritten by a focus on what MT members may have in common (Ashforth et al., 2000). Since MT members mainly define themselves in terms of MT membership interpersonal differences are almost non-existing and a "we are in this together" thinking among MT members is triggered (Mortensen and Hinds, 2001). Hence, when MT members' dual allegiance is not aligned and more geared towards the MT (depicted in the upper-left corner of Figure 2), relationship conflict is thus expected to be low.

Unaligned sub-unit orientation. Especially for upper echelon managers a sense of authenticity, prestige and status is important in their work (Hambrick, 1994; 2007). Recently, Carmeli, Shteigman and Haslam (2001) found empirical evidence that prestige and status are, indeed, important antecedents for MT members to identify with organizational groups. Perceptions of divergent group membership has repeatedly been proven to generate competitive and aggressive atmospheres that threaten social harmony (e.g. Hornsey and Hogg, 2000; Pelled et al., 1999; Tajfel, 1982). In situations where MT members identify strongly with the sub-unit (see lower-right corner of Figure 2), but alignment with the MT identity is not reached, the organizational subunit boundaries are impermeable and sub-unit goals, norms and values are easy to compartmentalize (Ashforth \& Mael, 1989). Each sub-unit representative then appears a "self-contained gestalt" (Ashforth et al., 2000; p. 477) and we assume the need for separation and autonomy to be strongest. In other words, we expect MT members, who are more strongly identified with the organizational sub-unit, to derive more value from their position as sub-unit representative and to sooner engage in differentiating behavior. Here, distorted group interactions such as tensions, disharmony, and animosity, commonly defined as relationship conflict, will be most likely (Hornsey \& Hogg, 2000; Richter et al., 2006).

Alignment of dual identification. According to optimal distinctiveness theory (Brewer, 1991), most harmonious group interactions and thus lowest levels of relationship conflict are achieved if identification with the MT and sub-unit are aligned. The optimal balance is experienced when MT members feel member of the MT and still feel distinctive enough as sub-unit representative. In such situations, the overarching MT identification settles awareness of the importance of the higher-order goals and buffers the sub-unit favoring behavior resulting from sub-unit identification.

In contrast, MT members who do not or only weakly identify with the MT and sub-unit do not derive any sense of belonging or distinctiveness from group membership. We do not expect these MT members to express any interpersonal animosity. Of course, weak identifiers may engage in intergroup comparisons based on demographical or personal differences, but this is beyond the scope of this paper. Hence, under conditions of strong MT identification, MT members' organizational subunit identification may foster less relationship conflict. Identification with organizational sub-units increases relationship conflict if strong MT identification is absent. Therefore we propose: 
Chapter 2

Proposition 2a: The more aligned MT members' dual identification, the lower relationship conflict.

Proposition 2b: Relationship conflict will be higher when MT members' dual identification is more unaligned and sub-unit-oriented than unaligned and MT oriented.

\section{Dual Identification Regarding Behavioral Integration}

According to Hambrick (1994), researchers should not use the functioning of project or work teams, which he calls 'real' teams, as benchmarks for MTs. Despite the fact that MTs cannot actually be considered 'real' teams; the degree that these teams function as integrative and coherent entities is important for MT functioning. While conflicts capture the extent to which valences in MTs differ, the construct does not sufficiently describe what happens within MTs (Hambrick, 2005). Hambrick (1994) therefore introduced the term behavioral integration and defined this as the mutual and collective interaction among MT members. MT success, he argues, depends on how well MT members share information, engage in joint decision making and collaborate. He integrated these constructs into the meta-construct behavioral integration.

Unaligned MT orientation. Because the character of MT work does not encourage too regular team interaction, MT members' identification with the collective may be an important prerequisite for effective MT behavioral integration. Recent research confirms that social identification effects transcend from person's cognitions and perceptions to behavior (Ashforth, Harrison \& Corley, 2008). Carmeli and Shteigman (2010), indeed, find supportive evidence of MT identification to associate with behavioral integration and that MT members who identify with the MT are inclined to make more efforts on behalf of the MT. Other studies have shown linkages with cooperative behavior and citizenship behavior (e.g. Brewer, 1999; Dukerich Golden \& Shortell, 2002; van der Vegt et al., 2003; Swaab et al., 2008). Hogg and Terry (2000), for example, suggest strong MT identification to improve the cooperative stance of team members and to promote open discussions and effective considerations of alternatives. Van der Vegt and colleagues (2003) imply that strong MT identification may mediate helping and loyal behavior of MT members. Lau and Murnighan (2005) demonstrate that less impermeable and weaker intra-group boundaries increase communication within teams. They find that team members exhibit more constructive team behavior such as asking questions or reflecting on team results when they perceive the team to be a strong unitary collective.

Unaligned sub-unit orientation. Strong organizational sub-unit identification is necessary, however, for a thorough representation of more specific subunit goals and interests (Vora \& Kostova, 2007). When MT members identify with their own organizational sub-unit, they are motivated to address unit specific doubts, problems or ideas they perceive relevant for organizational wide decision making (Glynn, 2000; Simon \& Klandermans, 2001). On the other hand, the saliency of subidentities also triggers interpersonal competition (Hornsey \& Hogg, 1999; Kreiner et al., 2006). When MT members identify one-sidedly with their organizational sub-unit, the 
boundary interface is strong and impermeable (e.g. Ashforth et al., 2000), causing unaligned dual identification with a strong sub-unit orientation in the MT.

Alignment of dual identification. Hornsey \& Hogg (2000) posit that to mitigate the need for self-enhancement and interpersonal competition aligned and strong dual identification with MT and sub-unit is needed. Recently, van Dick et al. (2008) have found evidence for the assumption that aligned and strong dual identification benefits behavioral integration. In a study among bank employees they demonstrated a positive relationship between dual identification and frequency of information exchange, helping behavior and loyalty-behaviors that are closely related to the behavioral integration constructs-among team members. Similarly, Vora, Kostova and Roth (2007) found a positive relationship between strong dual identification and role fulfillment among subsidiary managers of multinational enterprises. Building on the argumentation above, we expect MT members' alignment and strength of dual identification (with MT and sub-unit) to increase the quality of behavioral integration among MT members. We propose that:

Proposition 3a: Behavioral integration will be highest when MT members' dual identification is aligned and strong rather than aligned and weak.

Proposition 3b: Behavioral integration will be higher when MT members' dual identification is more unaligned and MT -oriented rather than more unaligned and sub-unit oriented.

\section{DYNAMICS OF DUAL IDENTIFICATION}

In our discussion thus far we have described the consequences of dual identification on MT processes, but we have not yet reflected on the dynamics of dual identification. A wide array of perspectives exists in the camp of social identification scientists regarding the stability of people's identifications. Whereas structural oriented researchers argue that identifications are mainly stable and fixed, more action oriented researchers see identifications as fluid and malleable (see Ashforth et al., 2010). In this section we argue that the strength and alignment of MT members' dual identification are constantly in flux and depend on the context within which MTs operate.

\section{Bottom-Up Formation of Dual Identification}

Earlier, we described the MT as a "locale" where lower and higher order identities should be integrated. We further explained that MT members develop stronger identifications with their lower-order organizational sub-unit than with the higher-order MT, because the sub-unit is more concrete and tangible (Ashforth \& Johnson, 2001; van Knippenberg \& Schie, 2000). Hence, it is very plausible to expect that MT members' sub-unit identifications shape their initial expectations regarding MT processes and therefore complicate the formation of an MT identification. Recent research by Eisenbeiss and Otten (2008) and Gleibs, Noack and Mummendy (2010), 
indeed, points in that direction. Eisenbeiss and Otten's (2008) study on cross-sectional and longitudinal predictors of dual identification in flight attendees suggest that lowerorder identifications negatively influence the formation of higher-order identifications. The study of Gleibs and colleagues (2010) hints into the same direction. They show pre-merger identification to increase in-group (i.e. pre-merger) favoring behavior and to negatively influence the attitude towards the merger.

Support for a bottom-up process of dual identification also comes from research on the intergroup contact theory (Allport, 1954). This theory proposes that interaction among MT members decreases interpersonal biases through the balancing of people's higher and lower-order identification (Giessner \& Mummendey, 2008). Recent research by Binder et al., (2009) demonstrates that interpersonal contact and interpersonal biases reciprocally affect each other over time. Thus, interpersonal contact does not necessarily improve interpersonal relations. Lower-order identifications may equally likely steer interaction processes and contribute to the formation of MT identifications (Postmes et al., 2005; Swaab, Postmes, Spears, 2008). What does this mean for dual identification dynamics in MTs? We will discuss this next.

\section{Dynamics of Dual Identification over Time}

In the context of the MT, MT members are continuously challenged to maintain a fit between their dual identifications (MT and organizational sub-unit). For example, MT members need to decide what resources to spend to the benefit of the MT or the subunit, what decisions or tasks deserve preference over others as the importance and relevance for the MT or sub-unit may vary etc. .These factors may influence the strength and alignment of MT members' dual identification and may prompt movements across the quadrants of the framework we introduced earlier (Figure 2). Kreiner and colleagues (2006a; 2006b) suggest that the dynamics in identification take place at the interface of the identity boundaries. They propose that, depending on the situation, MT members may perceive the identity boundaries as too segmented or too integrated and argue that this leads to perceived incongruency and conflictual identity boundary dynamics that MT members need to solve and ultimately may lead to identification changes. We argue that these circumstances may also arise in the context of the MT and thus influence MT members' dual identification strength. We describe two main conditions

First, the situation in the MT can be such that MT identification is perceived as extremely salient and MT members may feel their MT identification to dominate their sub-unit identification. For example, MT members may perceive the organizational financial performance targets to comprise a too dominant part of their overarching MT identification. MT members who represent different departments (i.e. $\mathrm{R} \& \mathrm{D}, \mathrm{HR}$ ) may have different foci and perceive different performance targets as core to their sub-unit. That is, when MT members perceive the higher-order MT goals to overrule the interests of the sub-unit, they may start to experience friction and anxiety that they want to have solved (e.g. Hogg \& Terry, 2000). Kreiner et al. (2006) introduced this construct as "intrusion" and argue that this occurs when "the identity boundary interface is perceived as being too permeable" (p. 1326). In the context of the 
MT, we believe this is most likely when MT members perceive their identification with the overarching MT to be stronger relative to their identification with the sub-unit. Given that MT members' sub-unit membership is central to their perception of self, as we discussed above (Ashforth \& Johnson, 2000; van Dick et al., 2008; van Knippenberg \& Schie, 2000), a strong perceived MT identification may thus subsume their sub-unit identification. This would violate their self-concept consistency and induce a state of anxiety.

Other conflictual situations may arise when the sub-unit becomes extremely salient. Then, MT members may identify so strongly with their sub-unit in comparison to the MT that they perceive their organizational sub-unit identification to be underrepresented in comparison to the overarching MT identification (Ashforth et al., 2000; Kreiner et al., 2006). Kreiner et al., 2006 labeled this as distance; "a situation where the boundary is perceived as too segmented or not permeable enough" (p. 1328). This situation is different from the situation described above as MT members now experience a too severe differentiation from, instead of integration with, the overarching MT identification. For example, in a MT setting such a situation could be described by an R\& D manager who feels that a larger part of the team's resources could be devoted to innovative measures rather than marketing practices.

In both circumstances a self-concept inconsistency thus needs to be resolved and we expect MT members to employ differentiating behavior and claim making processes to restore this imbalance (e.g. Brewer, 1991; Hornsey \& Hogg, 2000). In the situation in which MT members feel the MT identity to dominate, their behavior will be geared towards increasing the ratio of sub-unit identification versus MT identification in their self-concept and by this means restore the inconsistency. In the latter situation, MT members experience too much segmentation, and behavior will be directed towards a larger integration of MT identification in their self concept. Hence, various aspects in the context within which MTs operate make MT or sub-unit identifications more or less salient. These aspects may inflict a perception of self-concept inconsistency that direct MT members' behavior towards a dual identification change.

Whereas research is consistent regarding the context sensitivity of identification saliency (e.g. Ashforth \& Johnson, 2001; Hornsey \& Hogg, 2000), the time frame in which dual identification mechanisms take place is yet to be examined. Recent research by Fiol, Pratt and O'Connor (2010) suggest differences in the strength and intractability of experienced identifications on the work floor. They argue that the time frame in which dual identification change takes place is a function of the strength and intractability of identifications.

\section{DISCUSSION AND IMPLICATIONS}

To differentiate MTs from non-managerial teams, researchers have primarily stressed the complexity, ambiguity and higher impact of MT work (Bantel \& Jackson, 1999; Hambrick \& Mason, 1984). Significantly less attention has been given to the structural embeddedness of dual allegiances in MT work and the effects this bridging role of MT members has on overall MT functioning. While research on mergers and joint venture 
teams suggest that strong sub-unit identification poses a threat on the level of MT identification (e.g. Li et al., 2002), the simultaneous effect of sub-unit and MT identification has been only rarely investigated. For long MT scholars have recognized the complexities of strategic decision making in upper echelon teams and have developed theories on how MT members cope cognitively and behaviorally with these decision making complexities. Unfortunately, this research has rarely included the impact of multiple allegiances.

This chapter describes the importance of examining MT members' dual identification with MT and organizational sub-unit. We outline how dual allegiance influences MT processes in terms of task conflict, relationship conflict, and behavioral integration. In previous research, scholars have concentrated on understanding the functioning of MTs by focusing on team compositional variables as most critical determinants of MT processes and performance (Carpenter et al., 2004; Hambrick, 2007). We suggest MT processes to not only be the result of intra-team individual differences, but that MT processes may also be influenced by MT members' dual identification with the MT and organizational sub-unit. In doing so, we offer a new perspective on studying MT processes by recognizing the team-based structure that organizations are built on today.

\section{Theoretical Implications}

This view has three important implications for (management) team research. First, we answer a call to examine how MT members' social identification influences MT functioning in more detail (e.g. Carmeli \& Shteigman, 2010; Li \& Hambrick, 2005; Li, Xin \& Pillutla, 2002). Previous research that examined intra-team individual differences has proven to be inconsistent and inconclusive (Barrick et al., 2007; Certo et al., 2006). We introduce dual allegiance as a structural aspect of MT work and show how MT members' identification with these allegiances impacts MT processes. We add a fresh perspective to the study of MT processes and we shed some light on potential antecedents of MT dynamics. Building on recent work, we consider contextual factors influential determinants of MT work (cf. Joshi \& Roh, 2009), but expand the scope of analysis from an internal team to a more externally oriented perspective. We argue that MT work is as much a reflection of individual members' personal experiences and biases (Hambrick \& Mason, 1984) as a depiction of an institutionalized boundary crossing activity of MT members.

Second, we suggest using social identification as a "construct" instead of a "conceptual lens" to understand MT processes. Instead of using identification processes as unmeasured, implicit antecedents of MT processes, our perspective invites to test the underlying identification processes. By doing this, MT research may provide evidence of direct and explicit effects of identification processes and go beyond the currently often implied indirect effects via team compositional diversity components (e.g. Carpenter et al., 2004).

Third, our central ideas of the paper may be applicable to any organizational team where members are responsible for other intra-organizational entities. In modernday organizations, where team-based structures are increasingly becoming the norm, 
cross-team coordination and cooperation is critical (Mathieu et al., 2001). While an increasing number of scientists acknowledge the key role that social identification processes may play in inter-team processes, only a few actually measure it.

\section{Boundary Conditions}

Of course there are boundary conditions to the work presented. First, the suitability of the framework might be limited to organizations that encompass sufficiently interdependent organizational units. An important reason for this is that only organizations with relatively interdependent departmentalized or functionalist structures benefit from aligning diverging interests as their performance outcomes depend on the performance of others. For organizations where the organizational performance depends largely on the additive individual value of each organizational department, MTs might function best if partiality of sub-units is stressed. In these MTs, the assimilation of ideas and interests is much less of a problem to operate successfully (e.g. Brodbeck et al. 2007; Lau \& Murnighan, 2005).

Second, our model is built under the assumption that all MT members contribute equally to MT conflict and behavioral integration. However, it could well be that some MT members have a bigger impact on MT functioning than others or that over time MT members exercise differential effects on MT functioning. Similarly, we simplified the conceptual reasoning in this paper and conceptualized dual identification at the team level as an additive compilation of each MT members' experienced dual identification.

A third boundary condition of our model is the assumption that MT members' identification with MT is different from their identification with the organizational unit. Theory suggests that a distinction is necessary between holistic and ideographic organizations. Holistic organizations generally have an all encompassing organizational identity which is also strongly embedded in organizational sub-units. Ideographic organizations consist of departments who have differentiating organizational identities (Albert \& Whetten, 1985). Literature assumes there exists a relationship between the level of independence among organizational units and ideographic nature of the organization as a whole (e.g. Richter et al., 2006). The effects of organizational unit identification on MT interaction behavior might therefore be more pronounced in ideographic than in holographic organizations.

\section{Suggestions for Future Research}

The conceptual relationships we describe are used as a first means to explore the influence of MT members' identification with organizational groups. In this paper we focus on the ends of two social identification dimensions, but in practice, the configuration of MT members' identification with organizational entities is much more complex than suggested above. Future research should aim to further specify the functional form of these organizational group identifications and examine if any other combination of identification patterns may affect MT functioning differently. For instance, whereas we conceptualize how MT members' average levels of MT 
identification strength and organizational sub-unit identification strength influence MT processes, we have not conceptualized what effects diversity of identification strength within MTs could have on MT processes.

Second, we have indicated that MTs are different from non-managerial teams in terms of power and status differences. We do not deny that power and status differences play a pivotal role in MT processes, but have not formulated any specific propositions predicting potential effects of power on MT processes. Based on leadership literature that indicates the importance of leaders' levels of identification (e.g. Lord \& Hall, 2005; Day \& Harrison, 2007), more conceptual and empirical work in these areas would certainly provide interesting avenues for additional research in the context of (management) team leaders' identification effects on MT processes. For example, researchers could examine if the strength of team leader's dual identification has a bigger impact on MT processes than the strength of dual identification of other MT members.

Third, we shortly highlight the possibility that MT members' mutual and collective interaction may in itself influence the creation of MT identities. A more fine grained temporal perspective on how MT members' collective interaction would modify MT and organizational sub-unit identification could benefit upper-echelon team research. We suggest that the quality of behavioral integration among MT members influences the level of MT members' MT identification, but do not specify the temporal conceptualization for MT functioning in much detail. In the future, researchers are encouraged to test empirically if and how behavioral integration in MTs affects levels of team and sub-unit identification.

Lastly, we have not really addressed how dual identification may impact within person aspects. Studies investigating the effects of inter-role conflicts in top management teams suggest negative consequences on the individual level, but have not examined what this would imply when transcended to the team level (Li, Xin, Pillutla, 2001; Reade, 2000). MT members' dual identification may potentially cause within person conflicts and consequently have negative outcomes at the interpersonal and team level. We propose MTs with strong and aligned levels of identification to exhibit more positive interpersonal team behavior than MTs not experiencing such aligned levels of identification. We have not constructed propositions that specifically address how these process outcomes work out for individual MT members' levels of dual identification. For instance, do more constructive levels of task conflict enhance or mitigate the individually experienced tensions in dual allegiance?

\section{CONCLUSION}

Researchers have stressed the importance of investigating the black-box of the relationship between team composition and performance (e.g. Pelled et al., 1999). MT research has mainly focused on examining MT processes as if its members come to the MT as representatives of themselves ( $\mathrm{Li} \&$ Hambrick, 2005). To fully understand the functioning of MTs we contend that a thorough understanding of the structural divide present in the work of MT s is necessary. The suggested organizational allegiance 
framework is theoretically relevant as it enlightens a gap in upper-echelon team research taking into account that MT members represent organizational collectives within MTs. The extent to which MT members identify with these collectives contributes to the understanding of MT members' collective conflict perception and interaction behavior in the MT. In practical terms the framework sheds light on a structural aspect of the MT that can be adapted by changes in organizational and / or team design features. We encourage MT researchers to start contemplating and measuring how dual allegiance structures entrenched into MT design impact manager's behavior. 



\section{Chapter 3}

\section{Management Team Members' Individual Perception of Dual Allegiance: An Exploratory Interview Study ${ }^{4}$}

4 This chapter is based on the manuscript: - Cuijpers, M., Glunk, U. \& Heijltjes, M. Inside the Mind of the Management Team Member: The Perception of Dual Allegiancell, Manuscript submitted for publication. 


\begin{abstract}
In this chapter we explore management team members' individual perception and experience of dual allegiance in their daily work. More specifically, we explore to what extent and under which conditions management team members actually experience dual allegiance as problematic. We conducted an explorative interview study and use role theory in combination with social identity theory to interpret our findings. Main findings indicate that managers, due to dual allegiance, do experience role conflict in their daily job, but that the intensity of the experienced conflict is contingent upon specific conditions in the management team. Only under particular circumstances is the experienced dual allegiance perceived as problematic. We categorize and describe these circumstances in this chapter. Further, we highlight mechanisms that help alleviate problems of dual allegiance.
\end{abstract}




\section{INTRODUCTION}

Contemporary MT studies provide an ever growing body of literature on the contingencies under which MTs perform best (cf. Amason, 1996; Knight et al., 1999; Hambrick \& Mason, 1984; Li \& Hambrcik, 2005; Olsen, Parayitam \& Bao, 2007). In chapter 2 we built on this literature by indicating that an important factor often forgotten in MT research is how MTs are structurally embedded within more complex and larger systems and that MT members often fulfill multiple roles simultaneously. We defined this as dual allegiance; on the one hand, MT members are MT representative and support the interests and goals of the whole organization. On the other hand they are also responsible for a sub-ordinate organizational entity with different interests and goals that need to be sustained. When these two responsibilities are not well aligned, studies suggest that the conflict experienced by individual MT members will result in uncertainty and ambiguity regarding the accomplishment of these responsibilities. Consequently, the experienced uncertainty and ambiguity adversely affect MT processes and causes problems in the accomplishment of organizational goals (Katz \& Kahn, 1978; Li, Xin \& Pillutla, 201; Munyon, Summers, Buckley, Ranft \& Ferris, 2010).

Managing dual and divergent organizational accountabilities is thus a critical source of role conflict - the individual experience of incompatibility or incongruence in priorities of different organizational systems (Katz \& Kahn, 1978; Shenkar \& Zeira, 1992). Studies suggest that MT members at any hierarchical organizational level experience role conflict (e.g. Friedman \& Podolny, 1992; House \& Rizzo, 1972; Schuler, 1975). However, literature is equivocal in terms of the consequences of experienced role conflict. While studies on role conflict have found negative relationships with job performance and job satisfaction (House \& Rizzo, 1972; Tubre \& Collins, 2000), such detrimental effects have been less profound among MT members higher up the hierarchical organizational ladder (Gong et al., 2001; Shenkar \& Zeira, 1992). Thus, no consistent evidence exists that role conflict is actually problematic for MT members (e.g. Gong, Shenkar, Luo \& Nyaw, 2001; House \& Rizzo, 1972; Shenkar \& Zeira, 1992; Tubre \& Collins, 2000).

This inconsistency in findings has further been addressed in several metaanalyses (Abramis, 1994; Fisher \& Gitelson, 1983; Jackson \& Schuler, 1985; Tubre \& Collins, 2001), and resulted in a common conclusion that role conflict is less of an issue for organizational actors higher up in the organization (Floyd \& Lane, 2000). Regrettably, the lack of consistent evidence that perceived role conflict influences MT members differently has only received scant attention in the literature. As a result, literature is indecisive concerning the question if MT members, higher up the ladder, simply experience less role conflict or are confronted with any contextual or situational factors that mitigate the effects of incompatible expectations.

This is unfortunate as MT members are increasingly embedded in complex and multifarious networks of intra- and inter-organizational entities. MT members are thus confronted with more and more situations of dual allegiance in which contradicting job expectations may emerge. To properly understand the role of dual 
allegiance for individual MT members, we need to gain more in-depth knowledge about how MT members actually experience this dual allegiance at the individual level of analysis. Therefore, in this paper, we start to explore the following research question: How do MT members experience dual allegiance and under what conditions is this experience more or less problematic in their work.

The individual consequences of dual allegiance on MT processes can best be understood from role theory (Katz \& Kahn, 1978) and social identity theory (Tajfel, 1975; Turner, 1982). By combining these two theories we recognize MT members' organizational position as a job role and we go beyond seeing MT members as “isolated" individual actors (Li \& Hambrick, 2005). MT members' organizational position affords seeing MT members as representatives of the overarching organization as well as delegates of an organizational entity (i.e. department, division, unit). MT members' identification with both these organizational entities forms the lens through which they make sense of and enact upon the situation around them (Weick, 1995). Consequently, perceived conflict of organizational responsibilities may be a function of MT members' difficulties to appropriately balance the efforts to accomplish both parties' interests.

We conducted 11 explorative semi-structured interviews with MT members from five different organizations. In the sections that follow, we begin with a brief review of the literature on role theory and social identity theory relevant for explaining the experienced dual allegiance. Next, we describe the methodology used in this explorative study. In turn, we discuss how MT members actually experience the conflict based on dual allegiances and we describe what conditions strengthen and weaken the intensity of the experienced conflict. Lastly, we conclude this paper by describing our findings in light of existing theory and we provide theoretical and practical implications.

\section{CONCEPTUAL BACKGROUND}

\section{The Individual Experience of Dual Allegiance}

Role theory examines the multiple roles that people fulfill in a social system such as an organization. According to role theory, interpersonal exchanges shape people's expectations of the set of behaviors that fit to specific organizational roles (Biddle, 1979; Blau, 1964; Ashforth \& Saks, 1996). The theory posits that when MT members perceive a discrepancy of expectations in their job role, they are likely to experience a role conflict (Biddle, 1979; Fischer \& Gitelson, 1983; Van Sell, Brief \& Schuler, 1981). Nonetheless, role theory emphasizes the role of the individual MT member and how this person by means of enacting on the environment is able to take hold of or manipulate the various existing job expectations (Stets \& Burke, 2000). Dual allegiance is broader than this and entails MT members' perceived attachment to organizational entities. Therefore, we complement insights of role theory with insights of social identity theory.

Social identity theory suggests that when MT members attach value to the membership of an organizational entity (i.e. identification), they are more likely to 
prioritize the behavioral expectations that support the goals and interests of the organizational entity they feel attached to (e.g. Tajfel, 1982; Turner, 1975; van Knippenberg \& van Schie, 2001). This process of prioritization of some collective attributes over others is also referred to as a claim-making process (Albert \& Whetten, 1985; Glynn, 2000). Claim-making is a rhetorical activity conducted by organizational actors to convince others of the legitimization of their preferred solution (Glynn, 2000). The prioritization originates from the coalescence of a MT member with the interests and responsibilities of an organizational entity (organizational sub-unit and/or overarching organization). In general, a multiplicity of identities exists in a MT and through a process of claims and counterclaims MT members aim to persuade each other of the justification of their goals and interests (Ashforth \& Mael, 1996; Bunderson \& Sutcliffe, 2002). According to Ashforth and Mael (1996) we can relate this claim making process to strategic decision making.

It may occur that the dominant claims in the MT may not align with the claims that originate from MT members' role as organizational sub-unit representative. In other words, MT member's definition of "who they are" as representative of the overarching organization does not line up with "who they are" as organizational subunit representative (Hogg \& Terry, 2000). Literature suggests that the stress of complying with both sets of organizational expectations may then enhance role conflict (Li et al., 2002; Vora, Kostova \& Roth, 2007) and cause misunderstandings and ambiguity in the prioritization of organizational goals and interests (Frayne \& Geringer, 1995; Li et al., 2002; Shenkar \& Zeira, 1992). Hence, MT members' experience of dual allegiance may not only depend on a perceived discrepancy or incongruence in job role expectations, but also on the identification of MT members with organizational entities (Li et al., 2002; Turner, 1975; Vora \& Kostova, 2007).

\section{Impact of Dual Allegiance on MT Members}

Since Kahn and colleagues' (1964) seminal work on role conflict, an abundant number of studies have demonstrated the adverse consequences of role conflict on MT members' performance (e.g. Marrone et al., 2007; Van Sell et al., 1981). Role conflict, for example, creates distress, tension, anxiety and increases the intention to leave an organization, consequently harming performance (e.g. Jackson \& Schuler, 1985; Tubre \& Collins, 2000). Higher up the organizational ladder the negative association between role conflict and job performance is equivocal (see for meta-analyses Abramis, 1994; Fisher \& Gitelson, 1983; Jackson \& Schuler, 1985; Tubre \& Collins, 2001).

Why might MT members higher up the organizational hierarchical ladder experience role conflict less intensely than others? Literature provides a few hints for this. Some researchers argue that MT members at higher levels in the organization are confronted with less variety in role behaviors and therefore experience role conflicts less strongly (e.g. Floyd \& Wooldridge, 1992; Floyd \& Lane, 2000). Others posit that the managerial discretion and the increased experience of these MT members with ambiguous and complex systems makes role conflict less problematic (e.g. Shenkar \& Zeira, 1992). 
Other studies argue it is not so much the occurrence and familiarity with ambiguity that mitigates the experience of role conflict, but the way that MT members are capable of dealing with the discrepancy in role expectations in interaction with others. Studies demonstrate that the management of role conflicts is a function of the number of colleagues that experience a similar trade off (e.g. Marrone, Tesluk \& Carson, 2007; Tidd \& Friedman 2002). The higher the number of MT members that experience dual allegiance conflicts, the easier it becomes for individual members to alleviate the negative consequences of the conflicts involved (Marrone et al., 2007).Marrone et al., (2010) argue this is because MT members are all confronted with colleagues in similar organizational positions with similar dual responsibilities and role conflicts. MT members thus have access to homologous information and experiences that helps to actively manage-to act responsively and directly rather than inertly and indirectly (p. 241)- personal uncertainty and stress and to diminish adverse consequences of role conflict (Tidd \& Friedman, 2002).

Commensurable with the studies above, research also suggests that the perceived role conflict mitigates if MT members feel both their MT identity and their organizational sub-unit identity to be socially validated (Brewer, 1991; Hogg \& Terry, 2000). Irrespective of the strength of or similarity between the levels of identification, MT members are suggested to experience less conflict when both their MT member identity and organizational sub-group identity are positively represented in MT members' self-definition (i.e. who they are as MT member and organizational unit representative) (Vora, Kostova \& Roth, 2007). This finding suggests that the negative effects of role conflict are reduced if MT members can optimally distinguish themselves from colleagues by identifying with their organizational groups, while they simultaneously identify with the MT (Brewer, 1991). Thus, escalating experiences of dual allegiance can be regulated when MT member's social identities are managed aptly. By considering the goals, values and interests of all parties involved in the decision making process the negative consequences of discrepancies in role expectations decrease (e.g. Fisher \& Gittelson, 1983; Hogg, Abrams, Otten, Hinkle, 2004; Hogg \& Terry, 2000).

To conclude, given the duality in responsibilities which are structurally embedded in the task of MT members, perceived role conflicts in terms of incongruent organizational accountabilities seem inevitable. Unfortunately, little research efforts have been devoted to scrutinize when such discrepancies impact MT member's experience of dual allegiance. Extant research is inconsistent regarding the conditions under which dual allegiance may become problematic. To explore these mechanisms in more detail, we will now discuss our interview analysis.

\section{METHOD}

\section{Participants}

We conducted 11 semi-structured interviews with MT members in 5 different organizations. Contact with managers was obtained via personal contacts of the first 
author and the interviewed managers (snowball sample). Two organizations were in the petrochemical industry and the other organizations resided in the oil, information communication technology and car industry. All participants had at least 9 years of work experience. All participants were male. One of the participants was retired, but had extensive managerial experience in both retail and the information communication technology industry. Each interview lasted for approximately 1 hour and except for two interviews all were recorded on audiotape. The audio-taped interviews were transcribed verbatim and from the other two interviews detailed transcripts were made based on the documentation during the interviews.

\section{Procedure}

We conducted semi-structured interviews around three main themes:

1. How do MT members perceive role conflicts when experiencing dual allegiance?

2. What mechanisms strengthen the intensity of role conflict?

3. What mechanisms weaken the intensity of role conflict?

Aside from questions that deepened the understanding of these three main themes, the interview allowed other comments and ideas to emerge during the interview. At the beginning of the interview, we first explained to the interviewees what we defined as dual allegiance. We explained to the interviewees what social identity entailed and how this was different from role or professional identity. (Please see Appendix A for the interview protocol).

\section{Analysis}

We analyzed the semi-structured interviews using the qualitative software package NVivo 8. We used a coding system in which category labels were derived from the verbatim interview transcripts. We obtained relevant themes (i.e. categories) from our data and positioned them hierarchically to extract their meaning and relationships. Two of the authors went through the data independently and coding categories were discussed until agreement was reached.

Before we began the actual analysis process, we structured our responses according to the three main themes of the interviews, as described above. These three themes served as initial framing categories and we classified the interview data into these three categories before we engaged in a more inductive analysis method in which we went back and forth between the verbatim transcripts and theory (Glaser \& Strauss, 1999; van Maanen, 1979). The actual analysis proceeded in three stages and we summarized this process in Table 1. First, from the data that we assigned to the three framing categories, we extracted first-order category labels by classifying sections of text or statements with a reoccurring common theme. For example, when several interviewees addressed that interpersonal relations were characterized by personal differences in attitudes, we labeled these statements under the first order category attitudinal diversity. Multiple first-order category labels could be assigned to one section of text or statement, when multiple themes were found in that section. Example 
sections or statements for each first-order category can be found in Table 1. Second, we aggregated our first-order categories into higher-order more abstract categories to better understand and compare among and within our focal categories. Finally, we aggregated these second-order categories into more theoretical categories. We did this in an attempt to fit our categories into a coherent theoretical picture (Pratt, Rockmann, Kaufmann, 2006).

\section{FINDINGS AND DISCUSSION}

We organized the description of the findings of the interview analysis around the three framing categories that were guiding the interviews and the analysis. We first discuss how MT members experience dual allegiance. Then, we present our findings concerning the mechanisms that strengthen and weaken the intensity of the experienced dual allegiance.

\section{How do MT Members Perceive Role Conflicts when Experiencing Dual Allegiance?}

All MT members indicated that they, indeed, experienced dual allegiance. The accompanying role conflict was primarily perceived as a Tension. They characterized role conflict as a Fact of Life, a "surely identifiable" and "daily occurring" phenomenon in their job responsibilities. It is a "given" they have to cope with during their daily work duties. Often, the complexity of the organization in itself makes it difficult for MT members to appropriately align their dual responsibilities. Others characterized the conflict as "a constant" in their functioning, a "modus operandi". To illustrate: "Leaders are paid to manage dilemmas. It's just one tension extra, just one more." In this sense, our interview outcomes comply with previous findings (e.g. Shenkar \& Zeira, 1992; Tubre \& Collins, 2000) that role conflicts by virtue of dual allegiances are, indeed, existing phenomena, but not always considered an issue during the execution of the job.

MT members further characterized role conflict as a Contradiction of Interest; a sometimes inconvenient phenomenon without becoming a real problem. To exemplify we use the example of a business manager who describes a situation in which he was involved in a divestment procedure: "You could say that when everything is ok with [business unit], that everything is also ok for [company], but that is too simple. Also, when the current business of [business unit] is fine, that doesn't guarantee that future decisions fit nicely in the sales picture of [company]. In these situations, the decisions do not only depend on the best strategy for [business unit], but also on the success of the divestment. (...). When [company] wants to have those figures the best as possible, the company tends to round up the figures, while the management of [business unit] tends to round down those figure as the management of [business unit] still needs to demonstrate the predicted performance in the future."

Additionally, the interviewees designated incidents in which Sacrifices had to be made for the bigger organizational collective as origins of role conflict. We labeled 
Tabel 1: Summary of Data Structure

\begin{tabular}{|c|c|c|c|c|c|}
\hline Example statement & $\begin{array}{l}\text { First-order } \\
\text { category }\end{array}$ & $\begin{array}{l}\text { No. } \\
\text { man. }\end{array}$ & $\begin{array}{l}\text { Second-order } \\
\text { category }\end{array}$ & $\begin{array}{l}\text { Theoretical } \\
\text { category }\end{array}$ & $\begin{array}{l}\text { No. } \\
\text { man. }\end{array}$ \\
\hline $\begin{array}{l}\text { Leaders are paid to manage dilemmas. It's just one tension extra, } \\
\text { just one more. One more dimension. }\end{array}$ & Fact of Life & 8 & \multirow{3}{*}{ Tension } & \multirow{3}{*}{$\begin{array}{l}\text { Experience } \\
\text { of Dual } \\
\text { Allegiance }\end{array}$} & \multirow{3}{*}{8} \\
\hline $\begin{array}{l}\text { You could say that when everything is ok with [business unit], that } \\
\text { everything is also OK for [company], but that is too simple. Also, } \\
\text { when the current business of [business unit] is fine, that doesn't } \\
\text { guarantee that future decisions fit nicely in the sales picture of } \\
\text { [company]. }\end{array}$ & $\begin{array}{l}\text { Contradiction } \\
\text { in Interest }\end{array}$ & 4 & & & \\
\hline $\begin{array}{l}\text { The transition of the best employees is for [company] as a whole, } \\
\text { of course, wonderful, but sometimes you want to keep your best } \\
\text { employees because that is in the best interest of your customers } \\
\text { and of course you feel the tensions caused by such a trade-off, but } \\
\text { you also find a solution in due course. }\end{array}$ & $\begin{array}{l}\text { Sacrifices for } \\
\text { Collective }\end{array}$ & 3 & & & \\
\hline
\end{tabular}

When you represent the interests of your employees or business unit, it can blind you from the other interests in the organization.... The KPI that is linked to the business unit performance only reinforces the inclination to only be interested in

Reward Structure

your own patch.

Some parts are simply in your own sphere of influence. That is what you are accountable for. Eventually, everyone runs his own factory.

Personal Interests

You really have to be top dog to become MT member. At least, you want to be treated as an equal, but preferably you want to be considered as most important. Hence, being marketing, you won't Power Play accept from Sales to be only responsible for the leads and the availability of advertising material.

That's also part of it: "everything is invented in the Ivory tower, it's Ivory Tower far away from reality" and .... you keep receiving this type of Decision remarks, since I am located here at main office.

Making

For someone the topic is important and for someone else it is not.

However, there are topics I consider very important and that can Violation of

be content wise, but also because they touch my norms and values. Personal norms 4

Hence, the closer you get to my own team, the stricter and more and Values

persistent I become.

Reality is in my perception that personal relationships also color

the conversation. Thus, it is not always very rational. If you think Personal someone is a fool, you keep focusing on his arguments through the Differences same mirror. That is also how it works in human relations.

When an operational manager joins non-operational managers: Well, they work completely different, they think completely different.

Difference in

Perspectives

5

Sub-unit Identification

Reward system is adapted to the target of the MT as a whole. Most targets are shared and for those targets that mean that if I can't reach them someone else cannot either. We all accomplish the Shared Targets target or we all fail.

The core of an open organization is the communication. There, I believe, many organizations fail. We are very open en tell our employees a lot about how the organization is doing. There are not Transparency too many things that we keep a secret for our lower level employees. 
In order to avoid conflict escalation, you should create a sense of togetherness, shape changes together, give team members the idea that they can join in the creation process to smoothen the acceptation of the decision. It is important to involve your key stakeholders in the decision making process.

That people can be themselves, that they feel safe. Maybe there are Psychological many discriminatory factors, but people are very apt at noticing. Safety

We should not think that people work harder when they earn more. The perception of fairness is important. If your neighbor received more, due to unjust reasons, one really gets angry.

Standardization of processes makes the exchange of best practices easier. If you have different organizations and you use different materials and resources everything is different, standardization then helps to align processes.

You try to accept someone as he/she is, you are of course business manager but you always try to put some objectivity in your judgment. So, for example, to also deal carefully with R\&D. You Mutual Respect 5 try to be an impartial team in a way. Balancing the interests of manufacturing on the one hand and business on the other hand. You can reach internal effectiveness by increased trust among your team members; focusing on the quality of the interaction, by having team members better understand each other, by taking away misunderstandings. At the end, however, it remains a coalition of interests; you need to reach some kind of balance in the team.

The process also depends on the team leader. Is he / she prepared to make decisions, does he leave little opportunity to voice alternative opinions. Or is it someone who is looking for consensus. Someone who prefers keeping everybody happy. If you do the latter, you also create an opportunity for political games.

What I consider important for a team leader at this level is that he / she knows what he/ she stands for. He should have developed a vision on the basis of internal or external input he receives. He should create boundary conditions to also realize that vision. I don't expect him to the best of the class, but he should know how to run a place.

You should make sure that those people, who eventually experience the change, are also the one's initiating the change. They should have co-directed the change that they are extraordinarily interested.

He should walk the talk. He represents us in a variety of organizational groups. I should be able to trust him to, indeed, represent our interests towards others in the organization.

You should guide such a process and make decisions. The art is to avoid the conflicts. It is important to choose a process approach and take the time to also adjust the mentality, the new behavior, such that it fits the specific skill requirements of all your team members.
Perspective

Taking

Mutual

Understanding 5

Balance

between Direction and Consensus

Vision 5

Team leader as Identity Broker

Number of managers: the number of managers addressing one or more statements belonging to the respective category

situations in which MT members had to make a trade-off between retaining resources for their own business unit or placing it at the disposal of another unit in the interest of the larger organization as sacrifices for the collective (see Table 1). MT members 
considered these situations as "frustrating" and they definitely created a field of tension. To demonstrate: "The transition of the best employees is for [company] as a whole, of course, wonderful, but sometimes you want to keep your best employees because that is in the best interest of your own customers and of course you feel the tensions caused by such a trade-off, but you also find a solution in due course".

\section{Unilateral Intensifiers: Mechanisms to Strengthen the Intensity of Role Conflict?}

MT members felt that role conflict intensified under particular conditions. We captured these conditions under the theoretical category Unilateral Intensifiers. This means that role conflict due to dual allegiance increased under conditions that primarily emphasized MT members' attachment with the organizational sub-group rather than the overarching organization. Two second-order categories exemplify when role conflict due to dual allegiance intensified: MT member's Sub-unit Identification and Attitudinal Diversity.

Sub-unit Identification MT members experienced more intense role conflict between their dual responsibilities when their sub-unit identity and consequently their psychological and value attachment was accentuated: "When you represent the interests of your employees or business unit, it can blind you from the other interests in the organization". A majority of the interviewees opined that the Reward Structure of the organization boosted this inclination "to optimize and to be interested in their own patch only". For example: The KPI that is linked to the business unit performance reinforces this preference to only be interested in your own patch". The emphasis on sub-unit performance was thus strengthened by linking personal KPIs to the success of the sub-unit. MT members specified that this drove "a wedge between the short-term interests of the sub-unit and the long-term interests of the organization as a whole". Interestingly, the reward structure was more considered an additional barrier to align the divergent perspectives than that it was the cause of the role conflict. To illustrate we provide a section of text in which a MT member talks about his experiences as business team leader: "By nature there exist different interests, goals and targets. And there are a variety of ways people are evaluated. All those interests are linked to targets and then . . . when we show up, we want to try all new things to generate more money, since that is what we are evaluated upon. However, all these new things also mean extra risks and of course they [colleagues] want to weigh these risks first before getting engaged. So, when targets are all different, matching becomes a huge challenge". The reward structure built in a degree of decentralization, giving MT members a considerable degree of freedom and accountabilities to first think in the interest of their own unit before considering the interests of the overarching organization.

Prioritizing one's own unit, because of Personal Interests was considered another critical determinant of why role conflicts by virtue of dual allegiance intensified. To exemplify: "Unconsciously one puts more effort and energy in things you find interesting, and it are those things especially that you find worthwhile pursuing". As became evident from this research, sub-unit identification can emerge from organizational actors that coalesce with the particular interests vested in the responsibilities of an organizational position. This can bias their perception and make 
them ignorant of goals and interests critical to the success of the whole organization, thereby defining the organization's interests in ways that advantage them personally (Glynn, 2000). As a MT member described: "When you are the boss of an organization or department and you feel totally engaged with the goals of the organization, you eventually start identifying with these goals and are so inspired with the pursuit of these particular goals that you lose track of or even demolish the interests of the bigger entity".

Power Play in the team was also considered an intensifier of role conflict. Role conflicts swelled when MT members claimed dominance over others. The development of a social identity is defined as a claim making process about the centrality, distinctiveness and endurance of attributes that distinguish in-group from out-group members (Albert \& Whetten, 1985; Dutton et al., 1994). Claims of dominance are made in an effort to emphasize a group member's unique capabilities and to favor the group one represents (Dimmock, Grove, Ecklund, 2005). To characterize: "You really have to be top dog to become MT member. At least, you want to be treated as an equal, but preferably you want to be considered as most important. Hence, being Marketing, you won't accept from Sales to be only responsible for the leads and the availability of advertising material".

The theme of sub-unit identification further resonated through MT member's Ivory Tower rhetoric by means of which MT members expressed feelings of frustration and incomprehension concerning the decision making process: A "not invented here" syndrome; "everything is invented in the Ivory Tower and far away from reality". Thus, with their rhetoric, MT members claim their identity as sub-unit representative. Commensurate with this identity claim, MT members also expressed in-group bias and in-group favoring behavior. Interviewees indicated to become less flexible in the decision making process the closer topics got to their personal norms and values. Violations of these norms and values intensified the experienced role conflict by virtue of dual allegiance. To illustrate: "For someone the topic is important and for someone else it is not. However, there are topics I consider very important and that can be content wise, but also because they touch my norms and values. Hence, the closer you get to my own team, the stricter and more persistent I become”.

Attitudinal Diversity MT members claimed that Personal Differences also increased their dual allegiance conflict: "There exists a click, or there is no click with people". The trade-off between responsibilities became complicated and inconvenient, because MT members felt attracted to people who they liked and trusted and disregarded those they didn't know or disliked (see Tsui \& O'Reilly, 1989; Williams \& O'Reilly, 1998). In the words of one MT member: "Reality is in my perception that personal relationships also color the conversation. Thus, it is not always very rational. If you think someone is a fool, you keep focusing on his arguments through the same mirror. That is also how it works in human relations."

While we found evidence for the similarity-attraction paradigm (Williams \& O'Reilly, 1998) as intensifier of dual allegiance conflicts, MT members also addressed that Difference in Perspectives complicated the balancing of divergent accountabilities. "When an operational manager joins non-operational managers: Well, they work 
completely different, they think completely different". Thus, polarization in the claim making process and the lack of overlap in characteristics that delineate MT member's identity intensified the complexity for MT members to balance their dual responsibilities. These findings are in agreement with previous research evidence that intergroup conflicts worsen when sub-unit identities are strengthened by attitudinal differences. When people uncover differences in attitudes, it becomes less pleasant to work together (Harrison, Price \& Bell, 1998; Li \& Hambrick, 2005)

\section{Bilateral Connectors: Mechanisms to Weaken the Intensity of Role conflict?}

The intensity of the experienced role conflict further depends on how it is managed. We categorized the factors hinting towards this information under the theoretical category, Bilateral Connectors. With this term we want to underline that dual allegiance is considered less of a conflictual problem when the centrifugal forces of duality are actively managed by highlighting commonalities and acknowledging differences. We differentiated three categories: Creation of a Collective Identity, Perspective Taking, and the Team leader as Identity Broker.

Creation of a Collective Identity Team research demonstrates the importance of a collective identity for MT functioning (Bunderson \& Sutcliff, 2003; Van der Vegt \& Bunderson, 2005). In our research, we found the emphasis on a collective identity to mitigate the experienced role conflict of MT members. Dealing with dual allegiance simplified when the Reward System emphasized the collective effort and diminished the experience of allegiance conflicts. MT members recognized that an appropriate ratio between rewards assigned to individual and collective performance smoothens tensions due to dual allegiance. In business situations where alignment of business policies was critical for overall organization success, we documented that shared targets characterized the reward system design: "The reward system is adapted to the target of the MT as a whole. Most targets are shared and that means that if I can't reach the target, someone else cannot either. We all accomplish the target or we all fail".

In addition, a Transparent MT climate supported the efficient management of dual allegiance. When MT members openly shared information, the awareness of common goals and interests was facilitated, creating a shared team cognition as precursor of a collective identity among MT members (Swaab, Postmes, van Beest, Spears, 2007). To demonstrate: "Transparent communication concerning the reasons and goals behind decisions "creates a healthy atmosphere". The greater the clarity and strength of "role expectations," the less likely role messages will be misunderstood or distorted. Clear expectations strengthen the relationship between team members (Katz \& Kahn, 1978). As one MT member put it: "We often laughed heartily about the phenomenal transparency of each other's roles. You may think that you are acting intelligent, but eventually everything what happens in the MT is rather transparent. When you are able to seriously talk about those issues and you can swear once in a while and have a good laugh (. . .) then, you do not spoil the fun. You should make explicit what goal you are fighting for, make it discussable. What is it exactly what we are all striving for?" 
Additionally, MT members addressed the importance of a Sense of Togetherness in diminishing dual allegiance conflicts. The creation of a sense of "we are doing this together" among MT members was considered critical to solve potential role conflicts: "In order to avoid conflict escalation, you should create a sense of togetherness, shape changes together, give team members the idea that they can join in the creation process to smoothen the acceptation of the decision. It is important to involve your key stakeholders in the decision making process. When you grow into it, decisions are easier to understand. Learning a new language is also more difficult if it is not your native language".

Further, themes of Psychological Safety or Fairness and Standardization of best practices were stressed as boundary conditions to alleviate role conflicts. To truly align dual responsibilities, MT members indicated that being able to be themselves and feel safe were important antecedents. Also, fairness in the reward system was considered important to avoid role conflict escalations due to dual allegiance: "Fairness is important. . . . if your neighbor received more because of unjust reasons, you really get angry". MT members felt more inclined to 'go the extra mile' if everyone was treated fairly. The feeling of sincere acknowledgement for acquired skills and capacities is important to have employees act in the interest of the overarching organization. Finally, standardization of best practices was considered a means to mitigate conflicts. MT members argued that the standardization of best practices helps to facilitate the alignment of responsibilities by the efficient exchange of knowledge throughout the organization and by the decrease of the incongruence in information or resource needs among organizational entities.

Perspective Taking Besides the creation of a collective identity, MT members emphasized the importance of the recognition of the identity as sub-unit representative in the MT by means of MT member's capacity of Perspective Taking. The acknowledgement of sub-ordinate identities that are nested within a super-ordinate identity improves MT processes, due to the decrease of the "over-inclusion" threat (Hogg \& Terry, 2000). According to optimal distinctiveness theory (Brewer, 1991) it is critical for people to balance their need for belonging (i.e. MT membership) and at the same time their need for distinctiveness (i.e. Sub-unit identity). From this research we found the exhibition of Mutual Respect to decrease this optimal distinctiveness threat and as such is an important facilitator for allegiance conflict reduction. In cases MT members do not feel acknowledged risks are enhanced that intensify dual allegiance conflict: "You try to accept someone as he/she is, you are of course business manager but you always try to put some objectivity in your judgment. So, for example, to also deal carefully with R\&D. You try to be an impartial team in a way. Balancing the interests of manufacturing on the one hand and business on the other hand".

Parallel with the assigned importance to mutual respect, MT members designated significance to the mutual understanding among MT members as this increased the internal effectiveness of the MT. The mutual understanding is considered to facilitate the creation of common goals and interests: "You can reach internal effectiveness by increased trust among your team members; focusing on the quality of the interaction, by having team members better understand each other, by taking away 
misunderstandings. At the end, however, it remains a coalition of interests; you need to reach some kind of balance in the team".

Team Leader as Identity Broker The role of the team leader appeared to have a critical impact on the capacity of MT members to aptly manage their divergent dual responsibilities. The majority of MT members addressed the team leader's preferred management style as a determining factor in the management of allegiance conflicts. For example: "Is the team leader someone who operates from the principle "management through conflict" and, in this manner, makes sure everyone is on the edge and that fantastic ideas arise from conflict. . . . or is the team leader someone who, like in the current situation, sensibly examines the situation and keeps his lips sealed, only once in a while making a sagacious remark". According to the interviewees, the success of MT functioning very much depended on how the team leader guided MT member interactions. Finding a balance between a directive and more transformational leadership style was considered most critical.

Gradually, MT members learned, through experience, that the most effective leaders acted as intermediaries. Our research evidence suggests that team leaders, more so than MT members, should withdraw from identity claim making processes. Team leaders are considered important for the development of a clear Vision, for indicating direction: "What I consider important for a team leader at this level is that he / she knows what he/ she stands for. He should have developed a vision on the basis of internal or external input he receives. He should create boundary conditions to also realize that vision. I don't expect him to be the best of the class, but he should know how to run the place".

Further, the team leader should make sure all opinions are given voice to within the MT. That is, at the end, all identity claims should be interwoven in the strategic decision that has to be made. As one of the MT members explained: "You should make sure that those people, who eventually experience the change, are also the one's initiating the change. They should have co-directed the change so as to become extraordinarily interested".

Correspondingly, MT members considered Transparency of the team leader's behavior important. Interviewees saw the team leader as the one who should represent the identity claims that are exhibited in the MT: "He should walk the talk. He represents us in a variety of organizational groups. I should be able to trust him to, indeed, represent our interests towards others in the organization".

Critical to MT functioning and the management of dual allegiance is the impartiality of the team leader. Irrespective of the team leader's conviction, he/she should restrain the exhibition of his / her personal identity claim in service of the common goal: "as team leader you need to know that, eventually, you reach the least when you express your own opinion too soon. You need to take care of the fact that only when taking into consideration all interests, you are able to efficiently accomplish your overarching business goals." 


\section{Towards a Model on MT Member's Experience of Dual Allegiance}

We began this chapter by indicating that MT members are confronted with a dual allegiance that is embedded in their daily work. When incongruence exists in these dual organizational accountabilities MT members encounter role conflict. While literature found these role incompatibilities in dual responsibilities to cause anxiety and distress among most organizational actors, literature showed inconsistent evidence regarding MT members higher up the organizational ladder. Research pointed out a variety of theoretical suggestions for why, higher up the organizational echelons, MT members perceive role conflict to impact individual job performance inconsistently. Regrettably, the incoherence in explanations has only scarcely been dealt with empirically.

We found that MT members, higher up the organization, indeed encounter role conflict in their daily job but do not perceive the conflict to be a constant source of distress or anxiety. While acknowledging the incompatibility in dual responsibilities as being engrained in their daily tasks, they recognized this tension mainly as a structural, work related contingency that strengthened or weakened based on contextual factors. We distinguished Unilateral Intensifiers that strengthen the intensity of the experienced role conflict, from Bilateral Connectors, that weaken the intensity of the perceived dual allegiance conflict (see Table 1). To understand the concepts and relationships we constructed Figure 1.

\section{Figure 1: Interplay of Unilateral Intensifiers and Bilateral Connectors in MT member's experience of Dual Allegiance}

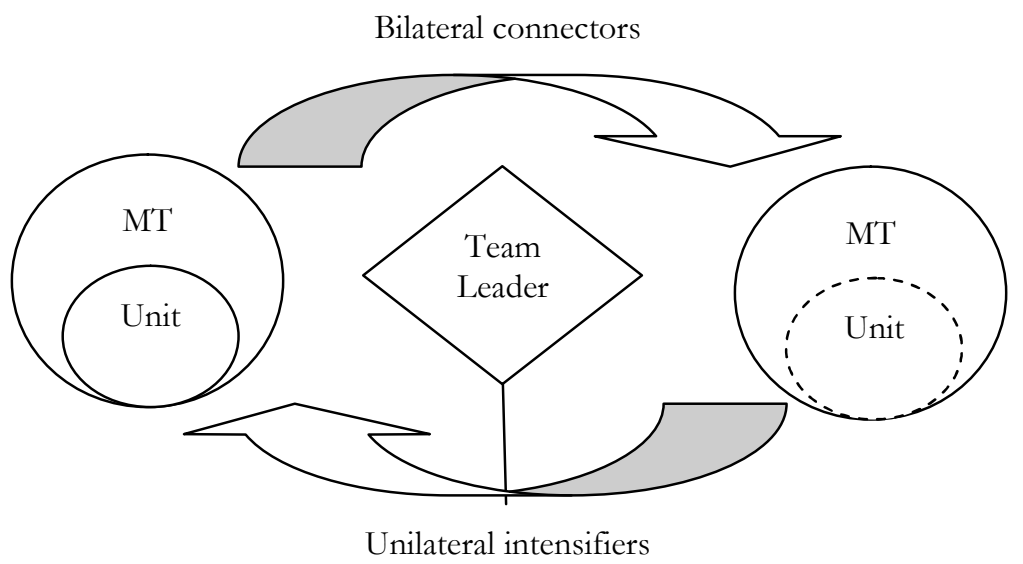

The lower arrow in the figure represents the influence of unilateral intensifiers that emphasize the distinction between the responsibilities as MT member and organizational unit representative. Here, the factors that emphasize MT member's uniqueness and distinctiveness in comparison to other members of the MT are labeled unilateral intensifiers. They drive a wedge between the different goals and interests of the two organizational entities. Unilateral intensifiers underline the criticality of accomplishing the goals of the organizational unit and obscure the importance of taking 
care of the overarching interests of the organization. We indicated this by drawing a firm line between the circle that represents the MT and the oval that represents the subunit. The intensifiers either increase awareness of the significance of pulling off organizational unit success (Sub-unit Identification) or amplify the differences between MT members (Attitudinal Diversity).

Also shown in Figure 1, bilateral connectors level the differences between the MT and organizational unit identity, indicated by the upper arrow. These factors create a shared identity among MT members by highlighting the commonality and importance of the divergent accountabilities. These connecting factors are capable of converging deviating goals and interests; both by emphasizing a collective identity and by accepting the existence of different ideas and concerns. In this situation the bilateral connectors unite the goals and values of the MT with those of MT member's organizational unit.

These two processes are interconnected, meaning that role conflicts by virtue of dual allegiance occur in waves and are context depended. The incompatibility of responsibilities is embedded in the job task of the MT member and as such unavoidable. By the process of claim and counterclaim making MT members are able to align the different interests and engage in strategic decision making. By means of bilateral connectors it is possible to control the eruption of role conflict. An important mediating factor in this process is the role of the team leader. The task of the team leader is considered one of brokerage. By constructing the frame of reference within which MT members can interact, the team leader and express their organizational entities' concerns the team leader, by means of his/her distinguishable organizational position is assigned an influential contribution in the strategy decision making process of organizations.

\section{Implications and Future Research}

Our research contributes to our understanding of MT functioning by describing the importance of the management of dual allegiance within MTs. Our work extends various studies that comprise literature on MT processes. We suggest that MT processes are affected by individual experiences of conflict in dual allegiances. Indeed, MT research has demonstrated an impressive increase in studies on what is happening within MTs (Carpenter, Geletkanycz \& Sanders, 2004). What has been missing however is the recognition that MT members, by virtue of their organizational position, are forced to wear two different hats at the same time (Ashforth \& Mael, 1989) and that this duality in responsibilities may be a serious source of role conflict.

More generally, we add to MT research by turning scholar's attention towards the social-emotional aspects of MT functioning. MT studies are generally dominated by a cognitive approach towards the analysis of MT functioning (Carpenter et al., 2004; Priem, Lyon \& Dess, 1999). In our study we show that values, attitudes and norms, inherent in various identification processes, can be expressed through MT members' job task and MT membership. By this means role conflicts can be mitigated improving overall MT functioning.

Our research further adds value to the field of social identity research. The identity claim making process has been studied in a variety of organizational contexts 
(e.g. Glynn, 2000; Sveningson \& Alvesson, 2003). The tendency of people to identify with organizational collectives has been primarily seen as a source of intergroup conflict. Only recently, researchers underscore the potential of collective identification to impact role conflicts among organizational actors (e.g. Li et al., 2001; Vora \& Kostova, 2007). We showed that within the context of the MT, role conflict is, indeed, an issue and is especially salient when MT members have difficulties to identify with the overarching organization because incompatibilities in norms and values are emphasized.

Finally, our research contributes to studies investigating the impact of leadership on team processes (e.g. DeChurch, Hiller, Murase, Doty, Salas, 2010; Zaccaro, Rittman, Marks, 2001). A meta-analysis of DeChurch et al. (2010) showed that relatively little research has been conducted that investigate how team leaders influence team processes. We show that the team leader has an important identity brokerage function in the MT and by these means has a significant impact on MT functioning. In so doing, we also add to top management team research where studies predominantly focus on the impact of higher echelon management team as a whole on organizational performance (e.g. Hambrick \& Mason, 1984). Our study revealed that, also in higher echelon teams, the exhibited behavior of the team leader impacts the team process.

We recommend future research to further investigate the brokerage role of the MT leader. Our study merely revealed that a team leader, by the enactment of impartial behavior, can mitigate role conflicts among his/her MT members. While we described how the balancing of diverging organizational responsibilities emerges in role conflict among MT members, future studies can deepen our understanding of how this balancing act within MT leader impacts their capacity to conduct the brokerage role. MT members indicated that impartiality was an important pre-condition for the team leader to effectively manage dual allegiances among his/her MT members. We encourage scholars to investigate how effective MT leaders are in maintaining this impartiality if they themselves experience a role conflict between their identification with the MT and their organizational unit.

In future work, researchers may wish to investigate the impact of dual allegiances on MT processes more objectively. In the current study, we tapped from the individual perceptions of a limited sample of MT members. Research might be expanded by the inclusion of observable MT processes. Past research suggests that role conflicts are most pronounced in organizations with a formalized business structure (Greene, 1978). The investigation of actual interaction among MT members in formalized businesses might open ways to adequately study the impact of dual allegiances on MT processes.

\section{Limitations}

Of course our study is not without limitations. As with many interview studies, the findings have limited generalizability to other settings. Given that the purpose of this study was explorative and not meant for theory testing, we believe that the disadvantages of a small sample size and lack of statistical representativeness is outweighed by the in-depth knowledge we gained. We are confident our results provide valuable insights for future research to build on. 
Interviewees in the study participated on a voluntary basis which could imply that they were predisposed and that the interviews provide a biased reflection of reality. However, participants were from 5 different organizations and MT members from the same organization were from different organizational levels, representing different organizational perspectives on MT functioning. Hence, despite a potential bias regarding the interests of participants in the topic under research, we are confident that within organizations we not only captured a one-sided perspective.

Four out of five organizations were typified by a high interdependent organizational structure. This implies that business processes and organizational unit success in these organizations strongly depended on each other. This high interdependence might have influenced our research results. Hence, in future research, it is critical to replicate our findings in different organizational contexts.

\section{CONCLUSION}

The aim of this study was to describe to what extent and when MT members experienced role conflict because of their exposure to dual allegiances by virtue of their organizational position. We conducted 11 semi-structured interviews to explore this research question. This resulted in four key findings. (1) MT members experience role conflict because of dual allegiance, but perceive this role conflict as part of their daily job, a fact of work life. (2) Under the influence of unilateral intensifiers, MT members become more aware of their organizational unit responsibilities and experience the dual allegiance conflict more intense. (3) Bilateral connectors can weaken the intensity of the experienced role conflict because these factors stress the shared aims and acknowledge the divergence in perspectives in the MT. (4) The team leader occupies a central and critical role in the management of dual allegiance among MT members. It is the team leader who should set the boundary conditions by means of which MT members can most effectively deal with the dual allegiance. 



\section{Chapter 4}

\section{Experiencing and Enacting Dual Allegiance in the Management Team ${ }^{5}$}

5 This chapter is based on the manuscript: - Cuijpers, M., Glunk, U. \& Heijltjes, M. Cuijpers, M, Heijltjes, M. \& Glunk, U. 2011. Experiencing and Enacting Dual Allegiance in the Management Team, Manuscript submitted for publication.

Earlier versions of this chapter were presented at the European Association for Work and Organization Psychology (EAWOP) Conference, May 13 - 16, 2009, Santiago de Compostella, Spain, and the Academy of Management Conference, August 12-16, 2011, San Antonio - Texas, United States. Further, the authors are grateful to Tanno Bregonje for the opportunity of opening data collection channels, cooperation in the data collection process and valuable insights during the research project. They are also thankful to Annelies van der Jagt, Gino van der Zijde en Inge Uriot for their assistance in the coding work of the project. 


\begin{abstract}
In this chapter, we describe underlying mechanisms of how MT members experience and enact on dual allegiance and how this materializes in observable behavioral integration processes. Based on the findings of a mixed-method study of a management team (MT) of a Dutch retail organization in which we use video-observation data and interviews with MT members, we built a dual identification framework that suggests the following patterns in our data: (1) The behavior of the chair person plays a dominant role in the alignment of MT members' expectations and perceptions of MT identity. (2) Incongruence in MT members' expectations and perceptions of MT identity is negatively related with MT members' attitude which is ultimately reflected in observable behavioral integration processes. (3) Interaction within the MT creates MT members' identification with that MT, suggesting an inductive MT identification construction process.
\end{abstract}




\section{INTRODUCTION}

Management team (MT) research has received extensive and distinctive attention in the management field (Jackson, Joshi, \& Erhardt, 2003; Williams \& O’Reilly, 1998). Following an upper-echelon perspective, MT studies have traditionally focused on the analysis of compositional and process contingencies (Carpenter, Geletkanycs \& Sanders, 2004; Hambrick \& Mason, 1984). While this type of research has increased our understanding of MTs' impact in terms of the influence of MT demographical characteristics on organizational behavior and outcomes, studies fail to shape a more comprehensive understanding of the nature of MT processes (Barrick, Bradley \& Colbert, 2007; Hambrick, 2007; Simsek, Veiga, Lubatkin, 2005). This is surprising as MT processes are considered essential in the accomplishment of organizational goals and the exploitation and configuration of an organization's resources (Eisenhardt \& Martin, 2000; Lubatkin, Simsek, Ling \& Veiga, 2006).

Upper-Echelon theory posits that managerial teams have unique features which make MT behavioral integration processes more complex in comparison to other organizational teams (Carmeli et al., 2011; Carpenter et al., 2004). More specifically, within the MT, members are subject to "centrifugal forces" that may easily disaggregate the team and negatively affect MT members' engagement with the overarching organizational goals (Carmeli \& Schaubroeck, 2006; Lubatkin et al., 2006). To better capture the mechanisms of MT processes, upper-echelon theorists introduced the construct of MT behavioral integration as an intervening construct to explain how MT characteristics influence organizational performance outcomes (Carmeli, Schaubroeck \& Tischler, 2011; Hambrick, 1994). This meta-construct reflects the integrative capacity of the MT- "the degree of mutual and collective interaction" (p. 188). As such, the construct represents a surrogate for measures of "teamness" (Hambrick, 1994).

Although scholars acknowledge the complex features in MT structures and the accompanying consequences this has for MT behavioral integration processes (e.g. Lawrence, 1997; Smith et al., 1994), only a few studies have examined the mechanisms that underlie the disaggregation problems of MTs (see Li \& Hambrick, 2005; Li, Xin \& Pillutla, 2002). The majority of MT research is performed following the upper-echelon tradition and is limited to the examination of a set of managerial demographical characteristics (e.g. age, functional background) that are used as psychological proxies in relation to process and output measures which are easily examined for "statistical regularities" (Carpenter, Geletkanycz, Sanders, 2004; Jarzabkowski \& Spee, 2009, p. 69). Unfortunately, these studies are not very informative concerning how and why specific MT characteristics are converted into organizational outcomes (Carmeli et al., 2011).

To create a more insightful picture on MT interaction processes researchers have called for more qualitative studies of (observable) MT behavior (Carpenter et al., 2004; Jarzabkowski \& Spee, 2009). Surprisingly little MT research has analyzed what actually happens within MTs and how MT members, as organizational actors, really work together (Cook \& Brown, 1999). Researchers have successfully captured MT strategic discourse and narratives (e.g. Raes, Glunk, Heijltjes, Roe, 2007; Svenningson \& 
Alvesson, 2003), but MT studies fail to grasp a better understanding of how people, by means of their emotions, individual perceptions and actions influence MT processes (Jarzabowski, 2003; Johnson, Melin, Whittington, 2003).

The rationale of this chapter is to enrich MT literature with a more finegrained understanding of what actually happens within MTs. By exploring observable MT behavioral integration processes and analyzing the psycho-social mechanisms behind them, "MT scholars can improve both their theories and their practical insights" (Hambrick, 2007, p. 337). To accomplish this goal we performed a mixed method case study design. We attended and video-taped five MT meetings over a five months period and documented observable behavioral integration processes within the MT of a Dutch retail organization. Further, we executed in-depth personal interviews with MT members to capture their retrospective impressions on the documented processes. By this, we are able to examine the origins of behavioral integration processes from a psycho-social perspective. Based on this analysis we build a dual identification framework to explain how MT behavioral integration processes unfold. By documenting MT behavioral integration processes and connecting these findings with MT members' perceptions thereof, we aim to increase our understanding of the mechanisms behind MT behavioral integration processes. In so doing, we answer the call for a more in depth examination of MT processes.

For this purpose, we begin with a brief theoretical review of the nature of MT behavioral integration processes and we will formulate our research question. Next, we describe our mixed-method design and explain our method of analysis. Further, we present our findings and conclude by discussing these in the context of existing theory. Finally, we formulate suggestions for future research.

\section{MT BEHAVIORAL INTEGRATION: A BRIEF REVIEW}

Behavioral integration processes are important intervening mechanisms by which MT members are capable of managing the task complexities of MTs. The construct which was firstly introduced by Hambrick (1994) consists of three interrelated processes. Two task dimensions, information sharing and joint decision making as well as one social dimension, collaborative behavior. Hambrick (1994) argued that these three processes together best captured the "team-like" nature of MTs. Though MTs have a key role in setting strategic decisions and shaping organizational performance by integrating diverse perspectives and orientations (Finkelstein \& Hambrick, 1996; Hambrick, 2007; Hambrick \& Mason, 1984), behavioral integration processes have deserved only little research attention (Hambrick, 2005; 2007). Yet, unraveling MT behavioral integration processes is vital for understanding MTs' influence on organizational performance (Boone \& Hendriks, 2009; Carmeli \& Schaubroeck, 2006; Lubatkin et al., 2006).

MT literature consensually addresses the fact that, due to MTs' unique role in the organization and their key role in strategic decision making and influence on organizational performance, MTs' structural characteristics complicate the formation of behaviorally integrated management teams (Carmeli \& Schaubroeck, 2006; Lubatkin et al., 2006; Smith \& Tushman, 2005). Though these MT characteristics hold important 
pieces of the puzzle, MT research is not very adequate in explaining the actual mechanisms by which characteristics influence the strategic decision making process. We believe this is because the complexities concerning MT behavioral integration are often implied by theories, rather than being the main focus of research projects. We explain this below.

\section{MT Structural Characteristics and Behavioral Integration}

Upper-echelon theorists uniformly agree that MT behavioral integration is difficult to accomplish because executives who are member of the MT generally operate their business unit independently and are accustomed to a certain degree of autonomy and discretion in decision making (e.g. Hambrick, 1994). These executives thus extract a considerable amount of status and power from being individually responsible for part of the firm's responsibilities. This perceived sovereignty complicates the creation of a collaborative and coherent organizational entity (Carmeli \& Shteigman, 2010; Hambrick, 1994; Simsek et al., 2005).

In addition to the higher degree of job discretion, MT scholars acknowledge that MT members are collectively responsible for and interdependent on each other for MTs' strategic decision making (Carmeli et al., 2011; Li \& Hambrick, 2005). So, MT members are compliant to the organization as a whole as well as to the business unit they represent within the MT (Li \& Hambrick, 2005; Li, Xin, Pillutla, 2002). We refer to this as dual allegiance-MT members are expected to be loyal to the overarching organization, while an important part of their organizational responsibilities reside in the nested and often independently operated sub-unit.

Further, this dual allegiance structure confronts MT members with a managerial role change. Some switch from a leading to a following role and for others this switch is vice versa. MT members thus need to make sense of the situation at hand by perspective taking (Weick et al, 2005; Balogun \& Johnson, 2003). On the one hand, their job description prescribes them to think and act in the best interest of the MT. On the other hand, their role also demands to support their individual business unit interests. Hence, MT member's attitudes and behavior depend, to a large extent, on the interpretation of the duality in their responsibilities.

Current MT literature has devoted only very limited research attention to elucidate how this dual allegiance structure, being inherent in the make-up of MTs, impacts the integration behavior among MT members (see for exceptions Johnson, 1999; Li \& Hambrick, 2005; Li, Xin \& Pillutla, 2002). Instead, following the upperechelon tradition, scholars simply acknowledged the complexities and benefits of behavioral integration for MT effectiveness and examined MT processes at a macro instead of a micro level of analysis (e.g. Hambrick, 2007; Simsek et al., 2005). As a result, the field's knowledge is limited regarding how behavioral integration processes actually unfold within managerial teams. 


\section{Social Identity Perspective}

The importance of social identification mechanisms in relation to the development of MT behavioral integration processes essentially emerged inductively from our dataanalysis, but we believe that an introduction to the main ideas of the social identity perspective, prior to our discussion of the data, helps to orient the reader towards our research findings. The social identity perspective is, as a general theory on self-concept and social groups, widely applied to explain group interactions (Hornsey \& Hogg, 2000). The perspective argues that people identify with a group for reasons of uncertainty reduction, self-enhancement and distinctiveness (Tajfel, 1982; Turner, 1975). Social identification influences MT members' self-concept and belief system and as such determines the lens through which people make sense of who they are, what they are doing and what is going on (Balogun \& Johnson, 2004; Weick, Sutcliffe \& Obstfeld, 2005). Consequently, MT members' self-concept and social beliefs affect their behavior and interpretation of the environment around them (Hogg, Abrams, Otten \& Hinkle, 2004; Hogg \& Terry, 2000).

MT scholars have regularly tapped from the social identity perspective to explain the deeper psycho-social mechanisms behind MT processes (e.g. Simons, Pelled \& Smith, 1999; Smith et al., 1994). However, the consequences of social identification on MT processes have not been assessed directly (see for exception Carmeli \& Shteigman, 2010), so the impact of social identification mechanisms on MT processes remains tentative. Moreover, social identification mechanisms have only been put to the fore in relation to the effects of MT demographical diversity on MT processes and outcomes, while the perspective may be especially useful in the context of MTs as it accounts for the MTs' dual allegiance property (Bizman \& Yinon, 2004a; 2004b; Hogg \& Terry, 2001). That is, the social identity literature increasingly nourishes the perspective that MT members are able to feel cognitively and emotionally connected to more than one organizational category at the same time (Hogg \& Terry, 2000; Vora \& Kostova, 2007).

This dual identification perspective helps us understand the complexities and challenges that accompany MT dual allegiance at the deeper, psycho-social, level of analysis (e.g. Hogg \& Terry, 2000). According to the perspective, behavioral integration processes can best be enhanced by the recognition of distinct sub-ordinate business unit identities within the context of the overarching MT (Brewer, 1991; Horsney \& Hogg, 2000). According to Hornsey and Hogg (2000), the acknowledgment of these business unit identity boundaries protects the distinctiveness that MT members derive from their status and power as business-unit representatives. Other researchers argue that dual identification (with MT and business-unit) makes MT members more aware of the interests and goals of both parties (Bizman \& Yinon, 2004; Vora \& Kostova, 2007). Acknowledging MT members' sub-ordinate business unit identity, while in the meantime gaining a positive awareness of membership to the higher-order MT identity, helps to increase MT members' generosity and cooperation towards other MT members (Gaertner et al., 1999; Van Leeuwen, van Knippenberg \& Ellemers, 2000).

The dangers for MT behavioral integration processes appear when MT

members identify divergently with their business-unit and MT (c.f. O’Leary \& 
Mortenson, 2010; Vora, Kostova, 2007). A discrepancy that due to contemporary business developments towards more complex and team-based organizational structures is increasingly more likely (Ashforth \& Johnson, 2000; Ashforth \& Mael, 1989; Martin \& Eisenhardt, 2010). The degree to which MT members identify with organizational categories determines how and what MT members value, think and feel in terms of the organizational category's responsibilities, concurrently influencing MT members' behavior (Albert, Ashforth \& Dutton, 2000; van Dick et al., 2008). Recent studies suggest that such an incongruity in identification levels results in unproductive behavioral integration processes (Chen et al., 2005; Edmondson, 1999; Li \& Hambrick, 2005), but the mechanisms that drive this process remain to be investigated.

In the section above we assert that the manner in which the specific dual allegiance character of MTs influences MT behavioral integration processes require exploration. We have suggested a need to examine the unfolding of MT behavioral integration processes at two levels. At the first level we document the observable MT behavioral integration processes. At the second level we examine the psycho-social aspects behind the MT behavioral integration processes we observed at the first level. To summarize the intentions of the chapter we have developed the following research question: How do MT members experience dual allegiance and how does this materialize in actual MT behavioral integration processes?

\section{METHOD}

\section{Research Design and Data}

We used a mixed method design to study the MT of a large Dutch retail organization. The first author attended and video-taped six of the organization's MT meetings during a five months period (November 2007 - March 2008). At the end of the observation period we interviewed MT members about their perceptions of their role as MT member and MT meeting dynamics. A mixed method approach was especially appropriate because we were interested in how the dual allegiance character of the MT manifested itself in observable MT behavioral integration processes. Gaining access to team meetings at the higher-echelons is difficult; therefore we used a personal contactan executive coach-of one of the researchers to approach the organization.

\section{The Organization and the Management Team under Study}

We promised anonymity to the organization when reporting our findings; therefore we refer to the organization as Delta. We only reveal limited details on the type of organization and do not reveal any information on the content of the strategic discussions. Delta has about 60.000 employees and is part of an internationally operating retail organization that distinguishes itself by efforts of continuous innovation of standard industry practices. The MT under study is responsible for the Dutch market, which is divided into six regions that are each lead by an operation manager. The operation manager is a member of the MT. The MT has strategic and operational 
decision making authority and the business units, operating regionally, have considerable autonomy. The MT meets bi-weekly and formally operates as a social entity. As such, the MT can be studied as an intact team.

The MT consists of ten members. The chairman of the MT is the Executive Vice President of Sales and Services and directly reports to the president (CEO) of the organization. Six operation managers are responsible for six business units and three managers are responsible for strategy development. One of the operation managers was newly introduced during the period of data collection. An MT assistant attended the biweekly meetings to take minutes. In this paper, we refer to the chairman and the three managers responsible for strategy development as central directorate (CD). We refer to the operation managers as OM. All but the MT assistant and one MT member were male. All managers are between thirty and sixty years of age and, except for the new MT member, reached their position through a career within the organization.

\section{Data Sources}

Video observation allowed us to structurally document observable MT behavioral integration processes. The meetings lasted between four to six hours and an agenda structured the course of the meetings, typically consisting of seven to eight agenda items. First, the minutes of the previous meeting were reviewed and approved. Second, strategic issues were discussed. This involved discussion of, reporting on or approving of policies that were always introduced by the chair and/or his staff members. Further, agenda items were scheduled according to topic relevancy and introduced by one of the operation managers. Regularly, other people were invited to the MT meetings to contribute to a specific agenda item when needed.

In observational research, it is possible that the presence of an observer influences the situation under study. We are confident that this effect has been minimized during the actual observation for two reasons. First, the duration of the meetings (4-6 hours) would have made it extremely inefficient for each individual to not act sincerely during the meetings and adjust their decisions afterwards in absence of a researcher. Second, we confronted MT members with "exemplary" scenes during the interviews. In this way we were able to cross-check our own interpretation of the MT meetings. Independently of each other, they judged the video fragments as "typical" and "characteristic" and indicated that MT dynamics were not different from other MT meetings.

Interviews were conducted three months after the observations. By means of the interviews we hoped to gain insights into the psycho-social mechanisms in the MT and explicate the observed behavioral integration processes. Interviews were conducted by the first author and the executive coach, lasted about one hour and allowed us to corroborate and extend our ideas about the MT meetings. We used semi-structured interviews to ensure that core topics were addressed.

We started each interview with the presentation of two short video fragments of approximately five minutes. We selected two video fragments that we considered characteristic for the observed behavioral integration process. By showing MT members these videos we were able to document their interpretation of what happened 
during the meetings, but also to immerse MT members into the experienced MT dynamics. By this, we hoped to restore their experiences and to gain more detailed and authentic information on how they perceived their MT role (as MT member and OM or $\mathrm{CD})$. We voice recorded and transcribed the interviews verbatim with permission of the interviewees. Please refer to Appendix B for a template of the interview protocol.

\section{Analysis of Video Data}

Video observation analysis progressed in three stages. First, we organized the raw material into episodes that were the smallest unit of analysis; the episode of a meeting in which only 1 specific topic was discussed. We organized the data based on agenda items and ultimately, partitioned the data into 47 agenda items, distributed over 5 MT meetings.

Second, we made use of a priori constructs derived from MT literature. According to Eisenhardt (1989), the use of a priori constructs facilitates the coding process and data analysis. We used Hambrick's (1994) conceptualization of behavioral integration, as consisting of information sharing, joint decision making and collaborative behavior to develop our coding scheme. The challenge here was to transform original survey measures (see Hambrick, 1994 and Simsek et al., 2005) into observable behavioral indicators. During the development of the coding scheme we tried to stay as close as possible to the original construct definitions, without losing sight of the special characteristic of the data. To avoid too complex data structures of word by word coding, we felt an examination of processes to be most appropriate. The reason for the construction of process variables is that previous research has proven the documentation of "who says what to whom" to ask for very detailed and specific analysis. Often this proves impossible in very complex and rich data sets, as is our data (Gorse \& Emmit, 2007). Please refer to the coding scheme section for further details on the variables.

Finally, two independent raters coded the data (i.e. all 47 agenda items). We trained the raters in four sessions of two hours. The first author explained the meaning of the constructs and explained what observable behavior we considered to be related to the behavioral integration constructs. As we were interested in observable behavioral integration processes, we asked our raters to judge the constructs holistically. That is, the raters paid attention to verbal as well as non-verbal reactions. The raters practiced on fragments of the dataset not included in the real analysis. In situations of discrepancies, raters were instructed to reach consensus. If no consensus was reached, raters coded the episodes according to their personal insights.

Coding scheme Hambrick (1994) defines information sharing as the quality and quantity of ideas exchanged. Since the quality of the information exchanged is difficult to assess by our raters as such an assessment requires topic experts (see Bales, 1950), we operationalized information sharing as: the exchange of ideas on the basis of factual and potentially verifiable observations or experiences (Hambrick, 1994; Simsek et al., 2005). As indicated above, we were interested in the process of MT information sharing and asked our raters to indicate on a 5 -point Likert scale $(1=$ fully disagree to 5 
$=$ fully agree) if they agreed with the following statement: "During the agenda item, team members share information with each other".

Joint decision making is operationalized as: Team members make a decision based on a mutually agreed upon understanding of each other's problems and needs (Hambrick, 1994; Simsek et al., 2005). We created an anchor based, 1-5 scale. Item 1 was labeled as: "The decision has been made "outside" the team and is only communicated to other team members. Team members are not aware of each other's range of duties (e.g. responsibilities and activities), nor have a clear understanding of the shared needs and problems of other team members". Item 5 was labeled as: "The decision has not yet been made and team members share each other's ideas, expertise and / or expectations. The team creates a clear understanding of the shared needs and problems of other team members and incorporates the different viewpoints in a (potential) decision".

Collaborative behavior is operationalized as: the mutual influence of persons by open and direct communication, the constructive settling of conflicts and mutual support (Hambrick, 1994; Simsek et al., 2005). Literature, however, distinguishes more positive (i.e. loyal and constructive) and negative (i.e. agonistic and disputative) styles of collaboration and predicts this to have different effects on team outcomes (c.f. Tekleab et al., 2009; Tjosvold, 1998). Going back and forth between data and theory, we considered a distinction between more positive and negative styles of collaborative behavior to best describe the data at hand (c.f. Bales, 1950). Therefore, we created separate measures. We labeled the loyal and constructive acts as constructive behavior and the agonistic and disputative acts as contentious behavior. We asked our raters to indicate to what extent constructive and contentious behavior was observable in each agenda item. Constructive behavior was documented by means of four statements on a 5-point Likert scale ( $1=$ totally disagree, $5=$ totally agree). Example statements are: "The discussions are characterized by listening to each other", or "The discussions are characterized by helping each other". Contentious behavior consisted of five statements, also scored on a 5-point Likert scale. An example statement is: "The discussions are characterized by criticizing each other". In this case we specifically paid attention to reactions like: "I disagree!"; or "We should do this differently!" The coding scheme can be found in Appendix B.

We calculated the intra-class correlation coefficient (ICC), type 2, for each of the behavioral integration constructs to check the inter-rater agreement. The closer the ICC (2) is to $100 \%$, the higher the agreement. According to LeBreton and Senter (2008), three constructs indicated strong agreement: information sharing $=.72$, joint decision making $=.82$ and contentious behavior $=.83$. Constructive behavior showed moderate agreement $=.53$. In appendix $\mathrm{A}$ we included an overview of the complete coding scheme.

\section{Analysis of Interview Data}

Interviews were analyzed by an iterative course of action, going back and forth between the verbatim data and theory (Glaser \& Strauss, 1999; van Maanen, 1979). The coding process was as follows. First, we framed our coding scheme based on the core themes 
of the semi-structured interviews. We were interested in MT members' perception of their role as OM or CD, their perception of the function of the MT, and their perception of the role of the chair person. We used these four themes as framing categories when designing the coding scheme.

Second, after framing the data we inductively derived codes from the transcribed interviews. Two of the authors - the person conducting the interviews and one of the co- authors-first read all the transcripts and independently coded the data. Then, the two authors compared and discussed their codes to determine a final coding scheme to analyze the transcripts. A code was assigned to interview statements when the phenomenon present in the statement was classified as a theme in the data. A theme was defined as a re-occurring phenomenon in the data. This stage finally resulted in a scheme consisting of our first-order categories.

Third, we aggregated our first-order categories into second-order more theoretical categories. This allowed us to better understand the relations between the categories and to create a coherent picture. To illustrate, some first-order categories highlighted the discrepancy between the perceptions and expectations of MT members, which we concurrently aggregated into the second-order category 'Incongruence in MT identity'. Other first-order categories merely emphasized MT member's perceptions per se. We aggregated these into the second order category 'identification as OM'. We summarized the categorization process in Table 1.

\section{FINDINGS}

\section{Findings from Video Observation}

In this section, we will first present the results of the analysis of the video observation data. We will do that by presenting our observations regarding each individual behavioral integration process. We describe the task dimensions information sharing and joint decision making and the social dimensions constructive and contentious behavior. For an initial idea of the unfolding of behavioral integration processes we calculated the mean scores over the agenda items across the five MT meetings. The means and standard deviations are shown in Table 2. Next, we will examine the development of the individual processes over time, and discuss any significant specific finding in more detail. Since MT video observation studies, to our knowledge, are nonexistent and we use a single case study design, we tap from existing literature and our own experiences during the observation period to draw inferences based on our data.

Based on our observations, the MT under study could tap from a wide array of experiences. Whereas OM all chaired unique business units and had different functional and educational backgrounds, they also shared similarities in terms of, for example, customers and administrative arrangements. This offered the MT a multitude of variety in information and knowledge. Extant MT literature argues that the sharing of information contributes to the quality of strategic decision making (Hambrick \& Mason, 1984; Olsen, Parayitam \& Bao, 2007; Wooldridge, Schmid \& Floyd, 2008). Researchers argue that information sharing creates a common understanding by which 
Tabel 1: Summary of Data Structure

\begin{tabular}{|c|c|c|c|c|c|c|c|c|}
\hline \multirow[t]{2}{*}{$\begin{array}{l}\text { Framing } \\
\text { categories }\end{array}$} & \multirow{2}{*}{$\begin{array}{l}\text { Example } \\
\text { statements } \\
\text { Perception }\end{array}$} & \multirow[b]{2}{*}{$\begin{array}{l}\text { No. } \\
\text { OM }\end{array}$} & \multirow[b]{2}{*}{$\begin{array}{l}\text { No. } \\
\text { CD }\end{array}$} & \multirow[b]{2}{*}{ Expectation } & \multirow[b]{2}{*}{$\begin{array}{l}\text { No. } \\
\text { OM }\end{array}$} & \multirow[b]{2}{*}{$\begin{array}{l}\text { No. } \\
\text { CD }\end{array}$} & \multirow[t]{2}{*}{$\begin{array}{l}\text { First-order } \\
\text { categories }\end{array}$} & \multirow[t]{2}{*}{$\begin{array}{l}\text { Second-order } \\
\text { categories }\end{array}$} \\
\hline & & & & & & & & \\
\hline \multirow{5}{*}{$\begin{array}{l}\text { Operational } \\
\text { managers }\end{array}$} & $\begin{array}{l}\text { I am the boss, I am } 100 \% \\
\text { responsible }\end{array}$ & 5 & & & & & $\begin{array}{l}\text { Pride and } \\
\text { responsibility }\end{array}$ & \multirow{5}{*}{$\begin{array}{l}\text { Identification as } \\
\text { OM }\end{array}$} \\
\hline & $\begin{array}{l}\text { I make use of the qualities of } \\
\text { my employees, working on } \\
\text { things together }\end{array}$ & 4 & & & & & $\begin{array}{l}\text { Sense of } \\
\text { belonging }\end{array}$ & \\
\hline & $\begin{array}{l}\text { I have a lovely independent } \\
\text { role, I can do what I want }\end{array}$ & 3 & & & & & Independence & \\
\hline & $\begin{array}{l}\text { This job inspires me. I consider } \\
\text { my job challenging and } \\
\text { motivating }\end{array}$ & 4 & & & & & $\begin{array}{l}\text { Intrinsic } \\
\text { motivation }\end{array}$ & \\
\hline & $\begin{array}{l}\text { Here the goals are clear, } \\
\text { everyone knows what to expect } \\
\text { from each other }\end{array}$ & & & & & & $\begin{array}{l}\text { Clear roles / } \\
\text { goals }\end{array}$ & \\
\hline $\begin{array}{l}\text { Central } \\
\text { directorate }\end{array}$ & $\begin{array}{l}\text { Statements addressing } \\
\text { hierarchical and executive } \\
\text { differences }\end{array}$ & & 3 & & & & Power / Status & $\begin{array}{l}\text { Identification as } \\
\text { CD }\end{array}$ \\
\hline \multirow{6}{*}{$\begin{array}{l}\text { Management } \\
\text { team }\end{array}$} & $\begin{array}{l}\text { In sum, everybody is busy with } \\
\text { telling their own story. } \\
\text { Ultimately, we think we } \\
\text { reached an agreement but } \\
\text { actually there is none }\end{array}$ & 6 & 4 & $\begin{array}{l}\text { I want to acquire } \\
\text { knowledge and to } \\
\text { bring knowledge. We } \\
\text { should enrich each } \\
\text { other }\end{array}$ & 6 & 4 & Dialogue & \multirow{4}{*}{$\begin{array}{l}\text { Incongruence in } \\
\text { MT identity }\end{array}$} \\
\hline & $\begin{array}{l}\text { What type of team are we? } \\
\text { What do we want exactly? }\end{array}$ & 4 & 3 & $\begin{array}{l}\text { We should create } \\
\text { transparency, what } \\
\text { type of team are we? }\end{array}$ & 4 & 4 & Vision & \\
\hline & $\begin{array}{l}\text { We do not correct each other. } \\
\text { We do tell, but nothing changes }\end{array}$ & $s^{6}$ & 2 & $\begin{array}{l}\text { Make each other } \\
\text { responsible for the } \\
\text { results, interrogate on } \\
\text { the spot }\end{array}$ & 4 & 3 & $\begin{array}{l}\text { Norms \& } \\
\text { agreements }\end{array}$ & \\
\hline & $\begin{array}{l}\text { We are called a team, but in } \\
\text { reality we are a team of } 5 \text { hours, } \\
\text { every } 14 \text { days. Further, } \\
\text { everyone is safely in their own } \\
\text { castle }\end{array}$ & 6 & 4 & $\begin{array}{l}\text { I would gain more, do } \\
\text { more things really } \\
\text { together, becoming "a } \\
\text { source" }\end{array}$ & 6 & 2 & Team unity & \\
\hline & $\begin{array}{l}\text { Pick up what I consider } \\
\text { relevant in my business unit }\end{array}$ & 4 & 1 & & & & Relay & $\begin{array}{l}\text { Dissociation } \\
\text { attitude }\end{array}$ \\
\hline & $\begin{array}{l}\text { I don't say anything anymore, } \\
\text { do not prepare for meetings }\end{array}$ & 5 & 4 & & & & Engagement & \\
\hline \multirow{3}{*}{ Chair person } & $\begin{array}{l}\text { Has no idea how things work } \\
\text { here, asks question but doesn't } \\
\text { want to know the answer }\end{array}$ & 6 & 1 & & 0 & 0 & Involvement & \multirow[t]{3}{*}{$\begin{array}{l}\text { Chair person as } \\
\text { identity broker }\end{array}$} \\
\hline & $\begin{array}{l}\text { Very instrumental, rational } \\
\text { person }\end{array}$ & 6 & 1 & $\begin{array}{l}\text { Use our qualities, be } \\
\text { more open, give trust }\end{array}$ & 4 & 1 & $\begin{array}{l}\text { Support \& } \\
\text { respect }\end{array}$ & \\
\hline & $\begin{array}{l}\text { Unclear messages, everything } \\
\text { gets mixed up, no consistency }\end{array}$ & 4 & 3 & $\begin{array}{l}\text { Practice what you } \\
\text { preach, show more } \\
\text { leadership }\end{array}$ & 3 & 3 & Direction & \\
\hline
\end{tabular}

No. OM / No. CD = number of operational managers / number of CD members addressing one or more statements belonging to the respective category 
communication among members improves and mutual understanding increases (Cannon-Bowers, Salas, Converse, 1993). Our initial observation was confirmed by our video-observation analysis. The average level of information sharing, over the five MT meetings, fluctuated around an average score of $3.89(\mathrm{SD}=.20)$ on a 5-point Likert scale. We infer from this that the level of information sharing in this MT is adequate enough to engage in high quality strategic decision making.

\section{Table 2: Mean and Standard Deviation for Information Sharing, Joint Decision Making, Contentious and Constructive Behavior, over meetings}

\begin{tabular}{|c|c|c|c|c|c|}
\hline & \multirow[b]{2}{*}{$\begin{array}{l}\text { No. Agenda } \\
\text { Items }\end{array}$} & \multirow[b]{2}{*}{$\begin{array}{l}\text { Information } \\
\text { Sharing }\end{array}$} & \multirow[b]{2}{*}{$\begin{array}{l}\text { Joint Decision } \\
\text { Making }\end{array}$} & \multicolumn{2}{|c|}{ Collaborative Behavior } \\
\hline & & & & $\begin{array}{l}\text { Contentious } \\
\text { Behavior }\end{array}$ & $\begin{array}{l}\text { Constructive } \\
\text { Behavior }\end{array}$ \\
\hline & & Mean sd & Mean sd & Mean sd & Mean sd \\
\hline Meeting 1 & 12 & $4.08(.79)$ & $2.89(1.31)$ & $2.11(.49)$ & $2.65(.62)$ \\
\hline Meeting 2 & 12 & $3.64(.64)$ & $3.15(.86)$ & $2.29(.79)$ & $2.91(.54)$ \\
\hline Meeting 3 & 8 & $3.88(.84)$ & $2.83(.83)$ & $2.26(.95)$ & $3.04(.65)$ \\
\hline Meeting 4 & 10 & $4.10(.63)$ & $3.2(1.14)$ & $1.76(.54)$ & $2.93(.39)$ \\
\hline Meeting 5 & 5 & $3.75(.84)$ & $3.25(1.30)$ & $1.35(.20)$ & $2.69(.45)$ \\
\hline All meetings & & $3.89(.20)$ & $3.07(.19)$ & $1.95(.40)$ & $2.84(.17)$ \\
\hline
\end{tabular}

Yet, we observed that despite the abundance of information, the MT did not manage to effectively bundle this information into effective strategic decisions. Information flows between $\mathrm{OM}$ and $\mathrm{CD}$ mostly had a sequential or pooled character. We mean by this that information in the MT was not shared reciprocally, but decision making processes were dominated by CD. Our observation of the overall joint decision making process, points in the similar direction. The average score was 3.07 ( $\mathrm{SD}=.19$ ), on a 5-point anchor based Likert scale. This implies that our raters interpreted the joint decision making process in the MT as follows: "While the decision has not been taken yet, team members share each other's ideas, expertise and/or expectations. The team does not create a clear understanding of the shared needs and problems of other team members and does not incorporate the different viewpoints in a (potential) decision". Research on strategic decision making and implementation demonstrates that for information to be effectively distributed and implemented managers need to thoroughly coordinate their actions (Floyd \& Wooldridge, 1997; Hambrick, 2007; Wooldridge \& Floyd, 1990).

In a MT context this implies that decisions should be made in cooperation with all MT members. Our analysis shows that the MT under study experiences difficulties with the joint decision making process. Recent research by Martin (2011) corroborates our findings. In a case study analysis of MTs in the nexus of six publicly held software firms he illustrates how MTs who fail to structurally make collective decisions perform worse than MTs who succeed.

Additionally we noticed that, in MT meetings, little time was devoted to openly discuss strategic decisions. That is, discussions were characterized by a relatively large amount of contentious behavior in comparison to constructive behavior and 
discussions concentrated around the process by which information was shared rather than the content per se. Previous studies indicate that normally functioning groups generally exhibit at least twice as much constructive behavior than contentious behavior. When this ratio is lower than two this generally indicates a problem with MT functioning (e.g. Bales, 1950; Martin, 2011; Ridgeway \& Johnson, 1990). The average score for constructive behavior in the MT under study was $2.84(\mathrm{SD}=.17)$. For contentious behavior our raters indicated an average score of $1.95(\mathrm{SD}=.39)$. Both on a 5 -point Likert scale. We calculated the ratio of positive versus contentious behavior and we found the ratio to vary between (1.25) in Meeting 1 (1.25) to (1.99) in Meeting 5. Hence, except for the fifth meeting, the ratio is always lower than two. This suggests that, indeed, the MT under study was not functioning as it should.

Subsequently, we analyzed the unfolding of the behavioral integration processes across MT meetings. The actual dynamics of the behavioral integration processes are visualized in Figure 1. To measure differences across MT meetings we conducted repeated-measures ANOVAs and the analyses revealed no mean differences in observed information sharing and joint decision making processes across the MT meetings. This suggests that information sharing and joint decision making, being aggregated to the MT level, are both relatively stable processes. For constructive behavior we didn't observe any significant mean differences either. However, for contentious behavior, the repeated-measures ANOVA revealed a significant decrease across MT meetings $\mathrm{F}(4,42)=3.23, \mathrm{p}<.05$. The LSD post-hoc test indicated mean differences in contentious behavior between meeting 1 and 5, meeting 2 and 5 and meeting 2 and 4 (all ps $<.05$ ).

Figure 1: Development of Information Sharing, Joint Decision Making, Contentious and Constructive behavior over MT Meetings

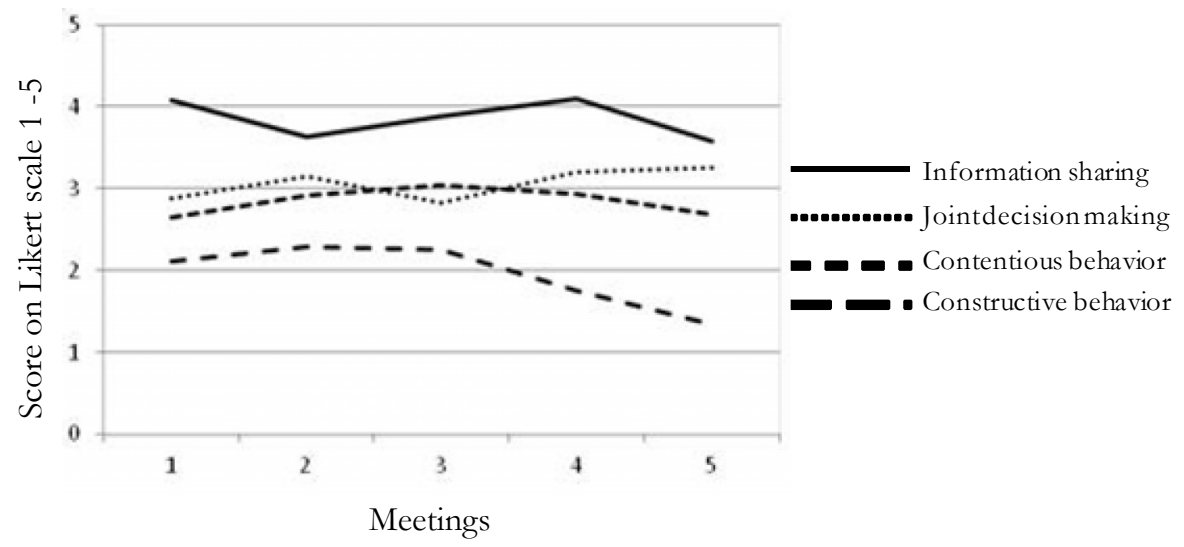

During the observation period, the chair person was only present in the first three meetings. The other two meetings the MT was chaired by another CD member. To examine if the presence of the chair person was associated with the level of the behavioral integration processes, we conducted one-way ANOVAs in which we 
compared Meeting 1, 2 and 3 (i.e. chair present) with Meeting 4 and 5 (i.e. chair absent). The analysis only showed a significant difference in the observed amount of contentious behavior. When the chair person was present the average level of observed contentious behavior $(\mathrm{M}=2.19, \mathrm{SD}=.73)$ was higher than when the chair person was absent $(\mathrm{M}=1.55, \mathrm{SD}=.47), \mathrm{F}(1,43)=7.42, \mathrm{p}<.05$. This result suggests a relationship between the presence of the chair person and the observed contentious behavior.

The absence of the chair person could also imply that the character of the fourth and fifth meeting were different from the first three. For example, the meetings could have been strategically unimportant and therefore have a less serious character and have lasted shorter than normally. We tested for this possibility by controlling for the level of joint decision making and meeting length.

After controlling for the level of joint decision making and meeting lengths, the difference in the observed contentious behavior score remained, $F(1,43)=8.79, \mathrm{p}<$ .05. The presence of the chair was thus positively associated with the level of observed contentious behavior. More specifically, our raters observed more mutual misunderstandings, $\mathrm{F}(1,44)=7.04, \mathrm{p}<.05$; more defensive behavior, $\mathrm{F}(1,44)=4.41, \mathrm{p}$ $<.05$; more frequent acts of passing judgments on each other, $\mathrm{F}(1,44)=7.24, \mathrm{p}<.05$; more openly expressed critique, $\mathrm{F}(1,44)=9.77, \mathrm{p}<.01$; and more frequently interrupted discussions, $\mathrm{F}(1,44)=6.25, \mathrm{p}<.05$ in meetings where the chair person was present.

\section{Findings from Interviews}

The strength of mixed-method designs is that one can analyze the same phenomena from different perspectives (Beck \& Keyton, 2009). We concluded above that the current MT might experience problems functioning effectively and that this probably relates to the unfolding of contentious behavior processes and the chair person's role. What underlying psycho-social mechanisms could explain our observation results? Our semi-structured interviews in which we confronted MT members with video fragments of the MT meetings revealed that the observed behavioral integration processes were associated with the manner in which MT members experienced the, in the MT embedded, dual allegiance. More specifically, we induced from the interview analysis that social identification processes underlie the observed MT behavior.

In the remainder we will, first, describe how MT members identified with their position as OM and CD. We continue by addressing the impact of MT members' identification as $\mathrm{OM}$ and $\mathrm{CD}$ on their perceptions and expectations of MT interactions and how this created incongruence in their MT identification. Next, we describe how this incongruence is associated with MT members' failure to have their MT identification corroborated in the MT and how this combines with MT members' psycho-social withdrawal from the MT, which can be reflected in observable processes. Finally, we elaborate on how MT members perceived the role of the chair person.

OM's identification with their position as BU director shows along five categories. As shown in Table 1, their identification with the business unit was, first, derived from the pride and responsibility they perceived having as business unit leader ( 5 of 6 OMs). Being head of the business unit provided a sense of status and perceived 
power which enhanced their self-concept. To illustrate: "As operation manager, I am the leader, and then I am responsible for what happens. If I enter a store, for example, everyone perceives me as the leader" (OM).

Second, OM addressed the creation of a sense of belonging (4 of $6 \mathrm{OMs}$ ) in their position as OM. They felt privileged to create boundary conditions in which their employees were able to excel and make the most of their skills and capacities. They further attached value to the fact that they were responsible for and capable of educating and developing skill sets in others. For example, OMs derived feelings of delight knowing they were on the threshold of someone's career, providing them the opportunity to develop their capacities. In this, OM stressed the collective responsibility in fulfilling their job tasks and the importance and pleasure they attached to developing their employees' capacities.

Third, as director of their business unit, OMs valued their independence (3 of $6 \mathrm{OMs})$. Their autonomy in decision making was perceived a precious good. Synonyms like "safe haven" or "own kingdom" characterize the value they attached to their organizational position and business unit, but at the same time sketch the cognitive boundaries OM used to demarcate their identification with the business unit, as unique organizational entity, from their other organizational memberships, such as the MT.

Fourth, they considered their job intrinsically motivating (4 of $6 \mathrm{OMs}$ ). The position invited OM to develop their self-concept. Their role as business unit director inspired and challenged them. In the meantime, they were passionate about the industry they were working in, indicating OM's positive identification with the function they fulfilled.

Finally, OMs appreciated the Clarity in job descriptions and goals (3 of 6 OMs) in the business unit and the transparency in their work. They valued the fact that business goals were unambiguous and job roles were clear. In other words, the clarity in job descriptions enabled them to make sense of their managerial self-concept and define who they are in terms of OM (Weick, 1995).

CD members' identification was unequivocal. Whereas OMs derived their identification with the business unit based on a variety of factors, CD mainly addressed the distinction in power and status (3 of $4 \mathrm{CDs}$ ) as critical difference between them and OMs. Their managerial self-concept was predominantly determined by their distinctiveness in hierarchical position. They regarded their function as more important and critical for business success than OM's function. CD did not consider OM as genuine executives. On repeated occasions, hierarchical and executive distinctions between $\mathrm{CD}$, as strategists, and OM, as executors, was emphasized. As one of the CD members elucidated: "My vision is that they [OM] are responsible for the execution of our policies. It sounds harsh, but I do not mean it like that, but they are no executives, they simply miss the overview for being an executive".

Incongruence in MT Identity emerged from a discrepancy that existed between what MT members perceived and expected to happen in the MT. We inferred from MT members' reactions about MT dynamics that the MT not fulfilled MT members' expectations. Reactions suggest that these expectations were formed by their identification with the business unit or CD. The MT identity, as perceived by MT 
members, appeared not to be core to how MT members expected themselves to define as MT member.

From four categories we inferred that MT members did not experience their expectations regarding the MT identity that was based on their identification as OM or CD, to be socially validated in the MT. First, MT members experienced difficulties regarding the Dialogue (6 OMs and $4 \mathrm{CDs}$ ) within the MT. MT members addressed difficulties in exchange of information and understanding of each other's ideas and perspectives regarding job responsibilities, knowledge creation and information sharing. In other words, the lack of discussion, based on mutual understanding, negatively influenced MT interaction. One of the OMs illustrates this: "The situation in the MT seems like a transmitter and receiver that are not on the same radio frequency; these two radio channels continue transmitting and just do not stop".

Both parties acknowledged that the lack of dialogue harmed MT functioning and performance, respectively. OM felt their experiences and qualities were not exploited enough in the MT, whereas CD members felt there was insufficient "bottomup" information provision from OMs to effectively devise business policies. This discrepancy emerged because $\mathrm{OM}$ and $\mathrm{CD}$ both had different expectations of their and the other party's role. To illustrate: "If I look around I see a lot of people living in their own world. Really two worlds and we don't know from each other what is actually demanded from us". Yet, all MT members expressed the desire to close the perceived gap between $\mathrm{CD}$ and $\mathrm{OM}$ and they believed that, by closing the gap, the MT would be able to exchange knowledge and information more adequately and create an environment of mutual understanding.

Second, MT members expressed concerns about the lack of and need for a clear Vision or strategic direction of the MT (4 of 6 OM, 2 of 4 CD). MT members had difficulties to comprehend what the MT actually stood for. They considered the tasks of the MT to be "too diverse" and "too cluttered". We present a description of an OM to illustrate this: " ( . . ) I consider it a difficult process. I receive more and more work and at the same time I need to execute it and I am asked to think and talk along about issues that were decided in my absence (...) Upstairs there are a bunch of men putting balls into pipes, I need to catch these balls when they come out of the pipes in my BU and then I am expected to do something with these balls immediately, while there are 10, 20, 30 balls coming down all at once, all with a different priority label ( . . ) I start juggling and think: well this ball becomes important in week 29 so I push that ball away and start juggling with other balls $(\ldots)$ they [CD] are disappointed that I did not deal with the other balls first and I am disappointed because they don't understand that I move ball 3 away to deal with ball 1 first." Both OM (4 out of 6) and CD (4 out of 4) argued for more transparency regarding the actual goals and tasks of the MT. As the interviews progressed, it became clear that all members appreciated answers on core strategic questions like: "what kind of team are we?", or "What exactly do we want to accomplish with this MT?" However, both parties would answer these questions differently, based on their identification as OM or CD.

Third and related to the concerns addressed above, we noticed that MT members (4 of $6 \mathrm{OM}, 3$ of $4 \mathrm{CD}$ ) were in need of Clear norms and stricter agreements 
regarding the work they had to perform. Statements regarding this issue concentrated on the discrepancy between the job responsibilities OM expected to have and the job responsibilities $\mathrm{CD}$ expected $\mathrm{OM}$ to have. Frustrations with respect to work norms and agreements emerged when $\mathrm{CD}$ started to do jobs that $\mathrm{OM}$ derived pride and enjoyment from. While CD started to complete specific jobs out of concerns of not reaching the deadline, OM expressed their dissatisfaction about CD interfering with their job. MT members were thus struggling with the sense making process of how to define the MT's responsibilities.

Lastly, MT members expressed a lack of Unity. As one OM emphasized "the MT is called a team, but basically, we are only a team that meets biweekly. OM (6 out of 6 ) and CD (4 out of 4) mentioned the lack of cohesion among MT members and that "we versus them thinking" was clearly salient within the MT. OM considered it difficult to voice their own opinion on subject matters. A major cause was the inequality in the group; "not everyone has an equal voice". Another OM replied: "I believe we should be inextricably bound up with each other, we are the eyes and ears for a piece of content that now is often produced by $[\mathrm{CD}]$ ".

The consequence of the unmet expectations among MT members is that MT dynamics were considered energy draining, tiring and no source of inspiration or enjoyment, but negatively impacting the atmosphere in the team. As one CD described: "You actually have to go to a meeting and return with new energy, our meetings cost more energy than that they provide." Further, OM experienced a lack of respect and trust when in MT meetings. They stress that for an effective MT it is important that all MT members are considered a source of strategic decision making as the following statements of OM illustrate: "We feel operators too often, we are not informed about the decisions made (. . .) we are insufficiently the source of the suggested movement". $\mathrm{OM}$ are convinced that when the MT acts as a unity, they will also feel more responsible for the collective result: "by truly doing things together and truly making strategic decisions together, the MT could become more of a unity".

Chairperson as identity broker. The behavior of the chair person was considered a vital factor in shaping MT dynamics. Regarding the functioning of the chair person, MT members also indicated an incongruence regarding the perceived and expected behavior of the chair person. Interestingly, MT members mainly expressed concerns about the socio-emotional processes of the team leader. A factor that, despite being considered as an important predictor for organizational outcomes, has deserved only limited research interest (Peterson, Martoran, Smith \& Owens, 2003; Priem et al., 1999). We distinguish three categories as being important aspects for the chair person's behavior: Involvement, Support \& Respect, and Direction.

The perceived Involvement (6 OMs and $1 \mathrm{CD}$ ) of the chair person concentrated on aspects dealing with the chair person's disinterest in what was actually going on in the business unit. As one of the CD members indicated: "He [chairperson] asks the OMs repeatedly to brain storm together, but when OMs make an effort, they are abruptly cut off or he says that they have to wait for a bit longer because ideas are not crystal clear yet. This raises so much frustration with these men." Fascinatingly, MT members' expectations regarding the desired behavior of the chair person centered on 
more trust and respect. All OMs, but only one CD considered the lack of Support and Respect from the chair person an issue in terms of MT dynamics. They complained that the chair person did not take them seriously and that they experienced a lack of trust in the MT. Especially a need existed for more motivational and respectful behavior. With respect to giving Direction, we observed a more balanced situation. Four OM and three $\mathrm{CD}$ considered direction giving by the team leader an issue. Example statements are: "He is not clear pointing out what he expects from us", or "it seems he doesn't have a real plan or direction".

A dissociation attitude emerged among MT members due to the mismatch between perceived and expected behavior in the MT. We distinguished two types of attitudes that MT members designated to engage in. One attitude is related to Engagement issues (5 OM, $4 \mathrm{CD}$ ) and the other relates to Relay issues (4 OM, $1 \mathrm{CD}$ ).

The experiences of MT members concerning unmet expectations during MT dynamics made them disengage from the MT. The absence of dialogue and the lack of team unity and vision resulted in the downgrading of the importance of MT meetings as strategic decision making entity. MT members indicated to employ "escape behavior" and to conceal themselves from taking on responsibilities.

In addition, they started seeing the MT as a relay; where policies and information were collected to be passed on and independently enacted upon. To illustrate: "When a story is presented in the MT, I listen to the story and think: OK, this practically means for [city in the Netherlands], that this is important and this is not, this I will extract from the information and the rest I forget, because it is not important to my business unit. Another OM expressed it as:

"I go back to [city in the Netherlands] and reformulate the story. In this way you get six totally independently operating OMs, extracting those things that they personally consider critical”.

\section{DISCUSSION}

\section{Towards a model of dual allegiance enactment in MTs}

1. The goal of this paper was to examine how MT members experience dual allegiance and how this materialized in observable MT behavioral integration processes. To make sense of the various categories and the relationships in our data, we constructed Figure 2. The figure summarizes our main finding that observable behavioral integration processes depend on the interplay between MT member's identification with their business unit or CD, and MT. through emotional contagion (Barsade, 2002) and their status and power position in the team (Finkelstein, 1992; Pitcher \& Smith, 2001).

We believe that the perceptions of MT members concerning the behavior of the chair person were also reflected in observed behavioral integration processes. Whereas information sharing, joint decision making and constructive behavior remained stable, regardless of the chair person being present or not, the degree of observed contentious behavior decreased when the chair person was absent. Hence, 
this pattern insinuates a prevailing role of the chair person in constructing positive behavioral integration processes among MT members.

Figure 2: Summary of Findings MT Members' Dual Allegiance Enactment in MTs

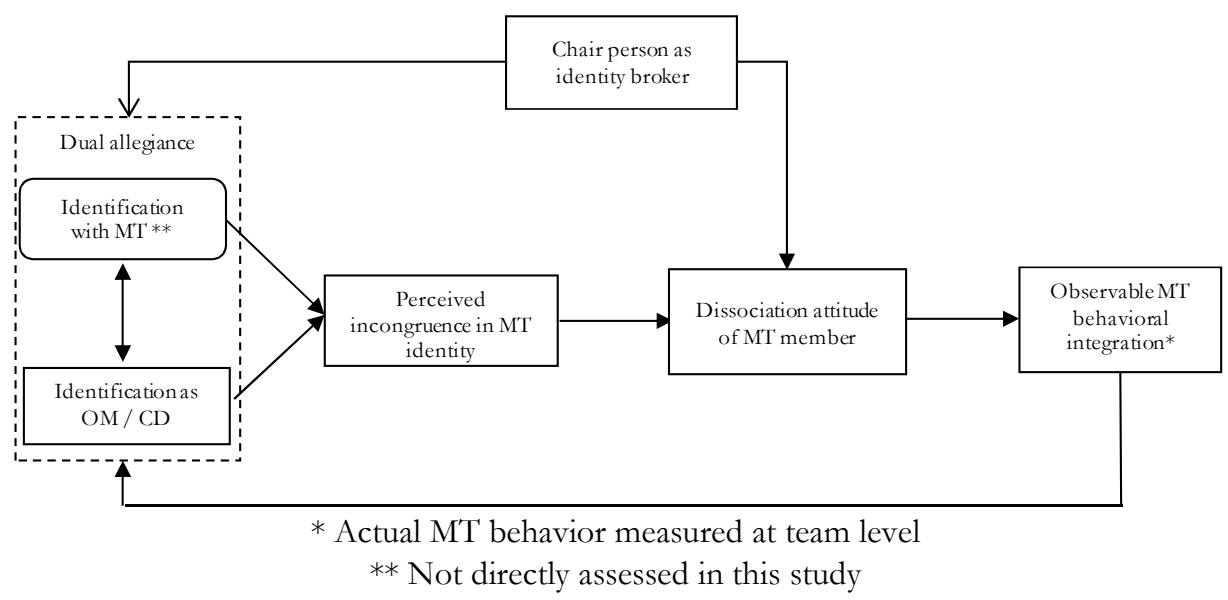

Further, our findings are consistent with findings of social identity theorists who suggest that people attach value to group membership when basic needs of belonging and distinctiveness are met. People will engage in claim making processes and defend their interests and values to support their identity (Albert \& Whetten, 1985; Ashforth \& Mael, 1989). Within the MT, MT members intend to integrate the divergent goals and interests of the interdependent organizational entities. Their business unit or CD identification form the basis for the interaction within the MT (Ashforth, Rogers, Corley, 2010; Weick, 1995). Via the exchange of MT member's ideas and perspectives it is possible to develop a shared identity that all members can relate to (Postmes et al., 2005). However, when a sub-ordinate identity is not acknowledged in the MT this causes problems in the behavioral integration process, as $\mathrm{Li}$ and Hambrick (2005) suggested in earlier work.

In our data, MT members reported feelings of frustration and disappointment when their expectations based on business unit or CD identification was not validated, eventually resulting in the withdrawal of MT members from the MT. This result underlines Brewer's (1991) optimal distinctiveness theory. According to this perspective, identification with a sub-ordinate organizational entity, such as a business unit is critical because it allows MT members to feel distinctive and unique and different from others (e.g. Brewer, 1991; Glynn et al., 2010). If members' expectations based on their business unit identification are not socially validated, members may feel "over-included".

To emphasize their uniqueness in comparison to other collectives in the organization, members thus engage in in-group favoring behavior, resulting in distorted inter-team interaction (e.g. dissociation attitude) (Brewer, 1991; Hornsey \& Hogg, 2000). To illustrate: one of the OMs reported that when he just started the job, he used 
to carefully prepare for the MT meetings, critically evaluating the decisions suggested by CD. He stopped these careful preparations when he realized that CD didn't really make use of the feedback provided. He told that he now got to a phase that he doesn't really prepare for the meetings anymore and waits and sees what comes across. He indicated that with the, in the meantime, collected experiences, he accomplishes his goals anyway.

Eventually, a dissociation attitude was reflected in observable MT behavioral integration processes. In our data, for example, the ratio of positive versus negative observed constructive behavior was relatively low in comparison to normal functioning MTs in previous studies. More specifically, we observed that despite the fact that information was shared within the MT, MT members did not manage to create a universal understanding of all concerns and experiences at work in the MT.

To conclude, we found the interplay between the experience of dual allegiance and its materialization to be a self-reinforcing cycle. "Who we think we are as organizational actors (identification) shape what we enact and how we interpret. This affects what outsiders think we are (image) and how they treat us, which stabilizes or destabilizes our identity (Weick, et al., 2005, p. 416). While OM start disengaging from the MT, the perceived boundary between OM and CD becomes larger. When the "we versus them thinking sharpens, less knowledge is shared and the creation of a dialogue is complicated. Consequently, this increases boundaries between MT members and obscures integration and collaboration behavior further.

\section{Research Implications}

Our study has several theoretical implications. First, the study directs attention to the role of team leadership. Researchers in the field acknowledge the importance of the leader in navigating and committing team members to the common interest of the team and emphasize examining structural team factors such as hierarchical differences as main determinants of team leader influence (Finkelstein, 1992; Hackman \& Wageman, 2005a; 2005b). However, under the influence of the upper-echelon tradition, MT researchers have devoted only little attention to the role of the individual MT leader in aligning and giving direction to the diverse perspectives present in a MT (Hiller et al., 2010). Our analyses disclose that, in the apex of organizations, interventions of the team leader may significantly link to MT dynamics. The team leader has a special function of which the alignment of various perspectives or identifications appears most critical to MT success. Further examining this, so-called, identity broker role of the team leader deserves future research attention and provide upper-echelon research with valuable new insights in terms of team leadership.

Second, our work contributes to studies that comprise literature on MT processes. To our knowledge, this study is the first to link MT member perceptions with observable MT behavioral integration processes. Previous work touched upon the dual allegiance character of MTs (e.g. Johnson, 1999; Li \& Hambrick, 2005), but failed to reveal the mechanisms behind the construal of collaboratively and collectively operating MTs. Additionally, researchers have successfully captured the functionality of observable interaction (e.g. Bales, 1950) and successfully investigated MT discourse (e.g. Raes et al., 2007), but a connection between discourse and observable interaction is 
needed to advance our understanding of MT functioning. This study adds value in that it demonstrates how factors beyond MT membership affect team functioning.

By extension, the study elucidates how psycho-social factors, beyond the commonly studied demographical proxies (e.g. Carpenter et al., 2004; Priem et al. 1999) are vital to appropriately understand MT processes. As noted earlier, the extant literature on upper-echelon research provides persuasive evidence in terms of the influence of MT demographical variety on organizational outcomes, such as performance or effectiveness (Carpenter et al., 2004; Hambrick \& Mason, 1984; Priem et al., 1999). However, the upper-echelon perspective is very rational and formal from character and as a consequence a gap remains that fails to explain the relationships between demographical proxies and organizational outcomes. This study aimed to start opening up part of this "black-box" (Lawrence, 1997) by linking behavioral integration, an increasingly used construct by upper-echelon researchers, to a psycho-social mechanism such as social identification. In doing so, we provided a more fine-grained understanding of the essential systemic of the black-box phenomenon.

Third, this study adds value to the social identification literature. Where previous research on dual identification has discovered antecedents of dual identification at the level of the organization (George \& Chattopadhyay, 2005; Reade, 2001; Vora \& Kostova, 2007), we suggest managerial roles to emerge correspondingly as sources of social identification. In line with George and Chattopadhyay's (2005) work on contract workers, we show that the perception of perceived similarity in organizational categories on key attributes is equally important at the managerial level. Yet, we add to the field of dual social identification in that we demonstrate how the acknowledgement, or in this case denial, of key attributes of a sub-ordinate identity may impede the formation of identifications with an overarching identity. In this sense, we may also provide empirical support for the interactive model of social identity formation of Postmes, Haslam and Swaab (2005). They empirically demonstrate that members' identification with the MT is not only a deductive phenomenon, but may also be created through interpersonal interaction.

\section{Limitations and Future Research}

Our results should be considered in light of some limitations. First, as with all case study research we must be careful generalizing our findings to organizational settings. Social identification processes are assumed to be context sensitive (e.g. Haslam \& Ellemers, 2006) and we have analyzed one MT in one country and one specific industry (e.g. the Netherlands). Hence, we must be careful regarding the unique nature of the setting. Some aspects of social identification and MT dynamics will be naturally impacted by cultural and organizational characteristics. By linking our findings to existing theory, though, we are confident our findings and conclusions are valuable across organizations and cultures.

Second, literature suggests that team identification can be socially reconstructed because of the collective interaction among MT members. Management literature argues that the degree of MT member interaction is dependent on structural characteristics, such as the level of task interdependence among MT members. Polzer et 
al., (2006) have demonstrated that the level of task interdependence impacts the functioning of teams and influences the degree of communication necessary for optimal team performance, consequently influencing the degree of MT members' identification with the MT (Gundlach, Zivnuska, \& Stoner, 2006). It might well be that the degree of task interdependence or the lack thereof might have influenced the interaction processes in the MT under study. Similarly, we admit that differences may exist between a tight-knit executive group like examined above which meets on a regular basis and a managerial team of top executives who do not meet as regularly. We believe, however, that our research findings regarding the fundamental inductive nature of MT identity formation, given the even higher impact sub-ordinate business-unit identities may play in a context of less frequent interaction (Rockmann, Pratt \& Northcraft, 2007), are equally applicable to top executive teams.

Third, we used the personal contacts of the researchers to gain access to the MT. We used a personal contact to get access to the organization as it is not very common that businesses allow an observer into their MT meetings (Hambrick, 2007), let alone to video-tape their meetings over a 5 months period. The fact that this MT allowed us access to the bi-weekly meetings could be an indication that this MT deviates from other MTs and as such is not representative for the whole population. The chair person, for instance, had personal affinity with academic research and was interested in hearing our observations concerning the MT's functioning. Although the deviation of this MT from the broader population can be considered a drawback in light of generalizability, our method underlines the importance of using action research based approaches to gain detailed insights into strategy as practice. We believe our methodology shows that innovative research methodologies are imperative to open the "black box" of MTs in the apex of organizations. The use of detailed recordings of MT behavioral integration processes enabled us to not only analyze our data in a structured and concise manner, but also to confront MT members in a with their observed behavior. We are confident that the direct confrontation of MT members with their observed behavior both enhanced their personal learning experience and triggered more authentic responses to our interview questions than if we would have used conventional research methods such as questionnaires or interviews without using video-fragments.

Fourth, we analyzed the observation data having our raters complete 5-point Likert scale behavioral integration constructs. We did this, because word by word coding has often proven impossible in the past (e.g. Bales, 1950; Gorse \& Emmitt, 2007). In hindsight, linking the observation data to the interview results would have been even more informative if we would have collected behavioral information of every individual MT member. Given the context sensitivity of social identities (Haslam \& Ellemers, 2006), we encourage future researchers to develop the link between social identification and behavioral integration processes further. For instance, some agenda items might be of more interest to a manager than others; it would be interesting to see how MT dynamics are affected on both a mutual or collective level by social identification changes over time. 
Research should also include the role of the team leader in MT dynamics. Our study revealed that the observed contentious behavior processes were affected by the presence or absence of the team leader. Unfortunately, we were not capable of collecting information on the team leader's identification. Hence, future studies could focus on how behavior among MT members is different when the team leader is absent and if levels of dual identification of the team leader impact this effect.

\section{CONCLUSION}

We began this paper by arguing that MT research has yet to investigate what mechanisms explain the integrative capacity of MTs. Our goal was to examine how MT members' experience of dual allegiance, a structural property of the MT, colors observable MT behavioral integration processes. Our analysis contributes to our understanding how psycho-social mechanisms such as MT members' identification with their business unit or other organizational category influence the construction of managers' MT identification. An inductive identity construction perspective suggests that MT members' identification with their business-unit or other organizational category can bias expectations about the MT to such an extent that the emergence of MT identification is thwarted. The misalignment between MT member's expectations and perceptions of the MT results in the dissociation of MT members with the MT, ultimately resulting into ineffective behavioral integration processes. In this situation, the chair person appears to fulfill a critical role in the facilitation of MT identification creation. In doing so, we expounded why and how MTs experience difficulties to act as a behaviorally integrated collective. 


\section{Chapter 5}

\section{Effects of Dual Identification and Conflict Development on Multi-Team System Performance $^{6}$}

${ }^{6}$ This chapter is based on the manuscript: - Cuijpers, M, Uitdewilligen, S. \& Günter, H. 2011. Effects of Dual Identification and Conflict Development on Multi-Team System Performance, Manuscript submitted for publication

This research was funded by the Network of Social Innovation (NSI), Maastricht University. We are grateful for the valuable feedback received when presenting earlier versions of this chapter at the 5 th annual INGRoup (Interdisciplinary Network for Group Research) Conference, July 22 - 24, 2010, Washington DC, the Network of Social Innovation (NSI) Seminar at Maastricht University, and the Academy of Management Conference, August 12-16, 2011, San Antonio - Texas, United States. In this chapter, -well refers to Hannes Guenter, and Sjir Uitdewilligen, both at Maastricht University. Also, we acknowledge the help of Elena Stamova, Julia Koch, Julia Nocker, Carolin Pfeifer and Viktoria Müller in data collection. 


\begin{abstract}
In this chapter, we investigate the influence of MTS and component team identification on inter-team conflict and MTS performance. Based on resource allocation theory and social identity theory, we build a longitudinal model to examine dual identification in multi-team systems. We measure our focal constructs on three consecutive performance episodes and use a real-time computer simulation to test our hypotheses. Using random coefficient modeling, we find MTS identification to be positively related with MTS performance. Inter-team task and relationship conflict temporally mediate this relation. Team identification initially furthers inter-team conflict, but this influence decreases over time. While the effects of MTS identification appear to be more prominent than the effect of team identification, our findings provide partial evidence for dual identification theory. We discuss implications for MTS theory and practice.
\end{abstract}




\section{INTRODUCTION}

A new stream of research is gaining momentum that goes beyond looking at the team as an isolated entity. This research focuses on the interactions that take place among multiple teams and investigates how collectives of teams perform (e.g. Faraj \& Aimin, 2009; DeChurch \& Marks, 2006). These collectives of teams, also referred to as multiteam systems (MTS), have common goals but also need to align individual team goals (Marks, DeChurch, Mathieu, Panzer, \& Alonso, 2005; Mathieu, Marks, \& Zaccaro, 2001; Kanfer \& Ackerman, 1989). For example, emergency management systems consist of police, fire brigade and medical teams that need to cooperate in case of emergencies (see Mathieu et al., 2001). While these component teams have their own team goals (e.g. treating injured persons and rescuing people from fire), together they share the overarching goals of containing the incident and saving people's lives (Mathieu et al., 2001). Previous research suggests that when interdependent teams have different goals, intergroup tensions may arise (DeChurch \& Zaccaro, 2010; Kanfer \& Ackerman, 1989). In particular, differences in team interests may demarcate perceived boundaries between teams and initiate negative perceptions of outsiders (Hornsey \& Hogg, 2000; Tajfel, 1975). Therefore, in order to ensure that an MTS functions as a collective entity it is crucial that inter-team tensions are kept at bay.

MTS research has identified a number of mechanisms for aligning potentially conflicting team interests, such as, inter-team coordination (e.g. Hoegl, Weinkauf, Gemuenden, 2004; Marks et al., 2005), interface project management (Hoegl \& Weinkauf, 2005), and leadership interventions (DeChurch \& Marks, 2006). While these findings are encouraging and important, we still miss research that studies the influence of MTS and component team goal preferences on inter-team functioning and performance more explicitly. The existence of both inter-team (i.e. MTS) and intrateam (i.e. component team) goals creates a complex structure that produces a constant trade-off between the accomplishment of distal MTS and proximal team level responsibilities.

To advance our knowledge of MTS, we build and test a longitudinal model that assesses how MTS and component team level identification interact and how these combined effects shape MTS performance over time. We draw from social identity theory (e.g. Horsney \& Hogg, 2000; Tajfel, 1975) and resource allocation theory (Kanfer \& Ackerman, 1989; Kramer \& Brewer, 1984) to derive hypotheses on how the discrepancy in MTS and team level responsibilities may cause inter-team conflicts and eventually hampers MTS performance. More specifically, we study how the extent to which team members identify with the overarching MTS and with the component teams influences MTS performance. In doing so, we take a dual identification perspective (Hogg \& Terry, 2000). In addition, we investigate the mediating role of inter-team conflict in this relationship. We expect that the extent to which team members identify with each entity (i.e. MTS and component team) impacts how much resources they will allocate to the attainment of the goals of that entity (Horsney \& Hogg, 2000; Kanfer \& Ackerman, 1989). Hence, if MTS members identify more with 
their component teams than with the MTS, team members will primarily assign resources to accomplish team goals. As a result, MTS performance will suffer. The dual identification perspective predicts that MTS performance will be highest if MTS members identify both with the MTS and with the team (Brewer, 1991; van Dick et al., 2004; Hogg \& Terry, 2000).

This research contributes to the growing MTS literature (DeChurch \& Marks, 2006; Marks et al., 2005; Mathieu et al., 2001) in three important ways. First, we add to the MTS literature in assessing how dual identification impacts inter-team conflict and performance. MTS studies have assessed the differential effects of inter-team and intrateam processes (DeChurch \& Marks, 2006; Marks et al., 2005), but we are not aware of studies investigating how team inputs (e.g., identification) are linked to inter-team outcomes (e.g., performance). Second, we provide insights into the mechanisms of dual identification and how these associate with inter-team processes over time. In doing so, we contribute to the social identity literature which is primarily conceptual and crosssectional in nature (e.g. Gonzalez \& Brown, 2003; 2006; Hornsey \& Hogg, 2000). Third, in accordance with temporal thinking (Marks et al., 2005), we measure our focal constructs over three points in time. While abundant research specifies longitudinal processes conceptually, only few provide empirical tests (see Pitariu \& Ployhart, 2010; Ployhart \& Vandenberg 2010).

We have structured the paper as follows. First, we elaborate on the characteristics of multi-team systems and explain why insights into resource allocation and social identity theory are critical to understanding MTS inter-team conflict and performance. Second, we describe our research methodology. Third, we present our empirical results, before discussing practical and theoretical implications of this study.

\section{THEORY AND HYPOTHESES}

\section{Multi-team Systems}

MTSs are constellations of component teams, that work autonomously towards team goals, but are functionally dependent on each other in terms of inputs, processes, and outcomes (Hornsey \& Hogg, 2000; Mathieu et al., 2001). An MTS is not a formal static organizational structure that binds teams together, but a functional structure characterized by strong task-related interdependencies among the component teams. The functioning of an MTS is determined by two main mechanisms, that is, goal hierarchy and episodic performance (Mathieu et al., 2001).

The notion of goal hierarchy entails the idea that the accomplishment of the overall goal of the MTS is a function of the accomplishment of the goals of the component teams (Marks et al., 2005; Mathieu et al., 2001). While each team executes different activities, MTS performance ultimately emerges from the goal achievement result of all individual component teams. For example, the goal accomplishment of an emergency management system is subject to how well the police, fire brigade, and medical teams comply with their proximal responsibilities of shielding of the premises, extinguishing fires, and rescuing victims. These component team goals, however, "must 
be aggregated to a higher level in a goal hierarchy for an MTS to exist" (Marks et al., 2005, p. 965). Finding the optimal balance between team and MTS goal preferences is thus important for MTS performance. The efficient exchange of resources in the MTS is an important means towards this end (Mathieu et al., 2001).

Further, MTSs are often characterized by episodic performance, meaning that specific periods can be identified that constitute of identifiable segments in the ongoing stream of behaviors (Mathieu et al., 2001). Based on the temporal framework of Marks and co-authors (2001) a distinction is made between action phases - in which the MTS members engage mainly in activities that are contributing directly to goal accomplishment - and transition processes in which the MTS members mainly engage in activities such as evaluation and planning that support the action processes. Transition and action phases cluster in performance episodes and these performance episodes are temporally related to each other; the output of one performance episode constitutes the input to the subsequent performance episode. To illustrate, the more carefully firefighting and medical teams prepare their joint rescue efforts (i.e. transition phase), the more efficient the teams can rescue victims. In the following sections, we will elaborate on how resource allocation theory and social identity theory help explain the emergence of MTS conflict and performance.

\section{Cross-level Goal Preferences and Accomplishment}

Resource allocation theory (Kanfer \& Ackerman 1989) suggests that an individual task performance depends in large part on the cognitive resources devoted to the execution of the task. Because individuals have limited cognitive resources, the attention devoted to one task cannot be assigned to a different task. Research of Barnes and colleagues (2008) indicates that the same principles applies for teams; teams have limited cognitive resources and if the members assign resources to the accomplishment of one team goal they may not have sufficient resources left for the accomplishment of other team goals. For MTSs this implies that when MTS members devote their resources to the accomplishment of component team goals fewer resources remain to be allocated to the MTS goals and vice versa. The successful accomplishment of either the component team or the overall MTS goals does not necessarily increase overall performance and may even reduce successful goal accomplishment on the other level (DeChurch \& Zaccaro, 2010). However, what determines MTSs to allocate its resources to either the distal MTS or proximal team goals?

Social identity theory offers a plausible explanation. The theory suggests that the focus of resource allocation depends on the attachment of MTS members to the team versus the larger entity. People attach cognitive and emotional significance to their membership of a collective (Ellemers \& Doosje, 1995; Tajfel, 1982). Identification with a collective fulfills a need for self-enhancement, reduces a sense of uncertainty, and creates a feeling of distinctiveness (Hogg \& Terry, 2000). Being part of a collective helps people to define who they are and to evaluate their status (Tajfel, 1982; Turner, 1975). People who identify with a collective favor its members, goals and interests over those of other collectives (e.g. Hogg \& Terry, 2000; Tajfel, 1982). The collective's goals and interests are internalized and regarded as the person's own, and as a consequence, 
the person's attitude and behavior are directed towards the accomplishment of the collective's objectives (e.g. Hornsey \& Hogg, 2000; Mael \& Ashforth, 1992). In short, social identification shapes people's goal preferences.

Recently, social identification researchers have recognized that as people often are members of more than one organizational entity at the same time, they can identify with more than one collective (e.g. Hornsey \& Hogg, 2000; Li \& Hambrick, 2005; Van Dick, van Knippenberg, Kerschreiter, Hertel, Wieseke, 2008). MTS members, for example, are member of the overarching MTS and of a component team and their identification with each of these entities determines their goal preference. Since the MTS is the larger entity that encompasses the component team, MTS members' identification with their component team is nested within their identification with the MTS. This overlap in identification has important implications in terms of resource allocation and intergroup relations. Studies suggest that performance of the MTS will be optimal when members identify with the overarching MTS and with their component team as this optimizes resource allocation (e.g. Brewer, 1991; Hogg \& Terry, 2000; van Dick, Wagner, Stellmacher, Christ, 2004; Richter, West, van Dick \& Dawson, 2006). Thus, we propose that MTS performance is contingent upon MTS member's identification with the MTS and their component team. In the following sections, we introduce our hypotheses in the order depicted in Figure 1.

Figure 1: Conceptual model: MTS and team identification, Conflict and MTS performance

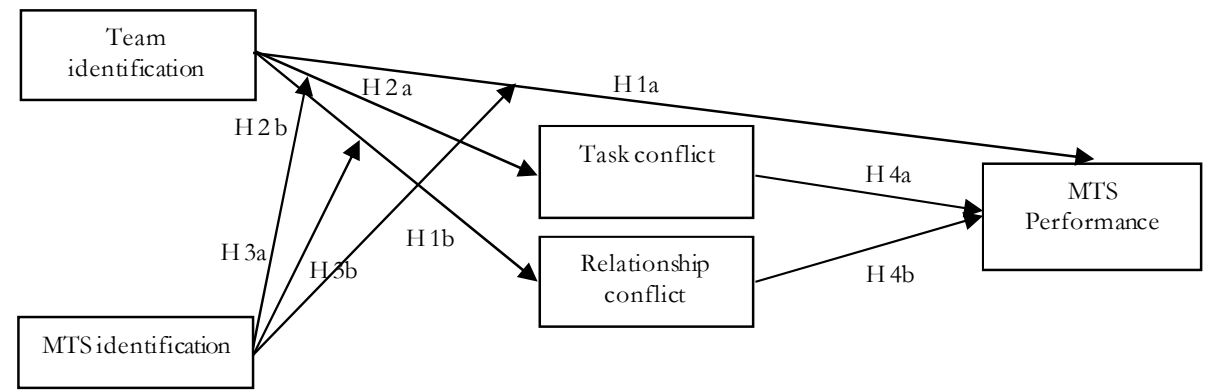

\section{Effect of MTS and Team Identification on MTS Performance}

Resource allocation theory posits that the effective distribution of resources among interdependent teams is critical to optimize MTS performance (Porter et al., 2010; Marks et al., 2005). Marks and colleagues (2005) demonstrate that MTS performance benefits most when resource allocation is coordinated at the MTS level. Similarly, DeChurch and Marks (2006) show that leadership interventions on resource allocation at the MTS level are most effective for MTS performance, while leadership interventions on the team level mainly improve team performance. 
Obviously, resource allocation at the MTS level, more so than at the team level, is critical for MTS performance. But what would increase chances that MTS members allocate resources to the MTS level? According to social identification theory, MTS members allocate resources to the MTS level to the extent that they identify with the overall MTS, because this makes them prioritize the accomplishment of MTS goals over team goals (Dutton, Dukerich \& Harquail, 1994; Kramer \& Brewer. 1984). Ullrich, Wieseke, Christ, Schulze, and Van Dick, (2007) demonstrate this in a study on organization and corporate identification among franchise employees. They show identification with the corporation (and not with the organization) to positively influence corporate citizenship behavior and organizational identification (and not corporate identification) to influence customer-oriented behavior.

Although Tajfel (1982) understood social identification as a process, extant research on the association of identification and performance is largely cross-sectional. Still, given that these results appear to be robust and Geibl, Noack and Mummendey (2010) show the functional mechanism that underpin these cross-sectional findings to hold over time, we extrapolate from these findings and suggest them to hold over time. Therefore, we hypothesize that:

Hypothesis 1a: Over time, MTS identification is positively related with MTS performance.

Resource allocation theory (Kanfer \& Ackerman, 1989) suggest that when members solely identify with only one of the two entities (component team or MTS), they only internalize the respective goals and interests of that entity and will allocate resources accordingly. If however team members identify simultaneously with the MTS and the team, they may allocate resources across these entities in a more balanced way. Dual identification-high identification with both the MTS and with the component team-may help MTS members to understand and integrate their twofold responsibilities (Glynn, Kazanjian \& Drazin, 2010; Pratt et al., 2006; Vora \& Kostova, 2007).

Supporting evidence for the positive cross-level effects associated with dual identification comes from research of Hoegl and colleagues (2004). They found that when commitment to overarching project goals was positively related to the accomplishment of team goals, a simultaneous high identification with the team, was positively related to inter-team performance. This implies that, for the accomplishment of both MTS and team level goals, dual identification is essential (e.g. Hogg \& Terry, 2000; Van Dick et al., 2008). MTS identification is needed for the allocation of resources to MTS goals and team identification for investing in team goals. We expect these effects to hold over time, and consequently predict that:

Hypothesis 1b: Over time, MTS identification is more strongly and positively related with MTS performance when team identification is high than when it is low. 


\section{Effects of MTS and Team Identification on Inter-team Conflict}

MTS component teams often differ in terms of functional background, expertise, and experience and bring divergent frames of reference to the task at hand. If members of the component teams consider the perspective of their team to be more valid than the perspective of the other team (e.g., Hogg \& Terry, 2000), disagreements and task conflict can arise (Jehn, 1995; Jehn \& Mannix, 2001). Task conflicts may further increase when members of one team lack an understanding for the goal and task execution preferences of the other team. Preferences may refer to the propensity to take risks, the use of time, and the use of control systems (Jehn, Chadwick, Thatcher, 1997; Wiesenfeld \& Hewlin, 2003).

Additionally, because MTS members belong to different teams, in-group/outgroup bias may result. Members of the in-group are perceived as commendable and trustworthy whereas out-group members are seen as lamentable and unreliable (Abrams \& Hogg, 2004). In other words, perceptions of team membership can create a competitive and hostile atmosphere that endangers the social harmony in the MTS (e.g., Hornsey and Hogg, 2000; Pelled et al., 1999; Tajfel, 1982; Turner, 1975). This tension, disharmony, and animosity among teams is commonly defined as relationship conflict (Jehn, 1995; Jehn et al., 1997).

MTS identification can decrease inter-team task and relationship conflict (Gaertner et al., 1994; Hornsey \& Hogg, 2000; Tajfel, 1975) and encourage component teams to "synchronize their actions in order to accomplish the overarching MTS goal" (Marks et al., 2005, p. 965). Intergroup relations theorists suggest that an overarching identity will decrease task and relationship conflict because the common identity helps to align various, potentially conflicting, team goals and ideas (Han \& Harms, 2010; Mortensen \& Hinds, 2001). Mortensen and Hinds (2001), for example, found that collective identification reduced both task and relationship conflict, by creating a "we are in this together" thinking. When people identify with the overarching MTS, attention to the differences between groups is substituted by an emphasis on what MTS members have in common. Identification with the MTS thus positively affects the alignment of thoughts, feelings, and actions, which is an important precondition for the integration of divergent ideas and perspectives (Haslam, 2001; Van Der Vegt \& Bunderson, 2005). Accordingly, Moore, Kurtzberg, Thompson, and Morris (1999) found that the absence of collective identification complicated rapport building and negatively impacted intergroup relations both on and off the task. We expect these cross-sectional findings, to also hold over time, and therefore hypothesize that:

Hypothesis 2a: Over time, MTS identification is negatively related to inter-team task conflict.

Hypothesis 2b: Over time, MTS identification is negatively related to inter-team relationship conflict.

While MTS identification satisfies MTS members' need for belongingness and inclusiveness, optimal distinctiveness theory suggests inclusiveness to have potential 
drawbacks (Brewer, 1991). If members identify only with a higher entity they may feel "over included" in the sense that their uniqueness and need for differentiation is threatened (Hogg \& Terry, 2000). As a result, team members may engage in in-group favoring behavior to differentiate themselves from other teams, which may distort inter-team relations (Brewer, 1991; Hornsey \& Hogg, 2000). Optimal distinctiveness theory suggests that identifying with a lower entity in addition to a higher entity may therefore be critical, as this allows MTS members to feel unique and different from other teams in the MTS (e.g. Brewer, 1991; Glynn et al., 2010). When team members identify with both the MTS and the component team, needs for inclusiveness and uniqueness are satisfied simultaneously, reducing inter-team biases, threats, and conflicts (Gaertner et al., 1999; Richter et al., 2006).

Hornsey and Hogg (2000) argue that distorted interaction can be transformed into constructive competition when team members are able to express their identification with their individual team within the context of the overarching MTS identity. Therefore, we expect that when MTS members identify with both the MTS and the team, they will experience more constructive levels of inter-team task and relationship conflict than when members identify only with the MTS. When MTS members cling too stringently to the goals and interests of the overarching MTS, they may neglect the interests and goals of the component teams (Brodbeck et al., 2007; Schulz-Hardt, Frey, Lüthgens, Moscovici, 2000). While mere emphasis on MTS identification increases the danger of closed mindedness and groupthink (Janis, 1982), members' team identification can bring about productive levels of inter-team task conflict.

Recent research provides empirical proof for a positive relation between dual identification and inter-team relations and productivity (Richter et al., 2006; Vora, Kostova \& Roth, 2007). Richter and colleagues (2006), for example, provided supportive evidence for a dual identification model among health care employees. Employees' organizational identification was more strongly related to effective interteam relations when their work group identification was high rather than low. The combined identification thus seemed to suppress experiences of being torn between MTS and component team responsibilities (DeChurch \& Zaccaro, 2010). We suggest this line of argumentation to also hold when assessed over time and conclusively hypothesize:

Hypothesis 3a: Over time, the relationship between MTS identification and inter-team relationship conflict is more negative when team identification is high than when it is low.

Hypothesis 3b: Over time, the relationship between MTS identification and inter-team task conflict is more positive when team identification is high than when it is low. 


\section{Effect of Inter-Team Task and Relationship Conflict on MTS Performance}

Research on the consequences of relationship conflict finds relationship conflict to be detrimental to group performance (e.g. De Dreu \& Weingart, 2003; Janssen, van de Vliert, \& Veenstra, 1999). There are several reasons for the negative implications of relationship conflict. First, time and effort that could be devoted to executing the task at hand go into resolving inter-team animosity (Jehn, 1995). Second, relationship conflict increases arousal and this reduces cognitive flexibility and negatively affects the teams' information processing capacity (De Dreu \& Weingart, 2003). Third, relationship conflict generates stress and anxiety, which reduces decision-making quality (Peterson \& Behfar, 2003; Simons \& Peterson, 2000). Overall, this leads us to predict that:

Hypothesis 4a: Over time, inter-team relationship conflict is negatively related with MTS performance.

Research on the consequences of task conflict, is rather inconclusive (DeChurch \& Marks, 2001; Jehn, 1995). For example, a study by Jehn (1995) reveals that task conflict can be both detrimental and beneficial to performance, depending on the type of task to be executed. While task conflict on routine tasks damages performance, task conflict on non-routine tasks can actually be beneficial. Jehn (1995) argues that for simple and routine tasks, substantial discussions on the execution of the task may appear redundant as people rely on standard operating procedures. Task conflict then interrupts and is counterproductive.

For non-routine situations task conflict encourages people to develop new ideas and approaches, to exchange diverse information, and to resist closed mindedness and/or groupthink (Janis, 1982). MTSs are generally confronted with non-routine situations where inter-team coordination is needed to align different goals and interests (Marks et al., 2005; Mathieu et al., 2001). Through the exchange of diverse ideas and experiences task conflict thus offers unity in the actions to be undertaken, improving MTS performance respectively (Postmes et al., 2005). We assume these effects to hold over time, and conclusively hypothesize that:

Hypothesis 4b: Over time, inter-team task conflict is positively related to MTS performance.

By extension we hypothesize that:

Hypothesis 5a: Over time, inter-team relationship conflict mediates the associations of MTS and team identification with MTS performance.

Hypothesis 5b: Over time, inter-team task conflict mediates the associations of MTS and team identification with MTS performance. 


\section{METHOD}

\section{Participants}

We recruited two hundred and sixty eight students from undergraduate and graduate management courses at a Dutch University. The study was embedded in these courses as course work material. Participants were randomly distributed over 67 four person MTSs. The MTSs consisted of two teams, each consisting of two participants. Students registered electronically for participation and were randomly assigned to MTSs. We administered all relevant demographic information (e.g. age, gender, game experience etc.) during this registration process. The three best performing teams and three best performing MTS received financial rewards; 60 Euros for the best team, and MTS, 40 Euros for the second-best team and MTS and 20 Euros for the third-best team and MTS.

\section{Context}

The study took place in a laboratory, using a two hour real-time command-and-control fire fighting computer simulation, called Networked Fire Chief (NFC; Omodei, Taranto, \& Wiering, 2003). The NFC simulation runs on a network of computers and each participant is seated in front of a simulation computer. During the simulation, fires occur at predetermined locations and time points and participants need to use fire trucks to extinguish fires and manoeuvre bulldozers to clear land to prevent fires from spreading.

For the present study we relied on Mathieu and co-authors (2001) to design scenarios that meet the main criteria of MTSs. In the scenarios the two teams were given the role of fire departments responsible for two neighbouring villages. The two fire departments were interdependent in terms of inputs, processes, and outcomes. They depended on each other for inputs as they shared limited amounts of vehicles and limited resources water and fuel, necessary to operate the vehicles. The teams were interdependent in that a team had access to either water or fuel and had possibilities to share resources. Moreover, since most fires occurred at the border between the two villages, the teams needed to cooperate and coordinate their actions in order to optimally contain these fires. If one team did not manage to contain a border fire, it would spread to the village of the other team.

Within each team, the members had different roles and responsibilities. One member saw the simulated area at large, but not the details. This person was able to move the vehicles but not to make them extinguish fires or bulldoze land. Consequently the person with this overview role was responsible for locating fires and supplying the other team member with vehicles and resources. The other team member had a more detailed view of the area and was responsible for the actually extinguishing fires and bulldozing land. 


\section{Procedure}

After arriving to the laboratory, participants first received an identification manipulation. We manipulated members' identification with their team and with the MTS. Based on previous studies that manipulated social identification (e.g. Gonzalez \& Brown, 2003), we used vignettes, names, and differently colored attributes to manipulate participants' identification. In the low team - low MTS identification condition, participants were provided with four differently colored vests and badges, read stories emphasizing individuality and personal achievement, and were instructed to come up with their own individual nickname. In the low team - high MTS identification condition, all participants were provided with the same colored vests and badges, they read stories emphasizing the glory and success of the overall fire department, and they were instructed to come up with a name for their MTS. In the high team - low MTS identification condition, participants from the two teams were provided with differently coloured vests and badges, they read stories emphasizing the glory and success of their village fire department, and they were instructed to come up with a name for their team. In the high team - high MTS identification condition, all participants received vests of the same colour and members of the two teams received badges of different colours, they read both the stories emphasizing the past glory and success of the village fire department and of the overall department, and they invented a name both for their team and for the MTS. We summarized our used manipulations in Table 1.

After the manipulation, team members first individually viewed a ten minute instruction video and then engaged in a ten minute practice trial. The actual simulation consisted of three transition and three action phases (Marks et al., 2001). In the transition phases, the two teams (i.e. 4 participants) were seated together around a table in the same room and were given eight minutes to develop a strategy for the next action period. As input to the planning session, participants were supplied with maps, weather forecasts, and fairly accurate information on the times and locations of fire outbursts in the subsequent round.

Transition phases were followed by action phases. During the action phases the two teams were located in separate rooms and participants communicated with each other via headsets. Participants were able to communicate freely within the teams, but only team members with the overview role were able to communicate with the overview member of the other team. Action periods, in which participants fought the simulated fires, lasted ten minutes. After each action phase participants were administered a questionnaire covering our focal measures.

\section{Measures}

MTS and team identification was assessed with an established four item measure, developed by Doosje, Ellemers, and Spears (1995). Responses were registered on a 5point Likert-type scale, ranging from (1) 'fully disagree' to (5) 'fully agree'. A sample item for team identification reads: "I see myself as a member of the team." For MTS identification we substituted the word 'team' for 'MTS'. The reliability for team 
identification for trial 1 to 3 was $.93, .96$, and .96, correspondingly. For MTS identification reliability was $.93, .96$, and .97 , respectively.

Table 1: Approach to the experimental manipulation of MTS and team identification

\begin{tabular}{|c|c|c|c|c|c|}
\hline $\begin{array}{l}\text { Experimental } \\
\text { condition }\end{array}$ & $\begin{array}{l}\text { Colored vests, } \\
\text { badges }\end{array}$ & Photo and poster & Vignette & Seating & Labeling \\
\hline Individuals & $\begin{array}{l}\text { Four separately } \\
\text { colored vests } \\
\text { and badges with } \\
\text { nick name }\end{array}$ & $\begin{array}{l}\text { Photograph of } \\
\text { each participant, } \\
\text { holding poster } \\
\text { with nick name }\end{array}$ & $\begin{array}{l}\text { Participants read story } \\
\text { on personal } \\
\text { achievements, } \\
\text { individuality is } \\
\text { emphasized in story }\end{array}$ & $\begin{array}{l}\text { Integrated: } \\
\text { Coordinator } \\
\text { between two } \\
\text { executors }\end{array}$ & $\begin{array}{l}\text { All four participants } \\
\text { invented a personal } \\
\text { nick name }\end{array}$ \\
\hline One group & $\begin{array}{l}\text { Four yellow } \\
\text { vests and four } \\
\text { yellow badges } \\
\text { with MTS name }\end{array}$ & $\begin{array}{l}\text { One photograph } \\
\text { of whole MTS } \\
\text { holding a poster } \\
\text { with MTS name }\end{array}$ & $\begin{array}{l}\text { All four participants read } \\
\text { story on past glory, } \\
\text { success of MTS }\end{array}$ & $\begin{array}{l}\text { Integrated: } \\
\text { Coordinator } \\
\text { between two } \\
\text { executors }\end{array}$ & $\begin{array}{l}\text { All four participants } \\
\text { invented a name for } \\
\text { the MTS together }\end{array}$ \\
\hline Two group & $\begin{array}{l}\text { Two yellow } \\
\text { vests, two } \\
\text { orange vests and } \\
\text { badges in similar } \\
\text { colors with team } \\
\text { names }\end{array}$ & $\begin{array}{l}\text { One photograph } \\
\text { of each team } \\
\text { separately holding } \\
\text { a poster of their } \\
\text { respective team }\end{array}$ & $\begin{array}{l}\text { All four participants read } \\
\text { story on past glory } \\
\text { success of team }\end{array}$ & $\begin{array}{l}\text { Segregated: } \\
\text { Coordinator and } \\
\text { executor of same } \\
\text { team next to each } \\
\text { other }\end{array}$ & $\begin{array}{l}\text { Participants of each } \\
\text { team invented a name } \\
\text { for their team }\end{array}$ \\
\hline Dual identity & $\begin{array}{l}\text { First: two yellow } \\
\text { and two orange } \\
\text { badges with } \\
\text { team name } \\
\text { Next: four } \\
\text { yellow vests and } \\
\text { white badges } \\
\text { with MTS name }\end{array}$ & $\begin{array}{l}\text { First: photograph } \\
\text { of each team, } \\
\text { holding poster of } \\
\text { their respective } \\
\text { teams } \\
\text { Next: one } \\
\text { photograph of } \\
\text { MTS, holding a } \\
\text { poster with MTS } \\
\text { name }\end{array}$ & $\begin{array}{l}\text { Participants read story } \\
\text { on past glory / success } \\
\text { of their team and MTS. } \\
\text { Integration of the team } \\
\text { within MTS is } \\
\text { emphasized in story }\end{array}$ & $\begin{array}{l}\text { Segregated: } \\
\text { Coordinator and } \\
\text { executor of same } \\
\text { team next to each } \\
\text { other }\end{array}$ & $\begin{array}{l}\text { First: Participants of } \\
\text { each team invented a } \\
\text { name for their team } \\
\text { Next: All four } \\
\text { participants invented a } \\
\text { name for the MTS } \\
\text { together }\end{array}$ \\
\hline
\end{tabular}

Inter-team task and relationship conflict was measured with a three item scale by Jehn and Mannix (2001). Answers were given on a five-point Likert-type scale, ranging from (1) 'none' to (5) 'a lot'. We adapted the scales for task and relationship conflict to fit the inter-team context. A sample item for inter-team task conflict reads: "How much conflict of ideas is there in your department?" The reliability for inter-team task conflict for trials 1 to 3 , was $.91, .90$, and .93, respectively. A sample item for interteam relationship conflict reads: "How much relationship conflict is there in your department?" The reliability for inter-team relationship conflict was $.82, .60$, and .78, correspondingly.

MTS performance was indexed as the percentage of land of the two villages that was saved. The simulation provides a score of how much land has been burnt during each trial. Not every area was equally important. For example, more points were subtracted for burnt houses than for burnt trees. We calculated MTS performance by 
dividing the amount of land that was burnt by the amount of land that could have been burnt in the specific action episode. We reversed this score, so that higher scores indicate better performance.

Control variables. Previous research suggests that the familiarity of team members can have an impact on interpersonal interaction and team performance (e.g. Binder et al., 2009; Gaertner et al., 1994). Therefore, we assessed member familiarity by a one-item measure, documenting participant's past experience. Answers were given on a 5 -point Likert scale $(1=$ not at all, $5=$ extremely). The item reads: "How often have you worked together with your team member in the past?" Furthermore, given that we use a computer simulated environment to test our hypotheses, it is possible that the amount of experience participants had with playing computer games influenced their task performance (Wilson et al., 2009). Therefore, we controlled for the number of weekly hours participants played computer games.

\section{Analytic Approach}

Aggregation statistics were calculated to validate aggregation of our constructs to the MTS level. Table 2 provides an overview of the $\operatorname{Rwg}(j)$ and ICC(1) values. MTS level consensus was estimated with the $\operatorname{Rwg}(j)$ index representing within-group agreement. All average $\operatorname{Rwg}(j)$ for our focal constructs are well above the generally agreed upon cut-off value of .70 (e.g. LeBreton \& Senter, 2008). We also calculated the intra-class correlation coefficient for our constructs. ICC(1) indexes the between group variance relative to the total variance. Over the three time points, the ICC(1) varied between .06 and .21. According to LeBreton and Senter (2008) these ICC(1) values indicate reasonable evidence for a group effect. Hence, our $\operatorname{Rwg}(j)$ and $\operatorname{ICC}(1)$ justify aggregation to the MTS level.

Table 2: Inter-rater reliability and intra-class correlation coefficients for the study variables

\begin{tabular}{llllll|lllllll}
\hline Constructs & Rwg(j) & & & & ICC $(1)$ & & \\
\hline & Trial 1 & Trial 2 & Trial 3 & Av & Trial 1 & Trial 2 & Trial 3 & Av \\
MTS Identification & 0.82 & 0.88 & 0.89 & 0.86 & 0.12 & 0.15 & 0.15 & 0.14 \\
Team Identification & 0.87 & 0.87 & 0.89 & 0.88 & 0.08 & 0.23 & 0.30 & 0.21 \\
Inter-team Task Conflict & 0.86 & 0.93 & 0.82 & 0.87 & 0.14 & 0.07 & 0.20 & 0.14 \\
Inter-team Relationship Conflict & 0.90 & 0.93 & 0.82 & 0.88 & 0.13 & 0.02 & 0.04 & 0.06 \\
\hline
\end{tabular}

Random Coefficient Modeling Framework. We used random coefficient modeling (RCM) to analyze our longitudinal MTS level data (Bliese \& Ployhart, 2002). RCM offers some advantages over regular statistical analyses like hierarchical linear regression or repeated measures ANOVA. RCM is capable to deal with non-independence of observations and reveals the richness of longitudinal data and is thus preferable over other statistical methods (Bliese, 2000). In addition, RCM accounts for inconsistent variances, provides tests of intra- and inter-team changes, and allows intercepts (e.g. initial status) and slopes (rate of change) to vary across MTSs (Bliese \& Ployhart, 2002; 
Hausknecht, Hiller \& Vance, 2008). Recent examples on the use of growth modeling techniques in experimental studies can be found in Adler and colleagues (2008) and Chen and Mathieu (2008).

We estimated our growth models by means of the Non-linear and Linear Mixed Effects (NLME) program for R. R is open source statistical software well suited for RCM and widely used in other fields like psychology or economics (Culpepper \& Aguinis, 2010). We coded time, indicated as trial 1, trial 2, and trial 3, as 0, 1, and 2, respectively. In this way, we were able to interpret the intercept of our performance growth model as the overall MTS performance on the first trial (see Bliese \& Ployhart, 2002). We grand-mean centered our dependent and independent variables to ease interpretation and enable cross-model comparison (Singer \& Willett, 2003).

\section{Manipulation Check}

We used MANOVA to test the effect of our manipulation of team and MTS identification. We found a significant effect of the manipulation on both team and MTS identification, $\mathrm{F}(6,126)=9,454, \mathrm{p}<.001$. Separate univariate ANOVAs revealed significant manipulation effects in the intended directions. We tested for differences between the high and low MTS identification condition $(\mathrm{F}(1,66)=8.461, \mathrm{p}<0.05)$, and high and low team identification condition $(\mathrm{F}(1,66)=14.920, \mathrm{p}<0.001)$. Outcomes revealed significant manipulation effects in the intended directions for high versus low MTS identification and high versus low team identification.

\section{RESULTS}

The descriptive statistics and zero-order correlations among the study variables are depicted in Table 3. Mean values of overall MTS performance ranged from 47.82 to 82.35 percent of saved land. Further, the dynamics in the zero-order correlations of the focal constructs over the three trials suggest relationships among the variables. However, it is important to realize that these between MTS results may obscure the actual within- and between MTS variance of our longitudinal model (Chen \& Mathieu, 2008). To test whether MTS identification, team identification, and team conflict exhibited sufficient convergent and discriminatory validity we performed a series of confirmatory factor analyses (CFA) at the MTS level. For identification, we found the two-factor model (assuming team and MTS identification to be distinct) to provide better fit to the data than the one-factor model. Therefore, we retained the two-factor solution for all subsequent analyses. The fit indices for a two-factor model of identification were for trial $1 ; \chi^{2}[19]=46.29, \mathrm{p}<.001$, comparative fit index $(\mathrm{CFI})=$ .94 , and standardized root mean residual $(\mathrm{SRMR})=.05$, for trial $2 ; \chi^{2}[19]=57.15$, $\mathrm{p}<.001, \mathrm{CFI}=.95$, and SRMR $=.03$, and for trial $3 \chi^{2}[19]=75.02, \mathrm{p}<.001, \mathrm{CFI}=.93$, and SRMR $=.04$. The fit indexes for a one-factor model of identification in contrast, were for trial $1 ; \chi^{2}[20]=175.17, \mathrm{p}<.001, \mathrm{CFI}=.68$, and SRMR .15, for trial $2 ; \chi^{2}[20]$ $=144.87, \mathrm{p}<.001, \mathrm{CFI}=.83$, and SRMR $=.06$ and trial $3 ; \chi^{2}[20]=279.43, \mathrm{p}<.001$, $\mathrm{CFI}=.67$, and SRMR $=.13$. 


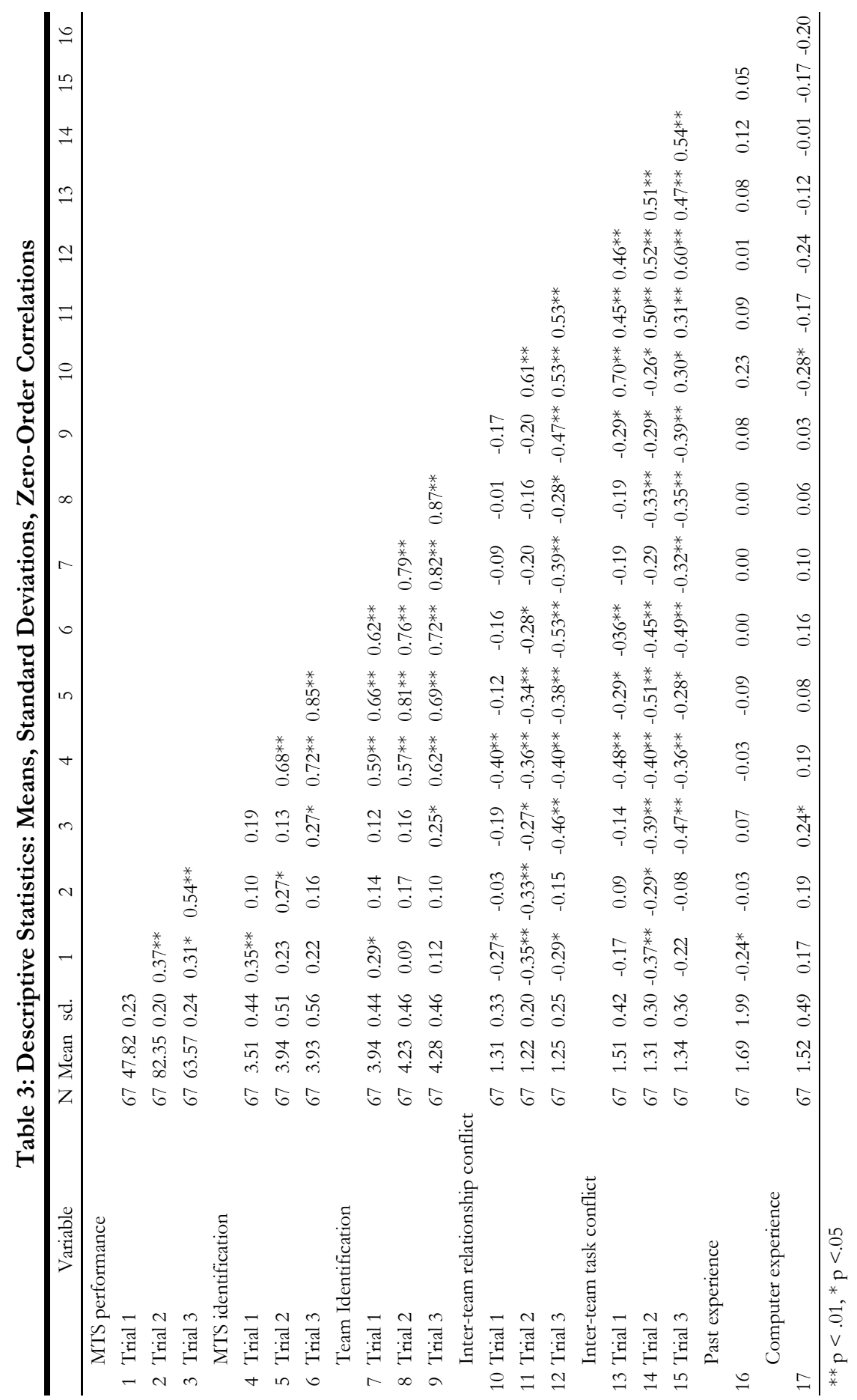


For inter-team conflict, we also found the two-factor model to provide better fit than the one-factor model. For trial $1 ; \chi^{2}[8]=29.73, \mathrm{p}<.001$, CFI $=.94$, and SRMR $=.06$. Trial 2; $\chi^{2}[8]=20.21, \mathrm{p}<.001, \mathrm{CFI}=.96$, and SRMR $=.06$. Trial 3; $\chi^{2}[8]=$ $11.20, \mathrm{p}=.19, \mathrm{CFI}=.99$, and SRMR $=.04$. Overall, these fit indexes were superior to the one-factor model. Trial $1 ; \chi^{2}[9]=76.42, \mathrm{p}<.001, \mathrm{CFI}=.81$, and SRMR $=.11$. Trial $2 ; \chi^{2}[9]=41.18, \mathrm{p}<.001, \mathrm{CFI}=.90$, and SRMR $=.10$. Trial 3; $\chi^{2}[8]=56.57, \mathrm{p}<.001$, $\mathrm{CFI}=.89$, and SRMR $=.11$.

\section{Modeling Trajectories}

We measured our focal constructs at three points in time. This allows us to trace changes in MTS performance over time and to examine how our time-varying predictors (MTS identification, team identification, and inter-team task and relationship conflict) influence these changes. We used the model building steps as indicated by Bliese and Ployhart (2002) to construct our growth model for overall MTS performance. As a baseline model we use a regression model with fixed intercept and slope. We test for model improvements by conducting maximum likelihood tests and compare the fit between the models by means of a chi-square test (Bliese \& Ployhart, 2002).

Intra-class correlation coefficient. The first step in building a random coefficient model is the calculation of the ICC(1) for MTS performance over time. In this context, the ICC(1) is the variance of MTS performance over time that is attributable to between MTS differences. This ICC indicates the degree of non-trivial non-independence of measures and is as such a benchmark for the appropriateness of RCM (Bliese \& Ployhart, 2002). Analyses revealed that ICC(1) for MTS performance was .16, indicating that between-MTS variance explained $16 \%$ of the variance in performance over time. According to Bliese (2000) this value signifies considerable differences in MTS' performance trajectories. From this we conclude that the estimation of more complex models to examine longitudinal change in performance is justified. For inter-team task and relationship conflict the ICC(1) was .44 and .50, respectively. Growth modeling is thus also justified for these constructs.

Building a growth model. The next step in model building is to examine whether a random intercept model (i.e., MTSs substantially differ in their initial performance levels) fits our data better than a baseline model derived with the Ordinary Least Square method. Then, we compared the fit of a random slope model (i.e., MTSs substantially differ in the way their performance changes over time) with the fit of the random intercept model. We used deviance tests and calculated chi-square differences to establish the optimal model. Results of these analyses indicate the random-intercept model to fit the data significantly better than the baseline model $(\Delta 2 \mathrm{LL}=4.405, \mathrm{p}<$ .05). The random slope model did not significantly improve upon the random intercept model $(\Delta 2 \mathrm{LL}=0.00, \mathrm{p}>$.1). This implies that, in our data, a model with initial differences in overall MTS performance provides better fit than a model in which also the rate of change varies across MTSs. Accordingly, we use a random intercept model for testing our hypotheses (see Bliese \& Ployhart, 2002). Before analyzing our hypotheses we tested for autocorrelation $(2 \mathrm{LL}=-10.91)$ and heteroscedacity (2LL = - 
10.89). The model in which we controlled for autocorrelation yielded an improved fit to our data $(\Delta 2 \mathrm{LL}=4.58, \mathrm{p}<.05)$ whereas the model controlling for heteroscedasticity did not improve model fit $(\Delta 2 \mathrm{LL}=0.03, \mathrm{p}>.1)$. We thus controlled for autocorrelation on all further analyses. We summarized the results in Table 4.

\section{Table 4: Results of Fitting Random Coefficient Models to Overall MTS Performance}

\begin{tabular}{|c|c|c|c|c|c|c|c|}
\hline Fixed Effect & $\begin{array}{l}\text { Model 1: } \\
\text { Linear }\end{array}$ & & $\begin{array}{l}\text { Model 2: } \\
\text { Random } \\
\text { Intercept }\end{array}$ & $\begin{array}{l}\text { Model 3 } \\
\text { Random } \\
\text { Slope }\end{array}$ & tercept \& & $\begin{array}{l}\text { Model 4: } \\
\text { Test for } \\
\text { Autocorrelation }\end{array}$ & $\begin{array}{l}\text { Model 5: } \\
\text { Test for } \\
\text { Heteroscedacity }\end{array}$ \\
\hline (Intercept) & $0.57 * * *$ & $(.03)$ & $0.56^{* * *}(.03)$ & $0.56^{* * *}$ & $(.03)$ & $0.58^{* * *}(.03)$ & $0.58^{* * *} \quad(.03)$ \\
\hline Time & $0.08^{* * *}$ & $(.02)$ & $0.08^{* * *}(.02)$ & $0.08^{* * *}$ & $(.02)$ & $0.08^{* * *}(.02)$ & $0.08^{* * *} \quad(.02)$ \\
\hline \multicolumn{8}{|c|}{ Goodness of Fit } \\
\hline $\log \mathrm{Lik}$ & -15.40 & & -13.20 & -13.20 & & -10.91 & -10.89 \\
\hline AIC & 36.81 & & 34.40 & 38.40 & & 31.82 & 33.79 \\
\hline $\mathrm{BIC}$ & 46.56 & & 47.41 & 57.92 & & 48.08 & 53.31 \\
\hline$-2 \mathrm{LL}$ & & & $4.405^{*}$ & & 0.00 & $4.58^{*}$ & 0.03 \\
\hline
\end{tabular}

$\mathrm{n}=67, * * * \mathrm{p}<.001, * \mathrm{p}<.05, \mathrm{tp}<.1$

Concerning inter-team task conflict, we found a random intercept model to best fit the empirical data. We found evidence for a significant improvement $(\triangle 2 L L=$ $39.82, \mathrm{p}<.001)$ from the base-model to the random intercept model, but no significant improvement from the random intercept to the random slope model. For inter-team relationship conflict, we found evidence for substantial variability in the intercept $(\Delta 2 \mathrm{LL}=48.24, \mathrm{p}<.001)$ as well as for variability in the rate of change $(\Delta 2 \mathrm{LL}=9.89, \mathrm{p}$ $<$.001). For relationship conflict, model fit further improved when controlling for autocorrelation $(\Delta 2 \mathrm{LL}=17.5, \mathrm{p}<.001)$. The results are summarized in Table 5 and 6.

Table 5: Results of Fitting Random Coefficient Models to Relationship Conflict

\begin{tabular}{|c|c|c|c|c|c|c|}
\hline Fixed Effect & $\begin{array}{l}\text { Model 6: } \\
\text { Linear }\end{array}$ & $\begin{array}{l}\text { Model 7: } \\
\text { Random } \\
\text { Intercept }\end{array}$ & $\begin{array}{l}\text { Model } \\
\text { Rando } \\
\text { \& Slop }\end{array}$ & Intercept & $\begin{array}{l}\text { Model 9: } \\
\text { Test for } \\
\text { Autocorrelation }\end{array}$ & $\begin{array}{l}\text { Model 10: } \\
\text { Test for } \\
\text { Heteroscedacity }\end{array}$ \\
\hline (Intercept) & 0.34 & $0.03 \quad(.03)$ & 0.03 & $(.04)$ & $0.25 \quad(.04)$ & $0.02 \quad(.35)$ \\
\hline Time & $-0.03 \quad(.02)$ & $-0.03 *(.02)$ & $-0.03 \dagger$ & $(.02)$ & $-0.03 \dagger(.02)$ & $-0.03 \dagger(.02)$ \\
\hline \multicolumn{7}{|c|}{ Goodness of Fit } \\
\hline $\operatorname{logLik}$ & -25.27 & -1.15 & 3.8 & & 7.61 & 7.88 \\
\hline $\mathrm{AIC}$ & 56.54 & 10.29 & 4.41 & & -1.23 & 0.24 \\
\hline $\mathrm{BIC}$ & 66.41 & 23.47 & 24.17 & & 21.83 & 26.59 \\
\hline$-2 L L$ & & $48.24^{* * *}$ & & $9.89 * * *$ & $17.5^{\text {*** }}$ & 0.54 \\
\hline
\end{tabular}


Table 6: Results of Fitting Random Coefficient Models to Task Conflict

\begin{tabular}{|c|c|c|c|c|c|c|c|c|}
\hline \multirow{2}{*}{$\begin{array}{l}\text { Fixed Effect } \\
\text { (Intercept) }\end{array}$} & \multirow{2}{*}{$\begin{array}{l}\text { Model 11: } \\
\text { Linear } \\
0.08+(.04)\end{array}$} & $\begin{array}{l}\text { Model 12: } \\
\text { Random } \\
\text { Intercept }\end{array}$ & \multicolumn{2}{|c|}{$\begin{array}{l}\text { Model 13: } \\
\text { Random Intercept } \\
\text { \& Slope }\end{array}$} & \multicolumn{2}{|c|}{$\begin{array}{l}\text { Model 14: } \\
\text { Test for } \\
\text { Autocorrelation }\end{array}$} & \multicolumn{2}{|c|}{$\begin{array}{l}\text { Model 15: } \\
\text { Test for Heteroscedacity }\end{array}$} \\
\hline & & $0.08+$ & $0.08 \dagger$ & $(.05)$ & $0.08+$ & $(.05)$ & 0.74 & $(.05)$ \\
\hline Time & $-0.08 *(.03)$ & $-0.08 * * *(.02)$ & $-0.08 * * *$ & (.03) & $-0.08 * * *$ & $(.03)$ & $-0.07 *$ & $(.02)$ \\
\hline \multicolumn{9}{|c|}{ Goodness of Fit } \\
\hline $\log \mathrm{Lik}$ & -88.30 & -68.39 & & -66.76 & & -68.28 & & -66.79 \\
\hline $\mathrm{AIC}$ & 182.59 & 144.78 & & 145.52 & & 146.56 & & 145.59 \\
\hline $\mathrm{BIC}$ & 192.48 & 157.95 & & 165.28 & & 163.02 & & 165.35 \\
\hline$-2 \mathrm{LL}$ & & \multicolumn{2}{|c|}{$39.82 * * *$} & \multicolumn{3}{|c|}{3.26} & 0.22 & 2.96 \\
\hline
\end{tabular}

\section{Time Varying Predictors of Overall MTS Performance}

To test our hypotheses, we included team and MTS identification as time varying predictors in the random intercept model predicting MTS performance (Hypotheses 1a \& 1b). We entered MTS (Hypotheses 2a \& 2b) and team identification (Hypotheses 3a $\& 3 b)$ as time-varying predictors of inter-team relationship and task conflict. We entered relationship and task conflict as predictors of MTS performance (Hypotheses $4 \mathrm{a} \& 4 \mathrm{~b})$ and tested whether these variables mediated the relationship between team and MTS identification and MTS performance (Hypotheses $5 \mathrm{a} \& 5 \mathrm{~b}$ ). We included control variables for member familiarity and computer game experience in all models. The results of our analyses are summarized in Table 7.

Hypothesis 1a predicts that MTS identification is positively related to overall MTS performance over time and hypothesis $1 \mathrm{~b}$ states that this relationship is moderated by team identification. As can be seen from Model 16, MTS identification exhibits a positive relationship with overall MTS performance $(\pi=.15, \mathrm{p}<.01)$, confirming hypothesis $1 \mathrm{a}$. However, neither the direct effect of team identification nor the interaction effect of MTS identification and team identification has a significant effect on MTS performance. So, no evidence is found for hypothesis $1 \mathrm{~b}$. To estimate the effect size of these predictors, Singer and Willet (2003) suggest calculating a pseudo R2 statistic. This statistic is based on the relative reduction of the residual variance when comparing the model with predictors, to the baseline model including only control variables. Adding MTS and team identification to the model amounts to a pseudo R2 of .14, indicating that $14 \%$ of the within MTS variance in overall performance is explained by identification measured at the MTS level.

Hypothesis $2 \mathrm{a}$ and $2 \mathrm{~b}$ predict that MTS identification will be negatively related to inter-team relationship and task conflict. As can be seen from Model 19 and 20, MTS identification shows an overall significant negative association with inter-team task conflict $(\pi=-.43, \mathrm{p}<.001)$ as well as with relationship conflict $(\pi=-.32, \mathrm{p}<$ $.001)$. In other words, MTS members who identify more strongly with the MTS experience less inter-team relationship and task conflict, confirming both hypotheses. 
Table 7: Results of Main Effect Models Predicting Overall MTS Performance (16 -18) and Inter-Team Task (19) and Relationship Conflict (20)

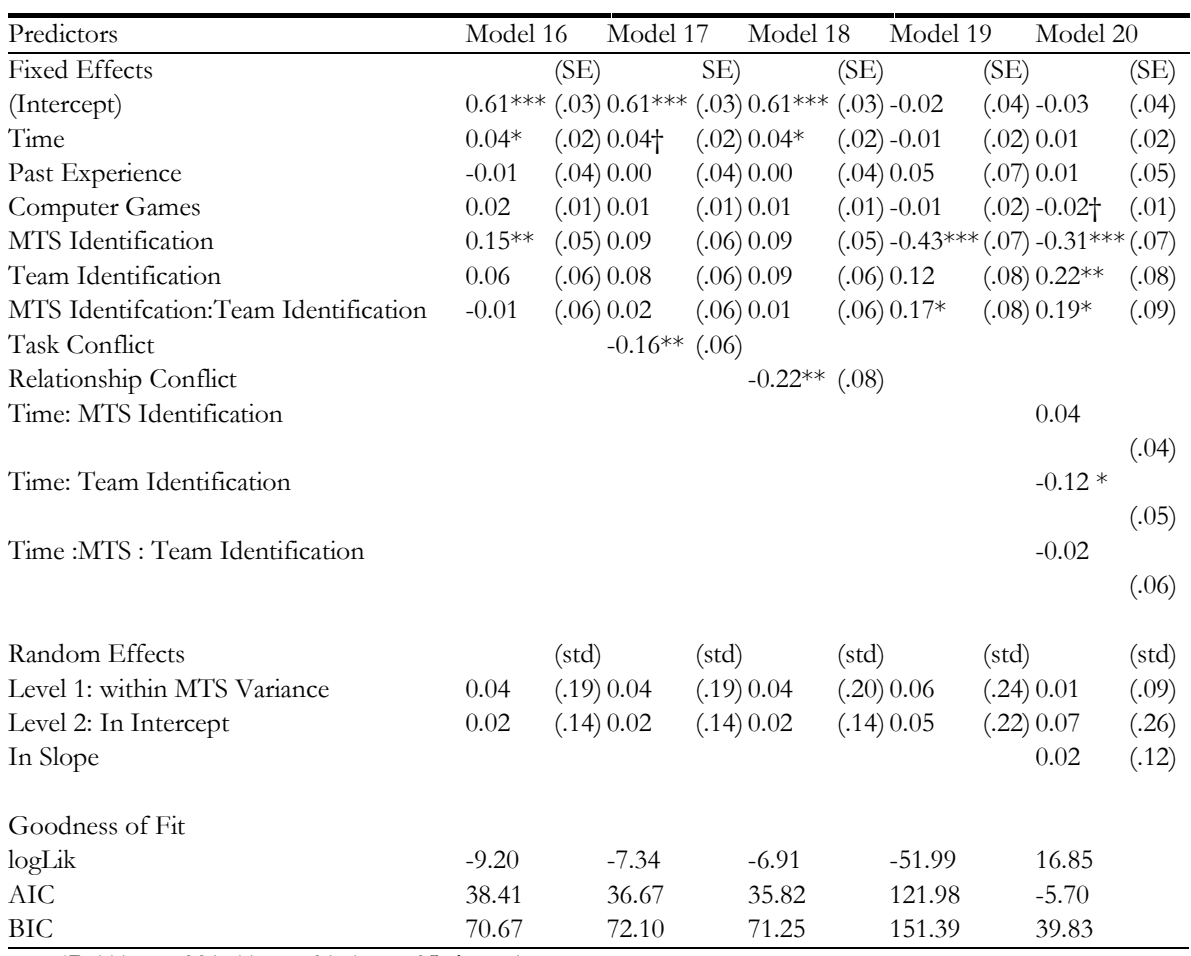

Hypothesis $3 \mathrm{a}$ and $3 \mathrm{~b}$ predict team identification to moderate the relation between MTS identification and both inter-team relationship and task conflict. As can be seen from Model 19 and 20, the analysis revealed an overall positive and significant interaction effect of team and MTS identification on both inter-team task $(\pi=.17, \mathrm{p}<$ $.05)$ and relationship conflict $(\pi=.19, \mathrm{p}<.05)$. To get a better understanding of what these interaction effects imply, we plotted these effects. As can be seen in Figure 2, MTSs with high MTS identification on average experience less inter-team relationship and task conflict than MT with low MTS identification. However, team identification partially counters this intercept effect in that when team identification is high, teams with high MTS identification experience less conflict than teams with low MTS identification. In other words, MTS members who identify strongly with the MTS as well as with the team, experience more inter-team relationship and task conflict than MTS members who identify strongly with the MTS but less strongly with the team. Therefore, we conclude that we only find supportive evidence for Hypothesis $3 \mathrm{~b}$. Our findings further show an overall positive and significant effect of team identification on the intercept of inter-team relationship conflict $(\pi=.22, \mathrm{p}<.01)$. Each unit-increase in team identification is related to an increase of .22 in inter-team 
relationship conflict. Additionally, team identification is negatively related to the rate of change of inter- team relationship conflict $(\pi=-.13, \mathrm{p}<.05)$. This implies that the positive relationship between team identification and inter-team relationship conflict becomes less strong over time. When we add MTS and team identification as predictors to the random intercept growth models, this results in a pseudo R2 of .24 for interteam relationship conflict and .20 for inter-team task conflict. Hypothesis 4 a stated that inter-team relationship conflict will be negatively related to MTS performance and hypothesis $4 \mathrm{~b}$ stated that inter-team task conflict will be positively related to MTS performance. As can be seen from Model 18, we found that inter-team relationship conflict is, indeed, negatively associates with overall MTS performance $(\pi=-.22$, p < $.01)$. As can be seen from Model 17 contrary to our predictions inter-team task conflict was also negatively $(\pi=-.16, \mathrm{p}<.01)$ related to performance. These research results thus only confirm hypothesis $4 \mathrm{a}$ and not hypothesis $4 \mathrm{~b}$. Adding inter-team relationship and task conflict to the random intercept model results in pseudo R2values of .03 and .04 respectively.

Finally, hypotheses $5 \mathrm{a}$ and $5 \mathrm{~b}$ suggested mediation effects of inter-team relationship and task conflict. To test these mediation effects, we extended the mediation framework of Baron and Kenny (1986) to fit a longitudinal framework and we followed the multiple step approach as suggested by Kenny and co-authors (2003). First, we calculated the unmediated effect path from MTS and team identification on overall MTS performance (see Hypothesis 1a \& 1b). Second, we calculated the path from the independent variable to the mediator. In this case this implies calculating the paths from MTS identification to inter-team task and relationship conflict (see Hypothesis 2a, 2b, 3a, \& 3b). Third, we simultaneously tested the pathway from the mediating variable to the outcome variable and from the independent variable(s) to the outcome variable. To assess a mediation effect, the unmediated path should substantially reduce in strength or become insignificant when entering the mediating variable.

As can be seen in Model 17 and 18, the association between MTS identification and MTS performance becomes insignificant when inter-team relationship, and subsequently task conflict are added to the equation. The link between inter-team task and relationship conflict to overall MTS performance becomes significant (see Hypothesis 4a \& 4b). Hence, we conclude that inter-team relationship and task conflict mediate the link between MTS identification and overall MTS performance. 
Figure 2: Interaction effect MTS and Team identification on Inter-Team Task and Relationship Conflict

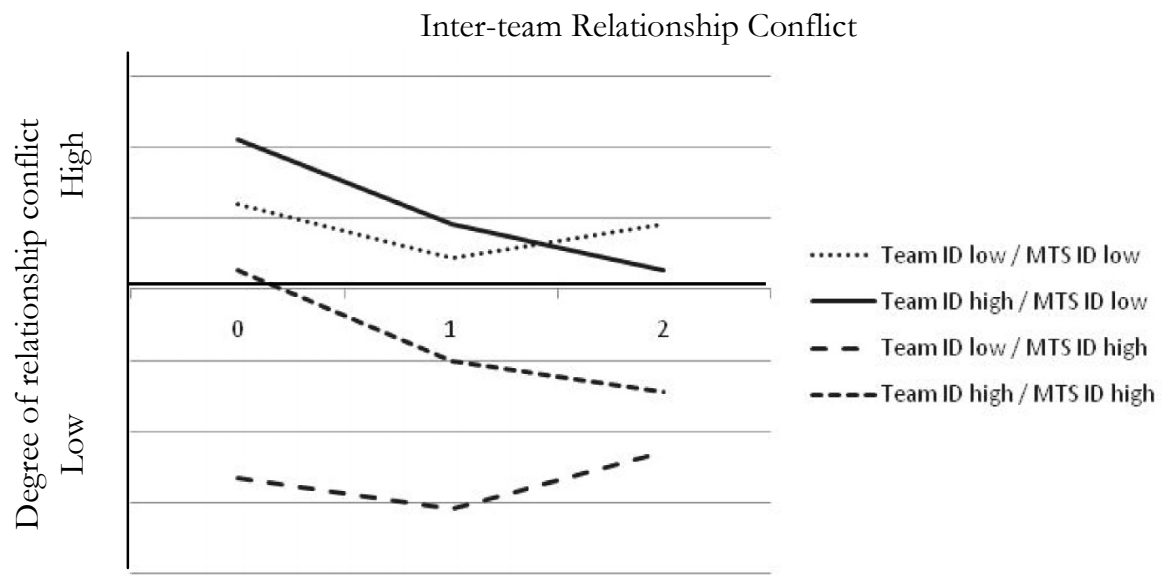

Time

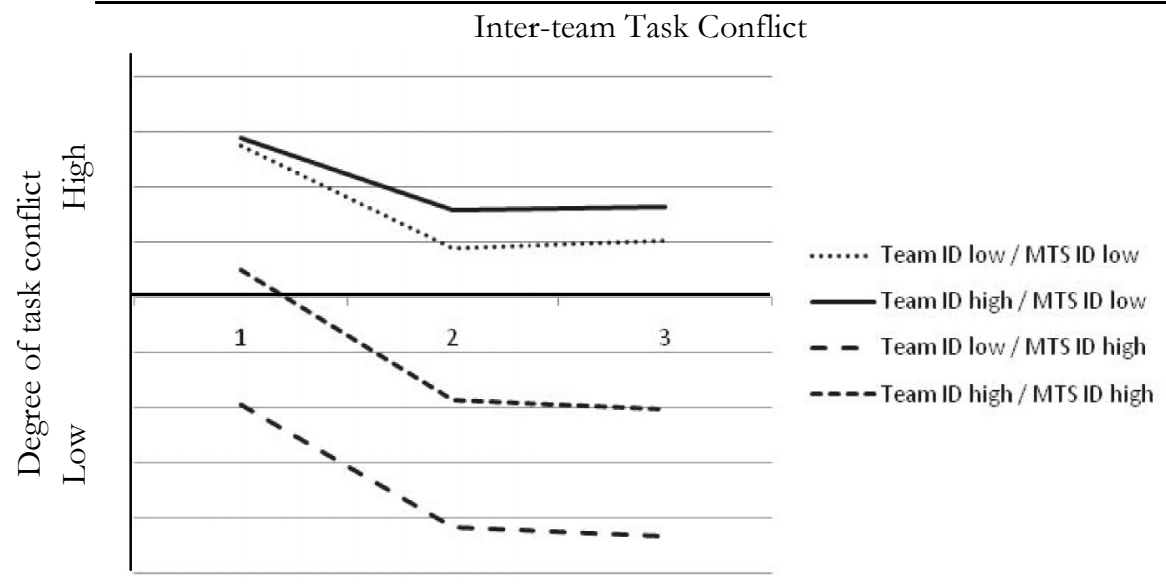

Time

\section{DISCUSSION}

In this study, we investigate the influence of MTS and component team identification on inter-team conflict and MTS performance. We provide initial evidence of how, over time, dual identification (i.e. simultaneous identification with the component team and MTS) influences inter-team task and relationship conflict. Inter-team conflict, in turn, influences MTS performance. In accordance with previous research on dual identification we find that identification with both the lower and the higher entity are important for team processes and performance (e.g. Brewer, 1991; Hornsey \& Hogg, 
2000). However, in contrast with previous studies, we do not find evidence for a positive interaction of identification with the two entities. Based on these studies we expected that MTS identification would have a stronger effect on reducing conflict when team members also identified highly with their team. Instead, we find MTS identification to be more important for reducing conflict when team identification is low than when team identification is high.

A possible explanation for this finding can be found in the nested nature of the two entities. Because teams are embedded in MTSs, team members' identification with their team is also embedded within their identification with their MTS. Therefore, when team members report low identification with their team, their focus of identification may be more strongly directed at the MTS. Consequently, MTS identification may become more important.

While team identification initially inflicts inter-team relationship conflict, this association weakens over time. This finding replicates results of Gleibs and colleagues (2010) and is in line with the contact hypothesis (Allport, 1954), which states that. intergroup contact is one of the most effective ways to reduce intergroup biases and disliking. The mere opportunity to interact with others is enough to increase the understanding and appreciation of different perspectives, which improves intergroup relationships.

Both inter-team relationship and task conflict negatively influenced overall MTS performance. This finding aligns with recent meta-analytic research that demonstrates overall negative implications of team conflict (DeDreu \& Weingart, 2003). In contrast to studies that found a positive effect of task conflict on team performance, in the present study the members had to make decisions under stringent time pressure and task conflict may well be more detrimental under such conditions as compared to less time pressured work contexts (Jehn, 1997).

\section{Theoretical Implications}

Our findings support and extend research investigating the effects of dual identification on multi-team processes and performance. To date, only a handful of empirical studies examine MTS processes and outcomes. Marks and colleagues (2005), for example, stressed the importance of inter-team processes for MTS performance. DeChurch and Marks (2006) demonstrated the importance of leadership for inter-team coordination. DeChurch and Zaccaro (2010) hinted at the positive implications of identification for MTS performance. While these studies have greatly increased our understanding of MTSs, we are not aware of research assessing how team and MTS identification simultaneously shape MTS processes and performance. Our study contributes to the field of MTS research by assessing the combined effects of team and MTS identification on MTS performance and in explicating the role of inter-team conflict in these relationships. We demonstrate the psychological attachment to inter-team goals to have a beneficial effect on performance; the attachment to team goals, however, increases inter-team conflict and negatively influences MTS performance.

Our results also have implications for social identification research. The fact that MTS identification keeps inter-team relationship and task conflict at bay confirms 
prior studies on the common ingroup identity model (Gaertner, Dovidio, Anastasio, Bachman \& Rust, 1993). This model indicates that when group members identify with their collective, ineffective intergroup relations can be transformed into effective ones (e.g. Dukerich et al., 2003; Gaertner et al., 1999). That we did not find evidence for a direct effect of dual identification on performance is in line with extant literature pointing out that dual identification influences group performance via interpersonal processes (Brewer, 1991; Richter et al., 2006).

Additionally, we found MTS identification to be most important when component team identification in MTS was weak, rather than strong. Given the nested nature of our research design this contributes to social identity literature in that social identifications apparently interact differently when entities are hierarchically embedded and not hierarchically even. As our results indicate, the positive association between strong component team identification and relationship conflict diminishes over time. Hence, when lower-order identifications are strongly represented within a higher order entity, merely strengthening the higher-order attachment of members is not sufficient in the short term. Especially for short-lasting teams with high stake assignments, such as emergency management teams, this can have detrimental effects. While our study is pioneering work in the area of nested identifications, we strongly encourage more research in this area.

In contrast to what we expected, task-conflict did not have a positive but a negative effect on MTS performance. While dual identification literature would predict that the more effective encapsulation and distribution of knowledge (e.g. Vora \& Kostova, 2007) would increase performance due to constructive levels of task conflict, in MTSs, task conflict appears to hamper performance. We believe that the complexity and temporary nature of MTSs (Mathieu et al., 2001) can be an explanation. It might well be that the mechanisms in temporary teams are different from those in established teams and that members in temporary teams are less inclined to compromise their position and identity (Hall \& Williams, 1966), resulting in task conflicts having more destructive consequences than in established teams.

Lastly, we provide empirical evidence for the view that dual identification mechanisms have predictive value for inter-team conflict. Previous literature has provided a conceptual rationale for this association, but empirical testing of this relationship is limited (see for an exception, Richter et al., 2006). We adopted a longitudinal design that goes beyond most of the existing cross-sectional MTS studies. Temporal research on MTS seems particularly interesting, given the dynamic character consisting of episodic performance phases that are characteristics of MTSs.

\section{Practical Implications}

This research has important practical implications. For managers, our research emphasizes that building effective MTSs takes times. Important for the creation of effective MTSs seem team building exercises that improve the interpersonal relations among MTS members. Generally, MTSs only work together for a short moment in time; during emergency management situations. MTSs may be formed in which its component teams are unfamiliar to each other. This study has demonstrated that, in 
such situations, MTS performance benefits most if component teams are able to connect on an inter-personal level. As shown, effective interpersonal relations take time to develop and thus, before action takes place, teams in MTSs should have experience working together, before actual action is needed.

When time is lacking or situations occur in which unfamiliar component teams need to join forces, our research evidence additionally suggests that, initially, the creation of an encompassing identity is an effective means to keep relationship and task conflict under control. Previous identification research has shown that effective means to create an overarching identity is the use of expressions of common cultural values, signs and symbols (e.g. Giessner \& Mummendey, 2008). In terms of MTS, it might thus be useful to stress the unity among component teams by means of attributes or marks that signal a "we are in this together". Such elements are an effective first means to indirectly increase MTS performance.

\section{Limitations and Directions for Future Research}

A limitation of our study is the fact that we used a student sample based laboratory simulation. Confronting students with a fire-fighting exercise does not reflect a realistic situation, and limits the generalizability of our findings. Nevertheless, research on MTS is still in its beginning and laboratory studies provide an important means to understand the basic mechanisms underpinning multi-team performance. Additionally, we were interested in basic psychological mechanisms (social identification with team and MTS) and perceived conflict. Hence, we thus preferred psychological realism over mundane reality (Marks, 2000). The fact that we tapped from widely accepted experimental designs and manipulation materials, makes us confident in terms of the psychological realism inducted.

We manipulated the extent to which team members identify with both the team and MTS by means of a minimal group paradigm. As evident from the manipulation check, our experiment successfully captured different combinations of identification ubiquitous in real world settings. While the minimal group paradigm is successfully and widely implemented in psychological experiments (e.g. Gaertner, 1994; 1996; 1999; Giessner \& Mummendy, 2008), recent research proposes a more finegrained distinction of identification to reflect the real organizational environment (e.g. Fiol, Pratt, \& O'Connor, 2009). Identities are often intractable and deeply embedded in the history and interpersonal interaction of people within organizations; these historical traces, obviously, are not well captured in experimental work. Thus, we see a chance for future research to examine the effects of forms of social identifications deeply embedded in the organizational context. For example, it would be interesting to see whether the positive effect of MTS identification on inter-team relations established in this study holds in situations where social identities are more deeply ingrained in MTS member's organizational history. While we found tentative evidence for inter-team contact to reduce initial differences in experienced inter-team relationship conflict, these initial differences might be less easily dissolved if identities are more embedded in long-term, organizational interactions (Binder et al., 2009). 
In our study, we constructed a situation where two fire fighting teams had to accomplish proximal goals to achieve a more distal overall goal. While in accordance with literature (e.g., Mathieu et al., 2001), it remains open to debate to what extent the goal hierarchy we designed actually reflects reality. Future research may benefit from investigating the horizontal and vertical communication processes between team members in more detail, for example by means of field research. In our experiment, for example, one of the team members of each team was able to oversee the complete situation, a condition that may only hold for some organizational context.

By extension, we have now examined the effects of dual identification on inter-team processes in the context of one particular kind of inter-team constellation, that is, MTSs. Scholars may benefit from studying other organizational forms dependent upon inter-team interaction in the future, such as, joint venture top management teams where team members represent the interests and values of different organizations. While the core interaction mechanisms might not be substantially different from multi-team constellations, phenomena like power, hierarchical differences or temporality of the teams might complicate interaction processes within these types of systems (Binder et al., 2009; Gaertner et al., 1996). 


\section{Chapter 6}

Discussion and Conclusion 


\section{INTRODUCTION}

In this last chapter, we summarize and reflect on the main findings and insights of the overall project. We will first summarize the main findings of the studies conducted in this dissertation project. Next, we will discuss the theoretical implications of this dissertation for organizational team research in the field of management and organization. Subsequently, we will address the managerial implications. Finally, we will describe the limitations of the project and explore some potential research trajectories to further deepen our understanding of the role of dual allegiance in organizational team functioning.

\section{MAIN FINDINGS}

The central goal of this dissertation was to explore the role of dual allegiance in organizational teams. We define dual allegiance in this dissertation as organizational members' simultaneous membership and compliance to a higher-order and lower-order organizational team. We used the (top) management team (MT) as the main context to analyze dual allegiance mechanisms. Additionally, we used a multi-team system (MTS) context in an experimental setting to gain better insights into the dynamics of dual allegiance.

We started this dissertation with a theoretical elaboration on how the experience of dual allegiance influences the MT's level of task conflict, relationship conflict and behavioral integration. Reasoning from the assumption that dual allegiance is an important contextual configuration of MT member's work, we argued that to truly understand MT processes it is necessary to classify MT members as organizational actors who go beyond representing their personal goals and interests (see $\mathrm{Li} \&$ Hambrick, 2005). We highlighted that MTs are not operating in a vacuum, but are encompassed in a network of multiple hierarchically embedded organizational groups and that the comprehension of how MT members balance the variety of interests of these organizational groups is vital to understand MT processes. We tapped from social identity and boundary theory to understand how MT members experience dual allegiance at both the individual and team level, and how their enactment on this experience influences MT processes. Specifically, we used the dual identification perspective to build propositions that related the level of alignment and strength of MT members' dual identification (with the MT and organizational sub-unit) to MT task conflict, relationship conflict and behavioral integration. The dual identification perspective affords us to recognize MT members' simultaneous attachment to higherorder and lower-order organizational groups (e.g. Ashforth \& Johnson, 2001; Hogg \& Terry, 2000). In so doing, we offered a fresh perspective to the examination of the black-box of MT processes and, by acknowledging the cross-level nature of dual identification, we went beyond the common intra-team analyses in the field. Further, by using the dual identification perspective, we highlighted the importance of psycho- 
social processes on MT dynamics and in this way added value to the literature that is generally dominated by a rational and cognitive perspective on the literature.

In the first empirical study we made use of semi-structured interviews and investigated how dual allegiance influenced the intra-personal experiences of MT members. Current organization literature is indistinct regarding the effects of dual allegiance on the individual MT member. This study confirmed that MT members, indeed, experience dual allegiance. However, dual allegiance was not immediately felt as a conflict, but as a continuously present tension in the job. Our qualitative analysis, using NVivo 8, revealed that dual allegiance was experienced as a conflict, only, when unilateral intensifiers were present. Unilateral intensifiers are aspects that emphasize the uniqueness and distinctiveness of MT members. For example, the personal interests of members or the organizational reward structures that reinforce the attachment with the organizational sub-unit. Under such circumstances, MT members experienced dual allegiance as a conflicting tension between lower-order sub-unit goals and the higherorder communal interests. Bilateral connectors, in turn, decreased the experienced conflict. When MT members experienced a sense of togetherness with the encompassing MT or when MT members experienced a sense of mutual respect and understanding, the dual allegiance was still noticed, but less intense. The role of the team leader emerged as an important mitigating factor in the interplay of intensifiers and connectors. The study thus adds to a better comprehension of the within person experience of dual allegiance and the context sensitivity of it; an area which had only been scarcely understood in the MT literature until today (see Shenkar \& Zeira, 1992).

In the second empirical study, a mixed method approach was used to investigate how the dual allegiance that MT members experience affects observable MT behavioral integration processes. In this study, five MT meetings of a large Dutch retail organization were observed and videotaped over a five months period. In addition, interviews were conducted with all MT members to better understand the observed behavioral integration processes that were exhibited during the MT meetings. The analysis of the video data revealed that members had difficulties to operate as a behaviorally integrated team. Subsequently, in combination with the interview data, the analysis suggested the role of the team leader to be pivotal in the emergence of MT behavioral integration processes. The team leader's role was suggested to be particularly formative in the creation of MT identification among MT members. In specific, the team leader was adversely associated with the amount of observed contentious (i.e. agonistic or disputative behavior) behavior in this MT. Furthermore, the results from this mixed-method study suggest an inductive MT identification formation process, driven by MT members' identification with their organizational sub-unit. In particular, analysis revealed that the difficulties in the behavioral integration process emerged because of inconsistencies between the expectations and perceptions of individual MT members regarding their role as an MT member. This perceived discrepancy had consequences for the attitude MT members exposed in the MT, which accordingly was reflected in the observed behavioral integration processes. This research contributes to the management team literature, because it deepens our insights of what 'actually' happens in a board room and how MT processes develop in 'real life'. These research 
outcomes also add value to the social identity literature by exposing such processes in a business setting. Further, the results tentatively validate recent assumptions concerning the existence of a cross-level inductive model of identity creation (see Ashforth, Rogers \& Corley, 2010; Swaab et al., 2005).

The final empirical study examined whether the suggested relationships between dual identification mechanisms and MT processes, as suggested in Chapter 2, would also hold over time. Longitudinal examinations of social or dual identification processes are scarce (see for exceptions Gleib et al., 2010). Therefore, we conducted an experimental team simulation in which we used an organizational team design that was comparable, but not similar, to the dual allegiance structure in MTs. Drawing from multi-team system literature (e.g. Mathieu et al., 2001) we built a laboratory study in which two teams of two persons had to accomplish a common system goal as well as an individual team goal in a fire fighting simulation. The focal constructs were measured at three points in time. Results indicated that, over time, teams with stronger higher-order goal identification experienced less task and relationship conflict. In addition, we found partial evidence for dual identification effects. Consistent with previous literature and our predictions (see Chapter 2 and chapter 5), we find that both higher-order and lower-order identifications matter for team processes. Yet, we did not find evidence for the commonly suggested interactive effect of a higher and lowerorder organizational group identity on performance. Instead, we found the interactive effect of identification with both the higher and lower-order organizational category to result in more task and relationship conflict than when identification with the lowerorder category was less strong. In other words, we found the higher-order identification to be most important for task and relationship conflict when the lower-order identification was weak rather than strong. We believe this is because of the nested structure of the higher and lower order identities. Intriguingly, strong identification with lower-order goals was positively related to relationship conflict in the beginning of the task, but this effect diminished over time, suggesting that the beneficial effects of dual identification need time to emerge. This study contributes to social identity literature in that nested identification mechanisms are examined in a longitudinal research design and are directly linked to team processes and objective performance. Previous research, investigating nested identification in merger contexts, primarily focused on the development of inter-group biases and only indirectly assessed processes and used subjective measures of performance, such as productivity of collaboration, organizational citizenship behavior or job satisfaction (e.g. van Dick et al., 2008; Richter et al., 2006). In addition, the study adds value to MT and MTS research in that the study pioneers studies on the unfolding of conflict in nested organizational team structures. In doing so, this research is in accordance with recent developments in the field on team-based organizational design structures (e.g. Martin, 2011; Martin \& Eisenhardt, 2010; Mathieu et al., 2001).

In sum, the research suggests dual allegiance to influence organizational team members' attitudes and behavior and, as such, to matter for organizational team functioning. The experience of role conflict due to dual allegiance is subject to conflict strengthening and weakening conditions (i.e. unilateral intensifiers and bilateral 
connectors). When bilateral connectors do their work, dual allegiance is merely experienced as a tension that is taken for granted. Tensions turn into within person conflict when unilateral intensifiers are present (Chapter 3). The acknowledgement of lower-order organizational team identifications influences team members' higher-order identification. In case of a 'mismatch' between team members' perceptions and expectations of the higher-order organizational team, its members psychologically distance themselves from the organizational team. This distance, eventually materializes into contentious team behavior (Chapter 4). An intriguing finding is that the team leader is assigned a critical role in the apt management and alignment of dual identifications. Both in chapters 3 and 4, the team leader's role as "identity broker" emerged as an important condition to contain dual identification conflicts. The final study documented the effects of dual identification over time (Chapter 5). The multiteam system simulation demonstrated that, team members' dual identification (with a higher and lower order team) does matter for the overarching team processes and performance. However, the effect of higher-order team identification on conflicts is most prominent when lower-order team identification is low rather than high. While our research outcomes for the relationship between dual identification and higher-order task conflict were as predicted, higher-order teams with strong levels of dual identification were, initially, related to higher levels of relationship conflict which decreased over time. The study suggests that growing familiarity among team members may reduce intergroup biases.

\section{THEORETICAL IMPLICATIONS}

This dissertation aimed to extend current knowledge on the importance of dual allegiance in organizational team research. Social identity theory, boundary theory and role theory framed the studies described in this project. Below we will discuss the theoretical contributions in light of these theories, but first we will elaborate on the contributions of this project for organizational team research in general.

First, the dissertation more broadly contributes to organizational team research and team composition research more specifically. While scholars have, for long, recognized the complexities of organizational team functioning, studies have mainly focused on organizational team members' individual characteristics (e.g. van Knippenberg \& Schippers, 2007; Williams \& O’Reilly, 1989). This dissertation might help team researchers to go beyond looking at the team as an isolated unit and boost awareness that sub-groups or faultines are not only due to demographic divergence that resides within the team. In specific, by more thoroughly tapping from other theoretical traditions, such as social identity literature and the dual identification perspective in specific, organizational team researchers may become aware that the understanding of organizational team processes can be enriched by incorporating organizational team members' cognitive and, especially, emotional attachments to multiple organizational sub-units. For example, organizational team research has acknowledged that team members' demographics and personal characteristics may be 
good proxies for people's individual perceptions and biases, but these perceptions and biases have been largely unexamined (see for exception Li \& Hambrick, 2005).

By extension, the results from this dissertation add value to the boundary spanning literature. As indicated in the introduction chapter, boundary spanning research primarily emphasizes the consequences that outward directed behavior of team members will have on team performance. The effects of boundary spanning for individual team members and the team process in general have largely gone unnoticed (Marrone, 2010). This dissertation may add to this field of research in highlighting potential obstacles in the psycho-social direction when teams do not manage their boundary spanning practices aptly.

Second, this project enriches the field of social identity dynamics and organizational team processes by introducing what happens when organizational identities are nested instead of cross-cutting (see Ashforth et al., 2010). Whereas most literature has emphasized the emergence of (inter) group conflict due to the existence of competing and cross-cutting identities in organizations like for example, conflicts among physicians and managers, musicians and business professionals, or workers and executives (Fischer, 1983; Glynn, 2000; O’Connor et al., 2006), literature has overlooked the consequences of conflicting nested identities. This oversight may be one reason why past attempts to understand and explain team conflicts have met with mixed results (Certo et al., 2006; Williams \& O’Reilly, 1989).

In general, researchers have considered the potential for nested identity conflicts as rather small (e.g. Ashforth \& Johnson, 2001). However, by more thoroughly investigating the influence of team members' lower-order organizational team membership, this dissertation helps to better understand the mechanisms by which organizational teams experience difficulties to operate as cohesive units. By extension, this dissertation contributes to the understanding of dynamics between higher and lower-order identifications (Ashforth et al., 2010; Wiley, 1988). Chapter 4 indicated that failure to secure MT member's sub-unit identities within the MT had repercussions on the process of MT identification. Chapter 5, in turn, demonstrated how the interaction between higher and lower-level team identification is associated with organizational team processes over time.

Third, extant work on social identity dynamics and organizational team processes failed to systematically consider the role of the team leader in identity claim making processes. An important contribution of this dissertation is the intriguing function of the team leader in the formation of higher-order team identifications among its members. Organizational team research has, sensibly, predominantly used a team level perspective and considered the role of individual team members as subordinate to the functioning of the team as a whole. Whereas the effects of leadership and teams on organizational performance are common fields of interest in the organization and management field, they have mainly been studied in isolation of each other and, as a result, the consequences of leadership on team functioning are only scarcely developed (DeChurch, Hiller, Toshio, Doty \& Salas, 2010). This dissertation redirects research attention to the importance of leadership in team work and in strengthening team members' dual allegiance, more specifically. 
Fourth, this dissertation adds value to role theory research. Role theory submits that role conflicts arise when people are confronted with discrepancies in divergent organizational responsibilities. In accordance with role theory, scholars assumed (e.g. Li et al., 2002) strong dual identification of organizational actors, with higher and lower-order organizational groups to strengthen role conflict. We demonstrated (Chapter 3) that dual identification may actually mitigate the experienced role conflict. This is in line with literature on social identity complexities (Roccas \& Brewer, 2006) that suggests people with more complex social self-concepts to better deal with and embrace divergent expectations. Being aware of multiple social identities, indeed, benefits a person's well-being, rather than detriments it. Thus, our research contributes to the understanding of solving role conflicts in situations in which multiple group membership is salient; not via the development of only one dominating higherorder identity, but by the simultaneous acknowledgement of lower-order identities.

\section{MANAGERIAL IMPLICATIONS}

The dual allegiance experienced by members of organizational teams has consequences in terms of team identification, behavioral integration as well as team conflict. Additionally, the team leader plays a significant role in the management thereof. These conclusions have compelling implications for management.

First, given the criticality of team members' simultaneous identification with both a higher-order and lower-order organizational unit, managers are well advised to integrate organizational sub-units in their perception of the overarching management team. It seems important for managers to foster dual identification to simultaneously consider both intra and inter-team accountability. (Van Dick et al., 2008; West, Hirst, Richter \& Shipton, 2004). The fact that the identities have a nested character makes dual allegiance important for organizational team members' perceived cognitive consistency (Festinger, 1957). In other words, the degree to which team members' level of identification with the lower-order sub-unit and higher-order organizational team is aligned, positively impacts team members' sense of who they are and, as a consequence, increases their person's well-being and motivation (Ashforth et al., 2000; van Knippenberg, van Knippenberg, DeCremer \& Hogg, 2004; Kreiner et al., 2006). Especially important is that team members feel secure and acknowledged in their subunit identification. The study described in Chapter 4 demonstrated that team members started alienating themselves from the group, when they, as representative, did not feel part of the overarching team.

Second, a challenge exists for team leaders. Based on their job role and hierarchical position within the team, team leaders derive special status and power. By means of their position, team leaders appear to have a strong impact on the interpersonal processes. While chapter 4 suggests that the team leader should carefully balance the various identities within the team and primarily act as identity claim making facilitator, chapter 3 indicated more specific behavior a team leader may engage in to avoid dual allegiance tensions to exacerbate. By giving voice to every team member and finding a correct balance between consensus seeking and directing, the team leader can 
make sure that tensions due to imparities in the experience of dual allegiance are minimized. These behaviors do not need directly be concerned with identification issues and are described well in extant literature. For example, according to the ASPIRe model of Haslam, Eggins and Reynolds (2003) leaders should build higher-order goals derived from the lower-order sub-goals from team members and create sufficient feedback opportunities for all members to join in the decision making process. Though, not directly dealing with dual identification issues, these measures may greatly help in developing a collective awareness among team members.

Finally, the big challenge for management is thus to train team leaders to become aware of and understand that team members are confronted with dual allegiances and that managers may identify with two (or more) organizational groups. At the same time, team leaders should be trained to realize themselves as well that they hold a dual allegiance and that their identification with organizational categories may bias their attitude, behavior and subsequently the functioning of their total team.

\section{LIMITATIONS AND FUTURE RESEARCH}

While the studies in this dissertation make a meaningful contribution to understanding the role of dual allegiance in organizational teams, some important limitations to the studies described merit discussion and generate ideas for future research. A first limitation is that this thesis consists of an interview study, a mixed method study and a lab simulation. While these types of study are important to understand why and how mechanisms function, a common problem with qualitative and lab studies is that the results are difficult to generalize to organizational team contexts. Future studies should therefore examine the role of dual allegiance in field studies in which the focal constructs are measured in a multitude of organizational teams. Based on the studies in this dissertation, this would be a logical next step in investigating the dual allegiance phenomenon.

A second limitation is that we tested the role of dual allegiance in two different contexts (i.e. MT and multi-team system). Indeed, the structural design regarding dual allegiance is homologous. Yet, the content and character of the tasks to be performed between MTs and MTSs are inherently different. While members of both types of team are confronted with complex and ambiguous tasks, the work of MT members is generally characterized by longer tenure and less time urgency than the work of MTS members. These differences in time perspective may significantly have influenced the functioning of each of these teams, potentially making a comparison between the two studies difficult. Future studies should thus examine how the difference in context may impact the role of dual allegiance on team functioning.

In addition, the comparison of results may be limited since the studies conducted within a MT setting were performed among (higher-echelon) managers and a real-life setting, whereas the MTS study was conducted among students in a controlled setting. Research results might be difficult to compare because of two reasons. First, managers may perceive dual allegiance different than students because of their dissimilar set of (work) experiences and age. People identify with collectives 
because of innate reasons for self-enhancement and distinctiveness (Tajfel, 1975; Turner, 1982). The differences in age and (work) experiences may have an influence on people's self-concept and thus their perceived dual allegiance. This may complicate generalizability across samples. Second, it is likely that students participating in the lab study will have experienced a different level of team identification than managers. The level of experienced identification is suggested to influence research results (Fiol et al., 2009). Thus, future studies should investigate how surface and deep-level identification (e.g. Fiol et al, 2009) impact team functioning over time.

Third, the framework in terms of dual allegiance assumes that organizations are inherently ideographic in nature, consisting of various organizational sub-units that to a larger or lesser extent have separate identities in comparison to the larger encompassing organizational identity. Despite evidence that multiple organizational sub-identities exist within the larger organizational context (e.g. Albert \& Whetten, 1985; Ashforth \& Johnson, 2001; Ashforth \& Mael, 1989; Bartels et al., 2006; Brickson, 2000 ), one can question to what extent well-designed organizations are ideographic in nature. Indeed, a well-structured organization can be expected to have its sub-units accomplish lower-order goals in service of the higher-order organizational interests. Future research that emphasizes the necessity of ideography for dual allegiance to exist within organizational teams would add value to the existing literature. While ideography is considered an important antecedent of the saliency of multiple organizational identities within organizations, our interview study suggests that also without a clear distinction between organizational sub-unit identities tensions due to dual allegiance is possible. Perhaps, for dual allegiance conflicts to emerge, a lack in overlap in organizational sub-identities is a sufficient condition to trigger tension when emphasis in the organizational team is on how team members are different instead of what they have in common.

Future research that unveils the multi-level mechanisms across lower and higher order organizational identifications would complement recent developments in the field of organizational identification (e.g. Ashforth et al., 200). The results in chapter 4 suggest a cross-level impact of organizational sub-identification on the creation of shared higher-order team identification. Ashforth and colleagues (2010) have posited that the creation of shared higher-order identification is affected by other lower-order shared identifications (i.e. organizational sub-unit identification) via social interaction among individuals. The social interaction sets the basis for a new shared social structure that, at the end, forms a shared sense of identification with a more abstract (i.e. higher order) organizational entity.

Future research could also focus on how identification with lower-order organizational categories shape shared mental models and, subsequently, the identification with higher-order categories. In the tradition of research on trans-active memory systems, the influence of lower-order sub-identifications on the formation of higher-order identities could be combined with shared mental model studies. Recently, studies have found that shared identities are precursors and successors of the creation of shared mental models (Swaab et al., 2007; Swaab et al., 2008). Examining how such a 
framework operates when dealing with higher and lower-order identities might help to understand how dual allegiance impacts organizational team functioning.

Results from this dissertation designate an important role for the team leader in managing the emergence of team identification. To date, the role of the team leader has been underrepresented in MT research (e.g. Hambrick \& Mason, 1984). Aside from controlling for hierarchical differences within the MT (e.g. Finkelstein, 1992), MT research has emphasized team level aspects and neglected individual level aspects on MT functioning. Research on other organizational teams has mostly ignored the role of leadership in team functioning as well (see for exceptions DeChurch \& Marks, 2006). Future research that examines how team leadership styles can manage tensions among team members due to dual allegiance can greatly contribute to our understanding of team leader's role in the team process. Additionally, future studies could address how the experienced dual allegiance by the team leader impacts his/her leadership behavior. For example, in this dissertation we suggested that organizational team members perform optimally if they identify strongly with both the higher-order organizational team and lower-order organizational unit. However, is this also the case for team leaders, or should they especially develop a strong identification with the team they are leading and consider their organizational unit membership as of minor importance?

\section{CONCLUSION}

In this thesis we aimed to increase our understanding of what is occurring in organizational teams. We started this dissertation by emphasizing that organizational team members are, predominantly, concerned with personal as well as organizational goals. But, when we better want to understand how organizational teams function, it is necessary to realize that most organizational teams do not function in a vacuum. In contemporary organizations, team members play multiple roles and represent multiple organizational groups (i.e. divisions, business units, departments). From this perspective, organizational team members are not simply acting for themselves, but are acting as member of an organizational group or as representative of other organizational actors. Organizational team members thus continuously wear different hats and knowing when to wear which hat can be challenging. The embedded notion of dual allegiance thus confronts MT members with a continuous negotiation process.

Much of the organizational team literature resides around notions of rationality and formality. By putting the emphasis on the critical role of dual allegiance and, in specific, the experience of this structural organizational team property, we hoped to re-direct research attention to the importance of psycho-social and nonrational aspects in the functioning of organizational teams. Organizational team research has made fundamental contributions to our understanding, yet further ground needs to be explored. By introducing dual allegiance we anticipate the field to advance toward the recognition of organizational teams as chains in a broader constellation of other (interdependent) organizational teams, where social emotional processes are considered pivotal in the quest to understand what is actually going on in organizational teams. 
Summary 


\section{SUMMARY}

Modern organizational structures become increasingly complex and organizational actors work together in teams ever more in which they are often members of multiple organizational groups (i.e. teams, departments, divisions). For example, organizational actors may not only be a member of the management team (MT), but also represent an organizational department or business unit. In this dissertation, I define this as dual allegiance; a structural property in the make-up of the work of organizational actors. Organizational actors are thus compliant to one organizational group, while representing another organizational group simultaneously. To better understand the role of dual allegiance when organizational actors need to cooperate in organizational teams, I explore the consequences of dual allegiance on organizational team processes. I suggest the experience of dual allegiance to be vital for organizational team processes and it is for this purpose that I take a dual identification perspective. This perspective posits that people have a need to attach cognitive and emotional value to multiple organizational groups for their optimal well-being and that the strength of the attachment determines people's attitude and behavior toward others. I draw from social identity theory and combine this with boundary theory and role theory. Social identity theory allows making predictions regarding the motivation of organizational actors to behave and act in a specific way. Boundary theory explains why organizational actors have difficulties switching between responsibilities (from MT to business unit or vice versa). Role theory describes the consequences for individual organizational actors when they experience a discrepancy between responsibilities. I employ numerous ways of scientific inquiry, among which theoretical, qualitative, and quantitative studies and execute research at the individual as well as team level of analysis.

In chapter 1, I explain why it is important to examine the role of dual allegiance on organizational team processes. Previous research on organizational teams has mainly focused on how internal team inputs transform into team processes or how external team inputs relate to team performance instead of team processes. Research that examines the relationship between external inputs and team processes is scarce. I argue that existing research on team processes and team performance has been driven by team compositional diversity studies in which team inputs have been mainly considered to reside in team members' characteristics like age, education or functional background. Implicit in these assumptions is that organizational actors come to the team as representatives of themselves. In this chapter, I posit that this is not necessarily the case in modern organizations. If we truly want to understand organizational team processes, research needs to recognize that aspects originating outside the organizational team also influence team members' attitudes and behavior. For example, the degree to which team members feel a sense of belonging to the business unit or department they represent in the team. Indeed, boundary spanning research focuses on the positive effects of external team inputs on team performance. Yet, despite the enormous contribution of this type of research to our understanding of team functioning, this stream of literature fails to uncover the processes by which inputs 
external to the team are transformed into team performance. From this, I conclude that investigating the role of dual allegiance as input to team processes is an interesting means to start filling this gap in the literature. In the remainder of the chapter, I explain how social identity theory, boundary theory and role theory add to our understanding of the consequences of dual allegiance on team processes. I introduce management teams (MT) and multi-team systems to be suitable research contexts to examine the consequences of dual allegiance, because these structures adequately reflect the dual allegiance design. At the end of this chapter, I specify the research gaps in current organizational team knowledge as I will address them in this dissertation.

In chapter 2, I develop a dual identification framework and research propositions to describe the effects of dual allegiance on MT processes (i.e. constructive task conflict, relationship conflict and behavioral integration). I explain that the examination of how MT members experience dual allegiance contributes to our understanding of MT processes. For this, I use the social identity theory and boundary theory. The theories are used to elaborate on the mechanisms behind the consequences of dual allegiance on MT processes. I argue that the strength as well as alignment of MT members' identification with the MT as well as another organizational group influences the experience of dual allegiance, and how this impacts attitudes and behaviors that eventually determine MT processes. I first describe the mechanisms at the individual level of analysis before I introduce the dual identification framework at the team level.

Chapter 3 reports an explorative semi-structured interview study on how and when individual MT members experience dual allegiance. I interviewed 11 MT members in boundary spanning positions from various organizations. This research method was chosen because of the explorative character of the study. This method provides the advantage of gaining lots of information on why and how things happen. Since I was interested in the individual experiences of MT members, I used role theory in combination with social identity theory to build my conceptual framework. Research on role theory indicates that when MT members are confronted with divergent role expectations, role conflict is experienced. However, higher-up the organizational ladder organizational actors experience less role conflict. Unfortunately, current research is not clear on why this happens. The results of this study indicate that, indeed, MT members experience dual allegiance. However, it is not perceived as a conflict, but as a constant tension as part of the job. Further, I show under what specific conditions, during MT member interaction, the tension may intensify (and emerge into conflict) or weaken. The study illustrates the importance of MT processes in the management of dual allegiance.

Chapter 4 builds on the results in chapter 3 and analyses the consequences of dual allegiance at the team level of inquiry. In this study, I adopt a mixed-method study to deepen the understanding in MT processes. By using video observation and interviews I gained insight into the effects of dual identification processes on observable behavioral integration processes. Three patterns in the data provide information on how MT members experience dual allegiance and influence MT behavioral integration processes. First, a common MT identity is created via a "bottom- 
up" interaction process in which MT members' identification with the sub-unit or department is key in the development of MT behavioral integration processes. Second, for MT members to identify with the MT the sub-unit or department identification first needs to be socially validated in the MT. Third, the chair person has an important role in managing the various identities present in the MT. These three patterns eventually determine the observable behavioral integration processes. The study answers the call for more qualitative and longitudinal approaches to gain a more insightful picture of MT processes. It also uniquely exemplifies how the combination of video observation and interviews may serve as a structured and comprehensive approach to understand what is really going on in MTs.

In chapter 5 , I describe a longitudinal team simulation study that examines if the relationships between dual identification and task and relationship conflict would also hold over time. For this purpose, I used an organizational team design that was comparable, but not similar, to the dual allegiance structure in MTs. For building the laboratory study, I used multi-team systems in which, in each session, two teams of two persons were responsible for their own team goals as well as an overarching common goal; in this case extinguishing fires. The focal constructs were measured three times in a 2 hour simulation in which I investigated 67, multi-team systems. The results revealed our expectations to be partially supported. Identification with both the team as well as the overarching multi-team system matters for multi-team system processes and performance, but the results are not in accordance with the commonly suggested interaction effect between team and multi-team system identification. The study adds value to social identity literature and MT research in that it shows how identification mechanisms function over time. Social identity and multi-team system researchers still know little about these dynamics. Moreover, the study uses organization structure with hierarchically nested organizational teams rather than the more commonly used hierarchically-even organizational team structures.

Chapter 6 summarizes the main findings of the studies presented in this dissertation and discusses the theoretical and managerial implications of the results for future research. All told, this dissertation contributes to understanding the consequences of dual allegiance as a structural property that is embedded in the task of organizational actors working in teams. How organizational actors experience dual allegiance (measured by dual identification) influences their attitude and behavior in team process. Further, this dissertation adds value to current academic knowledge by specifying factors that strengthen or weaken the experience of dual allegiance. By doing so, researchers may devise more specific models on how psycho-social factors influence organizational team processes and performance. From a more practical point of view MT members and consultants may benefit by considering psycho-social factors that originate outside the organizational team as critical to improve internal team processes. 
Samenvatting 


\section{SAMENVATTING}

Hedendaagse organisatiestructuren worden steeds complexer en managers werken steeds vaker in teams waarbij zij vaak lid zijn van meerdere "groepen" binnen de organisatie (dwz. team, afdeling of divisie). Zo zijn managers niet alleen lid van het managementteam (MT), maar vertegenwoordigen ze ook hun hele afdeling of divisie. In dit proefschrift definieer ik dit als "duale loyaliteit" (dual allegiance), een structurele eigenschap in de opbouw van het hedendaagse werk van managers. Managers zijn dus lid zijn van de ene groep, maar vertegenwoordigen tegelijkertijd ook een andere groep binnen de organisatie. Om de invloed van duale loyaliteit op de samenwerking tussen managers beter te kunnen begrijpen, verken ik in dit proefschrift de gevolgen van duale loyaliteit op teamprocessen. Ik beargumenteer dat de manier waarop managers duale loyaliteit ervaren van vitaal belang is voor teamprocessen binnen organisaties en daarom bekijk ik duale loyaliteit vanuit het duale-identificatieperspectief. Dit perspectief gaat ervan uit dat mensen een cognitieve en emotionele band met meerdere groepen nodig hebben voor hun optimaal welbevinden. Bovendien bepaalt de sterkte van deze band de houding en het gedrag van mensen ten opzichte van anderen. Ik makk gebruik van de sociale identiteitstheorie en combineer dit met de boundary-theorie en roltheorie. De sociale identiteitstheorie helpt in het doen van voorspellingen over waarom managers een bepaalde houding aanmeten of specifiek gedrag vertonen. De boundary-theorie legt uit of managers het makkelijk of moeilijk vinden om te switchen tussen verantwoordelijkheden (van de verantwoordelijkheden van het team naar die van de afdeling of vice versa). Roltheorie vertelt hoe managers een discrepantie tussen verantwoordelijkheden ervaren. Ik benut verschillende onderzoeksmethoden, waaronder theoretische, kwalitatieve, en kwantitatieve studies en voer het onderzoek uit op zowel het individueel als team niveau van analyse.

In hoofdstuk $1 \mathrm{leg}$ ik uit waarom het belangrijk is om de gevolgen van duale loyaliteit op teamprocessen na te gaan. Eerder teamonderzoek binnen organisaties heeft zich voornamelijk gericht op hoe de inbreng van binnenuit het team wordt omgezet in teamprocessen. Dit terwijl onderzoek naar externe invloeden zich voornamelijk richt op teamprestaties in plaats van teamprocessen. Onderzoek dat zich richt op de relatie tussen externe invloeden en teamprocessen is schaars. Ik beargumenteer dat bestaand onderzoek naar teamprocessen en teamprestaties wordt gedreven door studies die de interne inbreng van het team karakteriseren aan de hand van de teamsamenstelling. Deze teamsamenstelling wordt beschreven aan de hand van persoonskenmerken van de teamleden zoals leeftijd, opleiding en functionele achtergrond. Impliciet wordt hiermee er vanuit gegaan dat teamleden alleen zichzelf vertegenwoordigen. In dit hoofdstuk beargumenteer ik dat dit niet noodzakelijkerwijs het geval is in de organisaties zoals we ze op heden kennen. Als we echt willen begrijpen hoe teamprocessen binnen organisaties werken, dienen we in het huidige onderzoek te erkennen dat ook aspecten van buiten het team van invloed kunnen zijn op de houding en het gedrag van teamleden. Zoals de mate waarin teamleden zich verbonden voelen met hun bedrijfsunit of afdeling die ze vertegenwoordigen in het team. Onderzoek naar 
"boundary-spanning" richt zich op de productieve invloeden van externe teamfactoren op teamprestaties. Hoewel dit type onderzoek enorm heeft bijgedragen aan ons begrip over teamfunctioneren, zijn de processen waarop externe factoren de teamprestatie bevorderen nog niet ontrafeld. Hieruit concludeer ik dat onderzoek naar de invloed van duale loyaliteit op teamprocessen een interessante nieuwe invalshoek biedt om deze hiaat in de teamliteratuur op te vullen. In de rest van het hoofdstuk leg ik verder uit hoe verschillende theorieën uit het veld, te weten sociale identiteitstheorie, boundary-theorie en roltheorie het begrip over de gevolgen van duale loyaliteit op teamprocessen kunnen vergroten. Ook laat ik zien dat managementteams (MT) en multiteamsystemen door hun opbouw een adequate context bieden om de effecten van duale loyaliteit te onderzoeken. Aan het einde van dit hoofdstuk licht ik de hiaten in de huidige kennis over teams binnen organisaties, zoals ik ze zal behandelen in dit proefschrift, nader toe.

In hoofdstuk 2 ontwikkel ik een raamwerk van duale loyaliteit en onderzoeksproposities om de gevolgen van duale loyaliteit op MT-processen (dwz. constructief taakconflict, relatieconflict en integratief gedrag) te kunnen beschrijven. Ik leg uit hoe onderzoek naar de manier waarop MT leden de duale loyaliteit ervaren kan bijdragen aan onze kennis over MT-processen. Hiervoor gebruik ik de "sociale identiteitstheorie en de boundary-theorie. Deze theorieën worden gebruikt om de mechanismen achter de effecten van duale loyaliteit op MT-processen te begrijpen. Ik beargumenteer dat zowel de sterkte als de congruentie van de identificatie van MTleden met het MT en een organisatiegroep (duale identificatie) invloed heeft op de manier waarop zij duale loyaliteit ervaren, en hoe dit de houding en het gedrag beïnvloedt dat uiteindelijk de MT-processen bepaalt. Ik introduceer het raamwerk van duale loyaliteit eerst op het individueel niveau om het vervolgens op teamniveau te introduceren.

In hoofdstuk 3 rapporteer ik een exploratieve semigestructureerde interviewstudie over hoe en wanneer individuele MT leden duale loyaliteit ervaren. Ik heb 11 MT-leden van verschillende organisaties geïnterviewd die op basis van hun functieomschrijving geconfronteerd zouden moeten worden met duale loyaliteit. Ik heb voor deze onderzoeksmethode gekozen vanwege het exploratieve karakter van de studie en ik via interviews veel informatie kon verkrijgen over het hoe en waarom dingen gebeuren. Omdat ik geïnteresseerd was in de individuele ervaringen van MTleden ten aanzien van duale loyaliteit, heb ik voor het opbouwen van het conceptuele kader van de studie roltheorie gebruikt in combinatie met de sociale identiteitstheorie. Onderzoek op basis van roltheorie toont aan dat wanneer MT-leden worden geconfronteerd met uiteenlopende verwachtingen, rolconflict wordt ervaren. Echter, hoger op de organisatorische ladder vermelden MT-leden minder rolconflict. Helaas is uit huidig onderzoek niet af te leiden waarom dit zo is. De resultaten uit deze studie geven aan dat MT-leden inderdaad duale loyaliteit ervaren. Echter, het wordt niet gezien als conflict, maar als een constante spanning als onderdeel van de baan. Verder laat ik zien welke omstandigheden, die ontstaan tijdens de communicatie tussen MTleden, de spanning kunnen intensiveren (en zorgen voor conflict) of verzwakken. De studie illustreert wat het belang is van MT-processen in het goed managen van duale loyaliteit. 
Hoofdstuk 4 bouwt voort op de resultaten in hoofdstuk 3 en analyseert de gevolgen van duale loyaliteit op teamniveau. In deze studie pas ik een "mixed-method" studie toe om meer inzicht te verwerven in MT-processen. Door het gebruik van videoobservatie en interviews heb ik inzicht gekregen in de effecten van duale identificatie processen op observeerbare gedragsintegratieprocessen van een MT van een grote Nederlandse retailorganisatie. Drie patronen in de onderzoeksgegevens geven meer informatie over hoe MT leden duale loyaliteit ervaren en MTgedragsintegratieprocessen beïnvloeden. Ten eerste wordt een gemeenschappelijke MT identiteit gecreëerd via een "bottom-up" proces waarbij, in de ontwikkeling van gedragsintegratieprocessen tussen MT leden, de identificatie met de afdeling of divisie een belangrijke rol speelt. Ten tweede moet de identificatie van MT leden met hun afdeling of divisie eerst sociaal worden gevalideerd in het MT voordat MT leden zich identificeren met het MT zelf. Ten derde heeft de voorzitter van het MT een belangrijke rol in het managen van de verschillende aanwezige identiteiten binnen het MT. Deze drie patronen beïnvloeden uiteindelijk de observeerbare gedragsintegratieprocessen. Deze studie beantwoordt aan de toenemende vraag naar meer kwalitatieve en temporele onderzoeken naar MT-functioneren. Het is ook een uniek voorbeeld van hoe de combinatie van video-observatie en interviews kan leiden tot gestructureerde en gedetailleerde onderzoeksresultaten die meer inzicht geven in hoe een MT werkelijk functioneert.

In hoofdstuk 5 beschrijf ik een longitudinale teamsimulatiestudie om te onderzoeken of de relaties tussen duale identificatie en taak- en relatieconflict stand houdt over tijd. Ik heb gebruik gemaakt van een teamorganisatiestructuur die vergelijkbaar was, maar niet gelijk aan, de duale loyaliteitsstructuur van MTs. In het laboratoriumonderzoek heb ik gebruik gemaakt van multiteamsystemen waarbij in elke sessie twee teams van twee personen zowel verantwoordelijk waren voor een eigen teamdoel, maar ook voor een overkoepelend algemeen doel. In dit geval het onder controle krijgen van branden. De kernconstructen heb ik drie keer in de tijd gemeten over een tijdsbestek van 2 uur bij 67 multiteamsystemen. De resultaten tonen aan dat onze verwachtingen gedeeltelijk worden ondersteund. Identificatie met zowel het overkoepelende multiteamsysteem als het team blijkt belangrijk voor multiteamsysteemprocessen en prestaties, maar de resultaten ondersteunen niet het algemeen gehypothiseerde interactie-effect tussen identificatie met het team en multiteamsysteem. De wetenschappelijke bijdrage van deze studie aan de sociale identiteitsliteratuur en het multiteamsysteemonderzoek is dat de resultaten laten zien hoe duale identificatiemechanismen functioneren over tijd. Hierover is tot nog toe weinig bekend. Bovendien gebruikt de studie een organisatiestructuur met hiërarchisch ingebedde groepen, terwijl het meeste onderzoek gebruikmaakt van organisatiestructuren met hiërarchisch gelijkwaardige groepen.

Hoofdstuk 6 geeft een overzicht van de belangrijkste bevindingen van de studies in dit proefschrift en bespreekt de theoretische en praktische implicaties van de resultaten voor toekomstig onderzoek. Alles bij elkaar draagt dit proefschrift bij aan het begrijpen van de gevolgen van duale loyaliteiten als een structurele eigenschap die is ingebed in de taak van managers die in teamverband werken. De manier waarop duale 
loyaliteit wordt ervaren (gemeten met duale identificatie) heeft invloed op de houding en het gedrag van managers in het teamproces. Verder draagt dit proefschrift bij aan de huidige wetenschappelijke kennis door het specificeren van factoren die het ervaren van duale loyaliteit kunnen versterken of verzwakken. Deze kennis stelt onderzoekers in staat specifiekere modellen te ontwikkelen over hoe psychosociale factoren van invloed zijn op teamprocessen en prestaties. Vanuit een meer praktisch oogpunt kunnen managers en consultants profiteren door zich meer bewust te worden van het feit dat psychosociale factoren die hun oorsprong buiten het team kennen, een vitale invloed kunnen hebben op interne teamprocessen. 

Reference List 
Abrams, D. \& Hogg, M. A. 2004. Metatheory: Lessons from social identity research. Personality \& Social Psychology Review (Lawrence Erlbaum Associates), 8(2): 98-106.

Albert, S., \& Whetten, D. A. 1985. Organizational identity. In L. L. Cummings \& B. M. Staw (Eds.), Research in Organizational Behavior, 7: 263-295. Greenwich, CT: JAWEPress.

Allport, G. W. (1954). The nature of prejudice. Reading, MA: Perseus Books.

Amason, A. C. and Sapienza, H. J. 1997. 'The effects of top management team size and interaction norms on cognitive and relationship conflict'. Journal of Management, 23, 495-516.

Alper, S., Tjosvold, D., \& Law, K. S. 1998. Interdependence and controversy in group decision making: Antecedents to effective self-managing teams. Organizational Behavior and Human Decision Processes, 74(1): 33-52.

Amason, A. C. 1996. Distinguishing the effects of functional and dysfunctional conflict on strategic decision making: Resolving a paradox for top management teams Academy of Management Journal, 39(1): 123-148.

Ancona, D. G. \& Caldwell, D. F. 1992. Bridging the boundary: External activity and performance in organizational teams. Administrative Science Quarterly, 37(4): 634-661.

Ancona, D., Bresman, H., \& Kaeufer, K. 2002. The comparative advantage of x-teams. MIT Sloan Management Review, 43(3): 33-39.

Ashforth, B. E. \& Mael, F. 1989. Social identity theory and the organization. Academy of Management Review, 14(1): 20.

Ashforth, B. E., Rogers, K. M., \& Corley, K. G. 2010. Identity in organizations: Exploring cross-level dynamics. Organization Science.

Ashforth, B. K. \& Saks, A. M. 1996. Socialization tactics: Longitudinal effects on newcomer adjustment. Academy of Management Journal, 39(1): 149-178.

Ashforth, B. E., Kreiner, G. E., \& Fugate, M. 2000. All in a day's work: Boundaries and micro role transitions Academy of Management Review, 25(3): 472-491.

Ashforth, B. E., Harrison, S. H., \& Corley, K. G. 2008. Identification in organizations: An examination of four fundamental questions. Journal of Management, 34(3): 325-374.

Bales, R. F. (1950). Interaction Process Analysis. Cambridge: Addison-Wesley.

Balogun, J., Gleadle, P., Hailey, V. H., \& Willmott, H. 2005. Managing Change Across Boundaries: Boundary-Shaking Practices. British Journal of Management, 16(4), 261-278.

Balogun, J. \& Johnson, G. 2004. Organizational restructuring and middle manager sensemaking. Academy of Management Journal, 47(4): 523-549.

Bantel, K. A. and Jackson, S. E. 1989. 'Top management and innovations in banking: does the composition of the top team make a difference?' Strategic Management Journal, 10, 107-12.

Barsade, Sigal G. (2002). "The Ripple Effect: Emotional Contagion and its Influence on Group Behavior." Administrative Science Quarterly, 47, 644-675.

Bartel, C. A. 2001. Social comparisons in boundary-spanning work: Effects of community outreach on members' organizational identity and identification. Administrative Science Quarterly, 46(3): 379-414. 
Bartels, J., Pruyn, A., \& de Jong, M. 2009. Employee identification before and after an internal merger: A longitudinal analysis. Journal of Occupational and Organizational Psychology, 82(1): 113-128.

Binder, J., Brown, R., Zagefka, H., Funke, F., Kessler, T., Mummendey, A., Maquil, A., Demoulin, S., \& Leyens, J.-P. 2009. Does contact reduce prejudice or does prejudice reduce contact? A longitudinal test of the contact hypothesis among majority and minority groups in three European countries. Journal of Personality \& Social Psychology, 96(4): 843-856.

Bizman, A. \& Yinon, Y. 2004. Intergroup conflict management strategies as related to perceptions of dual identity and separate groups. Journal of Social Psychology, 144(2): 115-126.

Black, J.S. and Gregersen, H.B. 1992. Serving two masters: managing the dual allegiance of expatriate employees, Sloan Management Review 33(4): 61-71.

Bliese, P. D. 1998. Group size, ICC values and group-level correlations: A simulation. Organizational Research Methods, 1, 355-373.

Bliese, P. D. 2000. Within-group agreement, non-independence, and reliability: Implications for data aggregation and analysis. In K. J. Klein \& S. W. J. Kozlowski (Eds.), Multilevel theory, research, and methods in organizations: Foundations, extensions, and new directions.: 349-381. San Francisco, CA US: Jossey-Bass.

Bliese, P. D. 2009. Multilevel Modeling in R: A Brief Introduction to R, the Multilevel Package and the nlme Package,

Bliese, P. D. \& Ployhart, R. E. 2002. Growth modeling using random coefficient models: Model building, testing, and illustrations. Organizational Research Methods, 5(4): 362-387.

Boone, C. \& Hendriks, W. 2009. Top management team diversity and firm performance: Moderators of functional-background and locus-of-control diversity. Management Science, 55(2): 165-180.

Brewer, M. B. 1991. The social self: On being the same and different at the same time. Personality and Social Psychology Bulletin. Vol, 17(5): 475-482.

Brewer, M. B. (1999). The psychology of prejudice: Ingroup love or outgroup hate? Journal of Social Issues, 55 (3), 429-444.

Brewer, M. B., Manzi, J. M., \& Shaw, J. S. 1993. In-group identification as a function of depersonalization, distinctiveness, and status. Psychological Science, 4, 88-92.

Brodbeck, F. C., Kerschreiter, R., Mojzisch, A., \& Schulz-Hardt, S. 2007. Group decision making under conditions of distributed knowledge: The information asymmetries model. Academy of Management Review, 32(2): 459-479.

Brown, M. E. 1969. Identification and some conditions of organizational involvement. Administrative Science Quarterly, 14(3): 346-356.

Bunderson, J. S. \& Sutcliffe, K. M. 2002. Comparing alternative conceptualizations of functional diversity in management teams: Process and performance effects Academy of Management Journal, 45(5): 875-893.

Bunderson, J. S. \& Sutcliffe, K. M. 2003. Management team learning orientation and business unit performance. Journal of Applied Psychology, 88(3): 552-560.

Cannon M, Edmondson A. 2001. Confronting failure: antecedents and consequences of shared

beliefs about failure in organizational work groups. Journal of Organizational Behaviour. 22:161-77 
Carmeli, A. \& Schaubroeck, J. 2006. Top management team behavioral integration, decision quality, and organizational decline. The Leadership Quarterly, 17(5): 441453.

Carmeli, A., Schaubroeck, J., \& Tishler, A. 2011. How ceo empowering leadership shapes top management team processes: Implications for firm performance. Leadership Quarterly, 22(2): 399-411.

Carmeli, A., Sheaffer, Z., \& Halevi, M. Y. 2009. Does participatory decision-making in top management teams enhance decision effectiveness and firm performance? Personnel

Review, 38(6): 696-714.

Carmeli, A., \& Shteigman, A. 2010. Top management team behavioral integration in small-sized firms: A social identity perspective. Group Dynamics: Theory, Research, and Practice, 14(4): 318-331.

Carpenter, M. A., \& Fredrickson, J. W. 2001. Top management teams, global strategic posture, and the moderating role of uncertainty. Academy of Management Journal, 44: 533-545.

Carpenter, M. A., Geletkanycz, M. A., \& Sanders, W. G. 2004. Upper echelons research revisited: Antecedents, elements, and consequences of top management team composition. Journal of Management, 30(6): 749-778.

Certo, S. T., Lester, R. H., Dalton, C. M., \& Dalton, D. R. 2006. Top management teams, strategy and financial performance: A meta-analytic examination. Journal of Management Studies, 43(4): 813-839.

Chattopadhyay, P., George, E., \& Lawrence, S. A. 2004. Why does dissimilarity matter? Exploring self-categorization, self-enhancement, and uncertainty reduction. Journal of Applied Psychology, 89, 892-900.

Chen, G., Liu, C., \& Tjosvold, D. 2005. Conflict management for effective top management teams and innovation in china. Journal of Management Studies, 42(2): 277-300.

Chen, G. \& Mathieu, J. E. 2008. Goal orientation dispositions and performance trajectories: The roles of supplementary and complementary situational inducements. Organizational Behavior and Human Decision Processes, 106, $21-$ 38.

Choi, J. N. 2002. External activities and team effectiveness: Review and theoretical development. Small Group Research, 33(2): 181.

Christ, O., van Dick, R., Wagner, U., \& Stellmacher, J. 2003. When teachers go the extra mile: Foci of organisational identification as determinants of different forms of organisational citizenship behavior among schoolteachers. British Journal of Educational Psychology. Vol, 73(3): 329-341.

Cohen, S. G. \& Bailey, D. E. 1997. What makes teams work: Group effectiveness research from the shop floor to the executive suite. Journal of Management, 23(3): 239.

Cook, S. and Brown, J. 1999. Bridging epistemologies: the generative dance between organizational knowledge and organizational knowing. Organization Science, 10(3), 381-400.

Corley, K. G. 2004. Defined by our strategy or our culture? Hierarchical differences in perceptions of organizational identity and change. Human Relations, 57(9): 11451177.

Culpepper, S. A. \& Aguinis, H. R is for revolution: A cutting-edge, free, open source statistical package. Organizational Research Methods. 
Day, D. V. \& Harrison, M. M. 2007. A multilevel, identity-based approach to leadership development. Human Resource Management Review, 17(4): 360-373.

De Dreu, C. K. W. \& Weingart, L. R. 2003. Task versus relationship conflict, team performance, and team member satisfaction: A meta-analysis. Journal of Applied Psychology, 88(4): 741-749.

DeChurch, L. A. \& Marks, M. A. 2001. Maximizing the benefits of task conflict: The role of conflict management International Journal of Conflict Management (1997-2002), 12(1): 4.

DeChurch, L. A. \& Marks, M. A. 2006. Leadership in multiteam systems. Journal of Applied Psychology, 91(2): 311-329.

DeChurch, L. A., Hiller, N. J., Toshio, M., Doty, D., \& Salas, E. (2010). Leadership across

levels: Levels of leaders and their levels of impact. The Leadership Quarterly, 21: 10691085.

DeChurch, L. A. \& Zaccaro, S. J. 2010. Perspectives: Teams won't solve this problem. Human Factors, 52(2): 329-334.

van Dick, R. 2001. Identification in organizational contexts: Linking theory and research from social and organizational psychology. International Journal of Management Reviews, 3(4): 265-283.

van Dick, R., van Knippenberg, D., Kerschreiter, R., Hertel, G., \& Wieseke, J. 2008. Interactive effects of work group and organizational identification on job satisfaction and extra-role behavior. Journal of Vocational Behavior, 72(3): 388399.

van Dick, R., Wagner, U., Stellmacher, J., \& Christ, O. 2004. The utility of a broader conceptualization of organizational identification: Which aspects really matter? Journal of Occupational and Organizational Psychology, 77: 171-191.

Dimmock, J. A., Grove, J. R., \& Eklund, R. C. 2005. Reconceptualizing team identification: New dimensions and their relationship to intergroup bias. Group Dynamics: Theory, Research, and Practice, 9(2): 75-86.

Doosje, B., Ellemers, N., \& Spears, R. 1995. Perceived intragroup variability as a function of group status and identification. Journal of Experimental Social Psychology, 31(5): 410-436.

Dovidio, J. F., Gaertner, S. L., \& Validzic, A. 1998. Intergroup bias: Status, differentiation, and a common in-group identity. Journal of Personality and Social Psychology, 75:109-120.

Drath, W. H., McCauley, C.D., Palus, C.J., Van Velsor, E., O’Connor, P.M.G. \& McGuire, J.B. 2008. Direction, alignment, commitment: Toward a more integrative ontology of leadership. The Leadership Quarterly, 19(3):635-53.

Dukerich, J. M., Golden, B. R., \& Shortell, S. M. 2002. Beauty is in the eye of the beholder: The impact of organizational identification, identity, and image on the cooperative behaviors of physicians. Administrative Science Quarterly, 47(3): 507-533.

Dutton, J. E., Dukerich, J. M., \& Harquail, C. V. 1994. Organizational images and member identification. Administrative Science Quarterly, 39(2): 239-263.

Edmondson, A. 1999. Psychological safety and learning behavior in work teams. Administrative Science Quarterly, 44(2): 350-383.

Edmondson, A. C., Roberto, M. A., \& Watkins, M. D. 2003. A dynamic model of top management team effectiveness: Managing unstructured task streams. The Leadership Quarterly, 14(3): 297-325. 
Edmondson, A. C. \& Smith, D. M. 2006. Too hot to handle? How to manage relationship conflict. California Management Review, 49(1): 6-31.

Eisenbeiss, K., \& Otten, S. (2008). When do employees identify? An analysis of cross sectional and longitudinal predictors of training group and organizational identification. Journal of Applied Social Psychology, 38: 2132-2151.

Eisenhardt, K. M. 1989. Building theories from case study research. Academy of Management Review, 14(4): 532-550.

Eisenhardt, K. M. \& Bourgeois, L. J. I. 1988. Politics of strategic decision making in high-velocity environments: Toward a midrange theory Academy of Management Journal, 31(4): 737-770.

Eisenhardt, K. M. 1989. Building theories from case study research. Academy of Management Review, 14(4): 532-550.

Eisenhardt, K. M., J. A. Martin. 2000. Dynamic capabilities: What are they? Strategic Management Journal, 21(10-11): 1105-1121.

Faraj, S. \& Aimin, Y. 2009. Boundary work in knowledge teams. Journal of Applied Psychology, 94(3): 604-617.

Festinger, L. (1957). A theory of cognitive dissonance. Stanford, CA: Stanford University Press.

Finkelstein, S. 1992. Power in top management teams: Dimensions, measurement, and validation. Academy of Management Journal, 35(3): 505-538.

Finkelstein, S. and Hambrick, D.C. 1990. Top-management team tenure and organizational outcomes: the moderating role of managerial discretion. Administrative Science Quarterly, 35(3): 484-503.

Fiol, C. M. 1989. A semiotic analysis of corporate language: Organizational boundaries and joint venturing. Administrative Science Quarterly, 34(2): 277-303.

Fiol, C. M., Pratt, M. G., \& O’Connor, E. J. 2009. Managing intractable identity conflicts Academy of Management Review, 34(1): 32-55.

Fisher, R. 1983. Third party consultation as a method of intergroup conflict resolution. Journal of Conflict Resolution, 27: 301-334.

Fisher, C. D. \& Gitelson, R. 1983. A meta-analysis of the correlates of role conflict and ambiguity. Journal of Applied Psychology, 68(2): 320-333.

Fiske, S.T., \& Taylor, S.E. 1991. Social Cognition (2nd ed.). New York: McGraw-Hill.

Floyd, S. W. \& Wooldridge, B. 1992. Managing strategic consensus: The foundation of effective implementation. Academy of Management Executive, 6(4): 27-39.

Floyd, S. W. \& Lane, P. J. 2000. Strategizing throughout the organization: Managing role conflict in strategic renewal. Academy of Management Review, 25(1): 154177.

Foreman, P., and D. A. Whetten 2002 "Members' identification with multiple-identity organizations.” Organization Science, 13: 618-635.

Friedkin, N. E. \& Simpson, M. J. 1985. Effects of competition on members' identification with their subunits. Administrative Science Quarterly, 30(3): 377394.

Friedman, R.A. \& Podolny, J. 1992. Differentiation of boundary spanning roles: Labor negotiations and implications for role conflict. Administrative Science Quarterly, 37(1): 28-47.

Gaertner, S. L., Rust, M. C., Dovidio, J. F., Bachman, B. A., \& Anastasio, P. A. 1994. The contact hypothesis: The role of a common ingroup identity on reducing intergroup bias. Small Group Research, 25(2): 224-249. 
Gaertner, S. L., Dovidio, J. F., Anastasio, P. A., Bachman, B. A., \& Rust, M. C. 1994. The common ingroup identity model: Recategorisation and the reduction of intergroup bias. European Review of Social Psychology, 4: 3-24.

Gaertner, S. L., Dovidio, J. F., \& Bachman, B. A. 1996. Revisiting the contact hypothesis: The induction of a common ingroup identity. International Journal of Intercultural Relations, 20(3-4): 271-290.

Gaertner, S. L., Dovidio, J. F., Rust, M. C., Nier, J. A., Banker, B. S., Ward, C. M., Mottola, G. R., \& Houlette, M. 1999. Reducing intergroup bias: Elements of intergroup cooperation. Journal of Personality and Social Psychology, 76(3): 388402.

George, E. \& Chattopadhyay, P. 2005. One foot in each camp: The dual identification of contract workers. Administrative Science Quarterly, 50: 68-99.

Gladstein, D. L. 1984. Groups in context: A model of task group effectiveness. Administrative Science Quarterly, 29: 499-517.

Gibson, C. B. 2001. From accumulation to accommodation: The chemistry of collective cognition in work groups. Journal of Organizational Behavior, 22, 121-134.

Gibson, C., Cooper, C., D, \& Conger, J. A., Kanungo. 2009. Do you see what we see? The complex effects of perceptual distance between leaders and teams. Journal of Applied Psychology, 94 (1): 62-76.

Gladstein, D. L. 1984. Groups in context: A model of task group effectiveness. Administrative Science Quarterly, 29, 499-517.

Glaser, B. G. \& Strauss, A. L. 1999. The Discovery of Grounded Theory: Strategies for Qualitative Research. New York: Aldine de Gruyter.

Gleibs, I. H., Mummendey, A. 1., \& Noack, P. 2008. Predictors of change in postmerger identification during a merger process: A longitudinal study. Journal of Personality and Social Psychology, 95(5): 1095-1112.

Gleibs, I. H., Noack, P., \& Mummendey, 2010. A. We are still better than them: A longitudinal field study of ingroup favouritism during a merger. European Journal of Social Psychology, 40(5): 819-836.

Glynn, M. A. 2000. When cymbals become symbols: Conflict over organizational identity within a symphony orchestra. Organization Science, 11(3): 285-298.

Glynn, M. A., Kazanjian, R., \& Drazin, R. 2010. Fostering innovation in complex product development settings: The role of team member identity and interteam interdependence. Journal of Product Innovation Management, 27(7): 1082-1095.

Gong, Y., Shenkar, O., Luo, Y., \& Nyaw, M.-K. 2001. Role conflict and ambiguity of ceos in international joint ventures: A transaction cost perspective. Journal of Applied Psychology, 86(4): 764-773.

Gonzalez, R., \& Brown, R. J. 2003. Generalization of positive attitude as a function of subgroup and superordinate group identifications in intergroup contact. European Journal of Social Psychology, 33, 195-214.

Gonzalez, R., \& Brown, R. J. 2003. Maintaining dual identity as strategy for reducing intergroup bias. European Journal of Social Psychology, 33, 195-214.

Gonzalez, R. \& Brown, R. 2006. Dual identities in intergroup contact: Group status and size moderate the generalization of positive attitude change. Journal of Experimental Social Psychology, 42(6): 753-767.

Gorse, C. A. \& Emmitt, S. 2007. Communication behaviour during management and design team meetings: A comparison of group interaction. Construction Management \& Economics, 25(11): 1195-1211. 
Greene, C. N. 1978. Identification modes of professionals: Relationship with formalization, role strain, and alienation. The Academy of Management Journal, 21(3): 486-492.

Gregersen, H. B. \& Black, J. S. 1992. Antecedents to commitment to a parent company and a foreign operation Academy of Management Journal, 35(1): 65-90.

Gregson. T. . \& Wendell, J. 1994. Role conflict, role ambiguity, job satisfaction and moderating effects of job-related self-esteem: A latent variable analysis. Journal of Applied Business Research, 10, 106-113.

Gruenfeld, D. H., Mannix, E. A., Williams, K. Y., \& Neale, M. A. 1996. Group composition and decision making: How member familiarity and information distribution affect process and performance. Organizational Behavior and Human Decision Processes, 67: 1-15.

Gundlach, M., Zivnuska, S., \& Stoner, J. 2006. Understanding the relationship between individualism-collectivism and team performance through an integration of social identity theory and the social relations model. Human Relations, 59(12): 16031632.

Gupta, A.K., \& Govindarajan, V. 1986. Resource sharing among SBU's: Strategic antecedents and administrative implications. Academy of Management Journal, 27(1), 25-41.

Hackman, J. R. \& Wageman, R. 2005. A theory of team coaching Academy of Management Review, 30(2): 269-287.

Hackman, R., J. \& Wageman, R. 2005. When and how team leaders matter. Research in Organizational Behavior, 26: 37-74.

Hall, J. \& Williams, M. S. 1966. A comparison of decision-making performances in established and ad hoc groups. Journal of Personality and Social Psychology, 3(2): 214-222.

Hambrick, D. C. \& Mason, P. A. 1984. Upper echelons: The organization as a reflection of its top managers. Academy of Management Review, 9(2): 193.

Hambrick, D. C. 1994. Top management groups: A conceptual integration and reconsideration of the "Team" Tabel. Research in Organizational Behavior, 16: 171.

Hambrick, D. C. 1995. Fragmentation and the other problems ceos have with their top management teams. California Management Review, 37(3): 110.

Hambrick, D. C., Cho, T. S., \& Ming-Jer, C. 1996. The influence of top management team heterogeneity on firms' competitive moves. Administrative Science Quarterly, 41(4): 659-684.

Hambrick, D. C. 2007. Upper echelons theory: An update. Academy of Management Review, 32(2): 334-343.

Han, G. \& Harms, P. D. 2010. Team identification, trust and conflict: A mediation model. International Journal of Conflict Management, 21(1): 20-43.

Harrison, D. A., Price, K. H., \& Bell, M. P. 1998. Beyond relational demography: Time and the effects of surface- and deep-level diversity on work group cohesion Academy of Management Journal, 41(1): 96-107.

Haslam, S. A. 2004. Psychology in organizations: The social identity approach (2nd ed.).Thousand Oaks, CA: Sage Publications.

Haslam, S. A., Eggins, R. A., \& Reynolds, K. J. (2003). The ASPIRe model: Actualizing Social and Personal Identity Resources to enhance organizational outcomes. Journal of Occupational and Organizational Psychology, 76, 83-113. 
Haslam, S. A., \& Ellemers, N. 2006. Social identity in industrial and organizational psychology: Concepts, controversies and contributions. In D. J. K. F. Gerard P. Hodgkinson (Ed.), International Review of Industrial and Organizational Psychology. 2005 39-118.

Haslam, S. A., Powell, C., \& Turner, J. C. 2000. Social identity, self-categorization, and work motivation: Rethinking the contribution of the group to positive and sustainable organisational outcomes. Applied Psychology: An International Review, 49(3): 319.

Haslam, S. A. \& Reicher, S. 2006. Stressing the group: Social identity and the unfolding dynamics of responses to stress. Journal of Applied Psychology, 91(5): 10371052.

Hausknecht, J. P., Hiller, N. J., \& Vance, R. J. 2008. Work-unit absenteeism: Effects of satisfaction, commitment, labor market conditions and time Academy of Management Journal, 51(6): 1223-1245.

Hinds, P. J. \& Mortensen, M. 2005. Understanding conflict in geographically distributed teams: The moderating effects of shared identity, shared context, and spontaneous communication. Organization Science, 16(3): 290-307.

Hobman, E. V. \& Bordia, P. 2006. The role of team identification in the dissimilarity conflict relationship. Group Processes \& Intergroup Relations, 9(4): 483-507.

Hoegl, M., Weinkauf, K., \& Gemuenden, H. G. 2004. Interteam coordination, project commitment, and teamwork in multiteam r\&d projects: A longitudinal study. Organization Science, 15(1): 38-55.

Hoegl, M. \& Weinkauf, K. 2005. Managing task interdependencies in multi-team projects: A longitudinal study. Journal of Management Studies, 42(6): 1287-1308.

Hogg, M. A. 2001. A social identity theory of leadership. Personality \& Social Psychology Review, 5(3): 184-200.

Hogg, M. A. \& Terry, D. J. 2000. Social identity and self-categorization processes in organizational contexts. Academy of Management Review, 25(1): 121-140.

Hogg, M. A., Abrams, D., Otten, S., \& Hinkle, S. 2004. The social identity perspective: Intergroup relations, self-conception, and small groups. Small Group Research, 35(3): 246-276.

Homan, A. C., Hollenbeck, J. R., Humphrey, S. E., Van Knippenberg, D., Ilgen, D. R., \& Van Kleef, G. A. 2008. Facing differences with an open mind: Openness to experience, salience of intragroup differences, and performance of diverse work groups. Academy of Management Journal, 51(6): 1204-1222.

Hornsey, M. J. \& Hogg, M. A. 1999. Subgroup differentiation as a response to an overly-inclusive group: A test of optimal distincitiveness theory. European Journal of Social Psychology, ,29(3): 543-550.

Hornsey, M. J. \& Hogg, M. A. 2000a. Assimilation and diversity: An integrative model of subgroup relations. Personality \& Social Psychology Review, 4(2): 143-156.

Hornsey, M. J. \& Hogg, M. A. 2000b. Subgroup relations: A comparison of mutual intergroup differentiation and common ingroup identity models of prejudice reduction. Personality and Social Psychology Bulletin, 26(2): 242-256.

Hornsey, M. J. \& Hogg, M. A. 2000c. Intergroup similarity and subgroup relations: Some implications for assimilation. Personality and Social Psychological Bulletin, 26(8): 948-958.

Ilgen, D. R., Hollenbeck, J. R., Johnson, M., \& Jundt, D. 2005. Teams in organizations: From input-process-output models to imoi models. Annual Review of Psychology, 56(1): 517-543. 
Williams, K. Y. \& O'Reilly Iii, C. A. 1998. Demography and diversity in organizations: A review of 40 years of research Research in Organizational Behavior, 20: 77.

Jackson, S. E. \& Schuler, R. S. 1985. A meta-analysis and conceptual critique of research on role ambiguity and role conflict in work settings. Organizational Behavior and Human Decision Processes, 36(1): 16-78.

Jackson, S. E., Joshi, A., \& Erhardt, N. L. 2003. Recent research on team and organizational diversity: Swot analysis and implications. Journal of Management, 29(6): 801.

Janis, I. L. 1982. Groupthink: Psychological Studies of Policy Decision and Fiascos (2nd ed.). Boston, MA: Houghton Mifflin.

Jarzabkowski, P. 2003. Strategic practices: An activity theory perspective on continuity and change. Journal of Management Studies, 40(1): 23-55.

Jarzabkowski, P. \& Paul Spee, A. 2009. Strategy-as-practice: A review and future directions for the field. International Journal of Management Reviews, 11(1): 69_ 95.

Janssen, O., Van de Vliert, E., \& Veenstra, C. 1999. How task and person conflict shape the role of positive interdependence in management groups. Journal of Management, 25, 117-141.

Jehn, K. A. 1995. A multimethod examination of the benefits and detriments of intragroup conflict. Administrative Science Quarterly, 40(2): 256-282.

Jehn, K. A., Chadwick, C., \& Thatcher, S. M. B. 1997. To agree or not to agree: The effects of value congruence, individual demographic dissimilarity, and conflict on workgroup outcomes International Journal of Conflict Management (1997-2002), 8(4): 287-305.

Jehn, K. A. \& Mannix, E. A. 2001. The dynamic nature of conflict: A longitudinal study of intragroup conflict and group performance. Academy of Management Journal, 44(2): 238-251.

Johnson, J. P. 1999. Multiple commitments and conflicting loyalties in international joint venture management teams. International Journal of Organizational Analysis (1993 - 2002), 7(1): 54.

Johnson, G., Melin, L. and Whittington, R. 2003. Guest editors' introduction: micro strategy

and strategizing: towards an activity-based view. Journal of Management Studies, 40, 3 22.

Joshi, A. 2006. The influence of organizational demography on the external networking behavior of teams Academy of Management Review, 31(3): 583-595.

Joshi, A., Pandey, N., \& Han, H. 2009. Bracketing team boundary spanning: An examination of task-based, teamlevel, and contextual antecedents. Journal of Organizational Behavior, 30: 731-759.

Joshi, A. \& Roh, H. 2009. The role of context in work team diversity research: A metaanalytic review. Academy of Management Journal, 52(3): 599-627.

Kahn. R. L., Wolfe, D. M., Quinn, R. P., Snoek, J. D., \& Rosenthal, R. A. 1964.Occupational Stress: Studies in Role Conflict and Ambiguity. New York: Wiley.

Kanfer, R., \& Ackerman, P. L. 1989. Motivation and cognitive abilities: An integrative/ aptitude-treatment interaction approach to skill acquisition. Journal of Applied Psychology, 74, 657-690.

Katz, D., \& Kahn, R. L. 1978. The Social Psychology of Organizations, (2nd ed.). New York: Wiley. 
Katzenbach, J. R. 1998. Teams at the Top. Boston, MA: Harvard Business School Press.

Kramer, R. M. 1991. Intergroup relations and organizational processes. In B. M. Staw \& L. L. Cummings (Eds.). Research in Organizational Behavior, 13, 191-227. Greenwich, CT: JAI Press.

Keller, R. T. 2001. Cross-functional project groups in research and new product development:

Diversity, communications, job stress, and outcomes. Academy of Management Journal, 44(3), 547-555.

Kenny, D. A., Korchmaros, J. D., \& Bolger, N. 2003. Lower level mediation in multilevel models. Psychological Methods, 8(2): 115-128.

Klein, K. J. \& Kozlowski, S. W. J. 2000. From micro to meso: Critical steps in conceptualizing and conducting multilevel research. Organizational Research Methods, 3(3): 211.

Knight, D., Pearce, C. L., Smith, K. G., Olian, J. D., Sims, H. P., Smith, K. A., \& Flood, P. 1999. Top management team diversity, group process, and strategic consensus. Strategic Management Journal, 20(5): 445.

van Knippenberg, D. 2000. Work motivation and performance: A social identity perspective. Applied Psychology: An International Review, 49, 357-371.

van Knippenberg D, De Dreu CKW, Homan AC. 2004.Work group diversity and group performance: an integrative model and research agenda. Journal of Applied. Psychology. 89:1008- 22

van Knippenberg, D., van Knippenberg, B., De Cremer, D., \& Hogg, M. A. 2004. Leadership, self, and identity: A review and research agenda. The Leadership Quarterly, 15, 825-856.

van Knippenberg, D., van Knippenberg, B., Monden, L., \& de Lima, F. 2002. Organizational identification after a merger: A social identity perspective. British Journal of Social Psychology, 41(2): 233-252.

van Knippenberg, D. \& van Schie, E. C. M. 2000. Foci and correlates of organizational identification. Journal of Occupational \& Organizational Psychology, 73(2): 137147.

Kramer, R. M. \& Brewer, M. B. 1984. Effects of group identity on resource use in a simulated commons dilemma. Journal of Personality and Social Psychology. Vol, 46(5): 1044-1057.

Kreiner, G. E., Hollensbe, E. C., \& Sheep, M. L. 2006a. On the edge of identity: Boundary dynamics at the interface of individual and organizational identities. Human Relations, 59(10): 1315-1341.

Kreiner, G. E., Hollensbe, E. C., \& Sheep, M. L. 2006b. Where is the "Me" Among the "We"? Indentity work and the search for optimal balance. Academy of Management Journal, 49(5): 1031-1057.

Kreiner, G. E., Hollensbe, E. C., \& Sheep, M. L. 2009. Balancing borders and bridges: Negotiating the work-home interface via boundary work tactics. Academy of Management Journal, 52(4): 704-730.

Lau, D. C. \& Murnighan, J. K. 2005. Interactions within groups and subgroups: The effects of demographic faultlines Academy of Management Journal, 48(4): 645659.

Lawrence, B. S. 1997. The black box of organizational demography. Organization Science, 8(1): 1. 
LeBreton, J. M., \& Senter, J. L. 2008. Answers to twenty questions about interrater reliability and interrater agreement. Organizational Research Methods, 11, 815852

Li, J., Xin, K., \& Pillutla, M. 2002. Multi-cultural leadership teams and organizational identification in international joint ventures. International Journal of Human Resource Management, 13(2): 320-337.

Li, J. \& Hambrick, D. C. 2005. Factional groups: A new vantage on demographic faultlines, conflict, and disintegration in work teams. Academy of Management Journal, 48(5): 794-813.

Lord, R. G. \& Hall, R. J. 2005. Identity, deep structure and the development of leadership skill. Leadership Quarterly, 16(4): 591-615.

Louis, M. R. 1980. Surprise and sense making: What newcomers experience in entering unfamiliar organizational settings. Administrative Science Quarterly, 25: 226-251.

Lovelace K, Shapiro DL, Weingart LR. 2001. Maximizing cross-functional new product teams'

innovativeness and constraint adherence: a conflict communications perspective. Academy of Management Journal. 44: 779-93

Lubatkin, M. H., Simsek, Z., Ling, Y., \& Veiga, J. F. 2006. Ambidexterity and performance in small-to medium-sized firms: The pivotal role of top management team behavioral integration. Journal of Management, 32(5): 646-672.

Marks, M. A., Mathieu, J. E., \& Zaccaro, S. J. 2001. A temporally based framework and taxonomy of team processes. Academy of Management Review, 26(3): 356-376.

Marks, M. A., DeChurch, L. A., Mathieu, J. E., Panzer, F. J., \& Alonso, A. 2005. Teamwork in multiteam systems. Journal of Applied Psychology, 90(5): 964-971.

Marks, M. A., Zaccaro, S. J., \& Mathieu, J. E. 2000. Performance implications of leader briefings and team-interaction training for team adaptation to novel environments. Journal of Applied Psychology, 85(6), 971-986.

Marrone, J. A. (2010).Team Boundary Spanning: A Multi-level Review of Past Research and Proposals for the Future. Journal of Management, 36(4), 911 - 940.

Marrone, J. A., Tesluk, P. E., \& Carson, J. B. 2007. A multilevel investigation of antecedents and consequences of team member boundary-spanning behaviour. Academy of Management Journal, 50(6): 1423-1439.

Martin, J. A. 2011. Dynamic managerial capabilities and the multibusiness team: The role of episodic teams in executive leadership groups. Organization Science, 22(1): $118-140$.

Martin, J. A., K. M. Eisenhardt. 2010. Creating cross-business-unit collaborations in multi-business organizations. Academy of Management Journal. 53(2). 265-301.

Mathieu, J., Marks, M. A., \& Zaccaro, S. J. 2001 Multi-team systems. . In N. Anderson \& D. Ones \& S. H. C. \& V. H. K. (Eds.), International handbook of work and organizational psychology Vol. 2289 - 313 London Sage.

Mathieu, J., Maynard, M. T., Rapp, T., \& Gilson, L. 2008. Team effectiveness 19972007: A review of recent advancements and a glimpse into the future. Journal of Management, 34(3): 410-476.

Mayer, R. C., Davis, J. H., \& Schoorman, F. D. 1995. An integrative model of organizational trust. Academy of Management Review, 20(3): 709-734.

Mc Grath, J.E. 1964. Social Psychology: A brief introduction. New York, NY: Holt, Rinehart and Winston.

McGrath, J. E. 1984. Groups: Interaction and performance. Englewood Cliffs, NJ: Prentice-Hall. 
McGrath, J. E., Arrow, H., \& Berdahl, J. L. 2000. The study of groups: Past, present, and future. Personality \& Social Psychology Review (Lawrence Erlbaum Associates), 4(1): 95-105.

Michalisin, M. D., Karau, S. J., \& Tangpong, C. 2004. Top management team cohesion and superior industry returns: An empirical study of the resource-based view. Group Organization Management, 29(1): 125-140.

Miller, N., Urban, L. M., \& Vanman, E. J. 1998. A theoretical analysis of crossed categorization effects. In C. Sedikides, \& J. Schopler (Eds.), Intergroup cognition and intergroup behavior, 393-420. Mahway, NJ: Earlbaum.

Mooney, A. C., Holahan, P. J., \& Amason, A. C. 2007. Don't take it personally: Exploring cognitive conflict as a mediator of affective conflict. Journal of Management Studies, 44(5): 733-758.

Moore, D. A., Kurtzberg, T.R., Thompson, L. L., \& Morris, M.W. 1999. Long and short routes to success in electronically mediated negotiations: Group affiliations and good vibrations. Organizational Behavior \& Human Decision Processes, 77, 22-43.

Mortensen, M. \& Hinds, P. J. 2001. Conflict and shared identity in geographically distributed teams International Journal of Conflict Management (1997-2002), 12(3): 212.

Munyon, T. P., Summers, J. K., Buckley, M. R., Ranft, A. L., \& Ferris, G. R. Executive work design: New perspectives and future directions. Journal of Organizational Behavior, 31(2-3): 432-447.

Netemeyer, R. G., Burton, S., \& Johnston, M. W. 1995. A nested comparison of four models of the consequences of role perception variables. Organizational Behavior and Human Decision Processes, 61, 77-93.

O'Connor, E. J., Fiol, C. M., \& Guthrie, M. 2006. Separately together: Build unity by strengthening physician groups. The Physician Executive, 32: 16-21.

O’Leary, M. B. \& Mortensen, M. 2010. Go (con)figure: Subgroups, imbalance, and isolates in geographically dispersed teams. Organization Science, 21(1): 115-131.

Olson, B. J., Parayitam, S., \& Bao, Y. (2007). Strategic decision making: The effects of cognitive diversity, conflict, and trust on decision outcomes. Journal of Management, 33,196-222.

Omodei, M. M., Taranto, P. and Wearing, A. J. 2003, Networked Fire Chief (Version 1.33) [Computer program], La Trobe University, Melbourne.

O’Reilly, C. and Chatman, J. 1986. Organizational Commitment and Psychological

Attachment: The Effects of Compliance, Identification, and Internalization on Prosocial Behavior. Journal of Applied Psychology, 71(3):492-99.

Pearce, R.J. 1997 Towards understanding joint venture performance and survival: A bargaining and influence approach to transaction cost theory, Academy of Management Review, 22, 203-35.

Pelled, L. H., Eisenhardt, K. M., \& Xin, K. R. 1999. Exploring the black box: An analysis of work group diversity, conflict, and performance. Administrative Science Quarterly, 44(1): 1.

Peterson, R. S. \& Behfar, K. J. 2003. The dynamic relationship between performance feedback, trust, and conflict in groups: A longitudinal study. Organizational Behavior and Human Decision Processes, 92(1-2): 102-112.

Peterson, R. S., P. V. Martorana, D. B. Smith, P. D. Owens. 2003. The impact of chief executive officer personality on top management team dynamics: One mechanism 
by which leadership affects organizational performance. Journal of Applied Psychology. 88(5) 795-808.

Pettigrew, T. F. 1998. Intergroup contact theory. Annual Review of Psychology, 49(1): 65.

Pettigrew, T. F. \& Tropp, L. R. 2006. A meta-analytic test of intergroup contact theory. Journal of Personality and Social Psychology, 90(5): 751-783.

Pitariu, A. H. \& Ployhart, R. E. Explaining change: Theorizing and testing dynamic mediated longitudinal relationships. Journal of Management, 36(2): 405-429.

Pitcher, P. \& Smith, A. D. 2001. Top management team heterogeneity: Personality, power, and proxies. Organization Science, 12(1): 1.

Ployhart, R. E. \& Vandenberg, R. J. Longitudinal research: The theory, design, and analysis of change. Journal of Management, 36(1): 94-120.

Polzer, J. T., Crisp, C. B., Jarvenpaa, S. L., \& Kim, J. W. 2006. Extending the faultline model to geographically dispersed teams: How colocated subgroups can impair group functioning Academy of Management Journal, 49(4): 679-692.

Polzer, J. T., Milton, L. P., \& Swann Jr, W. B. 2002. Capitalizing on diversity: Interpersonal congruence in small work groups. Administrative Science Quarterly, 47(2): 296.

Polzer, J. T., K. J. Stewart, and J. L. Simmons. 1999, A social categorization explanation

for framing effects in nested social dilemmas. Organizational Behavior and Human Decision Processes, 79: 154-178.

Porter, C. O. L. H., Gogus, C. I., \& Chien-Feng Yu, R. 2010. When does teamwork translate into improved team performance? A resource allocation perspective. Small Group Research, 41(2): 221-248.

Postmes, T., Haslam, S. A., \& Swaab, R. I. 2005. Social influence in small groups: An interactive model of social identity formation. European Review of Social Psychology, 16: 1 - 42.

Pratt, M. G. \& Foreman, P. O. 2000. Classifying managerial responses to multiple organizational identities Academy of Management Review, 25(1): 18-42.

Pratt, M. G., Rockmann, K. W., \& Kaufmann, J. B. 2006. Constructing professional identity: The role of work and identity learning cycles in the customization of identity among medical residents. Academy of Management Journal, 49(2): 235262.

Priem, R. L., Lyon, D. W., \& Dess, G. G. 1999. Inherent limitations of demographic proxies in top management team heterogeneity research. Journal of Management, 25(6): 935.

Raes, A. M. L., Glunk, U., Heijltjes, M. 1. G., \& Roe, R. A. 2007. Top Management Team and Middle Managers. Small Group Research, 38(3): 360-386.

Reade, C. 2001. Dual identification in multinational corporations: Local managers and their psychological attachment to the subsidiary versus the global corporation, The Internationa Journal of Human Resource Management, 12(3): 405-424.

Richter, A. W., West, M. A., van Dick, R., \& Dawson, J. F. 2006. Boundary spanners' identification, intergroup contact, and effective integroup relations Academy of Management Journal, 49(6): 1252-1269.

Rizzo, J. R., House, R. J., \& Lirtzman, S. I. 1970. Role conflict and ambiguity in complex organizations. Administrative Science Quarterly, 15(2): 150-163.

Roccas, S. \& Brewer, M. (2002). Social identity complexity. Personality and Social Psychology Review, 6, 88-106 
Rockmann, Kevin W., Pratt, Michael G., \& Northcraft, Gregory B. (2007) Divided loyalties: Determinants of identification in inter-organizational teams. Small Group Research, 38, 727-751.

Rotondi Jr, T. 1975. Organizational identification: Issues and implications. Organizational Behavior \& Human Performance, 13(1): 95-109.

Sanchez, J. I., Spector, P. E., \& Cooper, C. L. 2000. Adapting to a boundaryless world: A developmental expatriate model. Academy of Management Executive, 14(2): 96-106.

Schulz-Hardt, S., Frey, D., Lüthgens, C., \& Moscovici, S. 2000. Biased information search in group decision making. Journal of Personality and Social Psychology, 78: 655-699.

Shenkar, O., \& Zeira, Y. 1992. Role conflict and role ambiguity of chief executive officers in international joint ventures. Journal of International Business Studies, 23(1), 55-75.

Silva, D. \& Sias, P. M. 2010. Connection, restructuring, and buffering: How groups link individuals and organizations. Journal of Applied Communication Research, 38(2): 145-166.

Simon, B. \& Klandermans, B. 2001. Politicized collective identity - a social psychological analysis. American Psychologist, 56(4): 319-331.

Simons, T., Pelled, L. H., \& Smith, K. A. 1999. Making use of difference: Diversity, debate, and decision comprehensiveness in top management teams Academy of Management Journal, 42(6): 662-673.

Simons, T. L. \& Peterson, R. S. 2000. Task conflict and relationship conflict in top management teams: The pivotal role of intragroup trust. Journal of Applied Psychology, 85(1): 102-111.

Singer, J. D. \& Willett, J. B. 2003. Applied longitudinal data analysis: Modeling change and event occurrence. New York, NY US: Oxford University Press.

Smith, K. G., Carroll, S. J., \& Ashford, S. J. 1995. Intra- and interorganizational cooperation: Toward a research agenda. Academy of Management Journal, 38, $7-$ 23.

Smith, K. G., Smith, K. A., Sims Jr, H. P., O'Bannon, D. P., \& Scully, J. A. 1994. Top management team demography and process: The role of social integration and communication. Administrative Science Quarterly, 39(3): 412-438.

Smith, W. K. \& Tushman, M. L. 2005. Managing strategic contradictions: A top management model for managing innovation streams. Organization Science, 16(5): 522-536.

Smith, A., Houghton, S. M., Hood, J. N., \& Ryman, J. A. 2006. Power relationships among top managers: Does top management team power distribution matter for organizational performance? Journal of Business Research, 59(5): 622-629.

Spector, P. E., Chen, P. Y., \& O’Connell, B. J. 2000. A longitudinal study of relations between job stressors and job strains while controlling for prior negative affectivity and strains. Journal of Applied Psychology, 85, 211- 218.

Stets, J. E. \& Burke, P. J. 2000. Identity theory and social identity theory. Social Psychology Quarterly. Vol, 63(3): 224-237.

Sveningsson, S. F. \& Alvesson, M. 2003. Managing managerial identities: Organizational fragmentation, discourse and identity struggle. Human Relations, 56(10): 11631193. 
Swaab, R., Postmes, T., van Beest, I., \& Spears, R. 2007. Shared cognition as a product of, and precursor to, shared identity in negotiations. Pers Soc Psychol Bull, 33(2): 187-199.

Swaab, R. I., Postmes, T., \& Spears, R. 2008. Identity formation in multiparty negotiations. British Journal of Social Psychology, 47: 167-187.

Tajfel, H. 1982. Social psychology of intergroup relations. Annual Review of Psychology. Vol, 33: 1-39.

Tannenbaum, R. \& Schmidt, W. H. 1973. How to choose a leadership pattern. Harvard Business Review, 51(3): 162-180.

Tekleab, A. G., Quigley, N. R., \& Tesluk, P. E. 2009. A longitudinal study of team conflict, conflict management, cohesion, and team effectiveness. Group \& Organization Management, 34(2): 170-205.

Terry, D. J., Amiot, C. E., 2008. Social identification processes, conflict, and fairness concerns in intergroup mergers, In: The psychology of conflict and conflict management in organizations. De Dreu, C. K. W., \& Gelfand, M. J.: 385-411. New York, NY: Taylor \& Francis Group/Lawrence Erlbaum Associates.

Tjosvold, D. 1998. Making employee involvement work: Cooperative goals and controversy to reduce costs. Human Relations, 51(2): 201-214.

Tsui, A. S. 1984. A role set analysis of managerial reputation. Organizational Behavior and Human Performance, 34 (1), 64-96.

Tsui, A. S., \& Ashford, S. J. 1994. Adaptive self-regulation: A process view of managerial effectiveness. Journal of Management, 20, 93-121.

Tsui, A. S. \& O’Reilly Iii, C. A. 1989. Beyond simple demographic effects: The importance of relational demography in superior-subordinate dyads. Academy of Management Journal, 32(2): 402-423.

Tubre, T. C. \& Collins, J. M. 2000. Jackson and schuler (1985) revisited: A metaanalysis of the relationships between role ambiguity, role conflict, and job performance. Journal of Management, 26(1): 155-169.

Turner, J. C. 1975. Social comparison and social identity: Some prospects for intergroup behaviour. European Journal of Social Psychology. Vol, 5(1): 5-34.

Ullrich, J., Wieseke, J., Christ, O., Schulze, M., \& Van Dick, R. 2007. The identitymatching principle: Corporate and organizational identification in a franchising system. British Journal of Management, 18: S29-S44.

Van Der Vegt, G. S., Van De Vliert, E., \& Oosterhof, A. 2003. Informational dissimilarity and organizational citizinship behavior: The role of intrateam interdependence and team identification. Academy of Management Journal, 46(6): 715-727.

Van Der Vegt, G. S. \& Bunderson, J. S. 2005. Learning and performance in multidisciplinary teams: The importance of collective team identification. Academy of Management Journal, 48(3): 532-547.

Van Maanen, J. 1979. The Fact of Fiction in Organizational Ethnography. Administrative Science Quarterly, 24(4), 539-550.

Van Sell, M., Brief, A. P., \& Schuler, R. S. 1981. Role conflict and role ambiguity: Integration of the literature and directions for future research. Human Relations, 34(1): 43.

Vora, D. \& Kostova, T. 2007. A model of dual organizational identification in the context of the multinational enterprise. Journal of Organizational Behavior, 28(3): $327-350$. 
Vora, D., Kostova, T., \& Roth, K. 2007. Roles of subsidiary managers in multinational corporations: The effect of dual organizational identification. Management International Review (MIR), 47(4): 595-620.

Walsh, J. P. 1988. Selectivity and selective perception: An investigation of managers' belief structures and information processing. Academy of Management Journal, 31(4): 873-896.

Webber, S. S. \& Donahue, L. M. 2001. Impact of highly and less job-related diversity on work group cohesion and performance: A meta-analysis. Journal of Management, 27(2): 141.

Weick, K. E. 1995. Sensemaking in organizations: Thousand Oaks, CA: Sage.

Weick, K. E., Sutcliffe, K. M., \& Obstfeld, D. 2005. Organizing and the process of sensemaking. Organization Science, 16(4): 409-421.

West, M. A., Hirst, G., Richter, A., \& Shipton, H. 2004. Twelve steps to heaven: Successfully managing change through developing innovative teams change. European Journal of Work and Organizational Psychology, 13, 269-299.

Wiesenfeld, B. M., Hewlin, P. F. 2003. Splintered Identity and Organizational Change: The predicament of Boundary Spanning In Research on Managing Groups and Teams, (5), n. 27-52: JAI.

Wiley, N. 1988. The Micro-Macro Problem in Social Theory. Sociological Theory 6(2), 254-261.

Williams, K. Y. \& O'Reilly Iii, C. A. 1998. Demography and diversity in organizations: A review of 40 years of research Research in Organizational Behavior, 20: 77.

Wooldridge, B., Schmid, T. \& Floyd, S. W. 2008. A middle management perspective: Current contributions, synthesis and future research. Journal of Management, 34: 1190-1221. 

Appendix 
Appendix

\section{APPENDIX A}

\section{Interview Protocol Chapter $3^{7}$}

Introduction of research question. In this interview I am interested in the research question: What makes management teams successful? Much information is available on how team members are able to cooperate successfully. The question remains, though, why one management team succeeds in operating like a real team while another does not. Recent studies indicate that the dual loyalty of managers, embedded in the "make-up" of management teams, is an important determinant of team functioning. With dual loyalty we mean that, on the one hand, managers are expected to endorse the interests of the organization as a whole and on the other hand are expected to support the goals and interests of their own subunit. In the current interview study we are interested in the consequences of this dual loyalty on interaction processes within management teams.

Relevancy of the research to management team functioning. Research suggests that the way in which managers deal with a dual loyalty situation influences the quality of interaction processes within management teams. Knowledge on the identification of managers with the diverse goals of their organization increases the insights on management team processes and can improve the quality of interactions. This research helps to measure the degree of identification and enables you, as a manager, to anticipate potential tensions among team members and to optimize team processes.

Explanation of social identification. Before we start with the interview I would like to explain to you in a bit more detail what I mean with social identification and the conflict that may emerge from this. As a person you derive part of your identity to the job function you fulfill. A person's identity exists of a personal and social identity. The personal identity defines who you are as a person or how you perceive yourself in terms of your job role. For example, questions core to your personal identity would be: who am I as a manager?

The social identity defines who you are in relation to the social groups you feel a member of. For example, you define yourself as a member of [the organization the interviewee works for], but you can also define yourself as supporter of the Dutch national football team. The identification to these social groups determines your attitude and behavior. In this interview, I am interested to what extent the identification with your management team and business unit influence your daily work.

\footnotetext{
${ }^{7}$ Please note: All interviews, protocols and coding schemes were translated from Dutch into English for this dissertation
} 
Goal of the Interview. I would like to discuss your personal experiences; so how, in your current or past job functions, you experienced dual allegiance and what the consequences were for the team's functioning.

\section{Interview Questions}

\section{Occurrence of dual allegiance}

Do you consider dual allegiance a familiar phenomenon in your work?

If so, how does dual allegiance manifest itself in your daily responsibilities? Could you give a practical example?

Could you give an example of a situation in which dual allegiance emerged into a social identity conflict as described above?

\section{Factors influencing the experience of dual allegiance}

To your opinion, what aspects within the MT influence how you experience dual allegiance?

Do you identify with the organizational groups you are a member of?

Do you experience a difference in the extent of identification with these organizational groups?

When in the management team, do you experience tensions based on differences in identification with organizational groups?

How would you typify this tension, as a tension or as conflict?

Could you give a practical example of such a tension / conflict?

\section{Impact on attitude and behavior}

If you are aware of an internal tension based on differences in identification, does this influence your attitude and/or behavior within the team?

In what manner did this influence your behavior towards team members?

Could you describe a situation in which the tension did affect your attitude and/or behavior?

Did you experience this tension in identification differences to affect other people's attitudes and/ or behaviors in the team?

\section{Team functioning}

How do you perceive your role within the team regarding the representation of the interests of the overarching organization and your own organizational unit? Does your job role change when attending / leaving a management team meeting. In what manner?

During a management team meeting, do you feel team member or (unit) director? Is it possible to split these roles?

Do you experience a difference in identification with the roles you execute? If you experience such a tension, what are your strategies to solve it? You have a leading position yourself, how do you perceive your role as team leader within the team? 
Appendix

In general, what should be the function of the team leader in terms of team functioning?

\section{Closing}

Thank you very much for your participation

Do you know others who may find it interesting to share their thoughts on this topic? 


\section{APPENDIX B}

\section{Interview Protocol Chapter 4}

\section{Explanation of goals interview in relation to observation study:}

Based on the analysis of the video observation in the months before, we have constructed a picture about the team's interactions. The purpose of the interviews is to check our ideas regarding the functioning of the team and to gain more insights on why we see what we see. In essence we are interested in how you as MT member perceive your MT role.

We will start the interview by showing you 2 fragments from the video observation data of $3 / 4$ minutes each. These fragments we consider characteristic for how the MT is functioning. We would like you to describe and comment on what you in these two fragments.

Furthermore, we have prepared some questions related to your experiences and perceptions concerning your role as MT member.

The results of the interview will be treated confidentially and will only be used for research purposes.

\section{Questions Related to Video Scenes}

In front of you, on the table, you see a voice recording device with which we would like to record the conversation as this eases the transcription and analysis process. Do you allow this interview to be voice recorded?

Let's start with the first video fragment.

This video fragment is drawn from the 2nd Meeting I observed (Description of situation before the specific video fragment).

\section{After video fragment:}

What have you seen happening in this fragment?

Now I would like to show you the second video fragment

This video fragment is drawn from the 4th Meeting I observed (Description of situation before the specific video fragment).

\section{After video fragment:}

What have you seen happening in this fragment?

\section{Interview Questions:}

\section{MT member's perception of their MT role}

How do you perceive your role as MT member?

How do you perceive your role as operation manager, member of central directorate, chair?

What is, according to you, the role of the chair person and its staff? 
Appendix

\section{Perception of tension between various MT roles}

How would you define your functional responsibilities as operation manager?

How would you define your functional responsibilities as MT member?

How do these job roles match?

Do you perceive a difference between the different job roles?

How do you deal with these differences?

Through what perceptual lens do you see your role as MT member? Through the lens of operation manager, member of central directorate, chairperson, or MT member?

Do you feel more attached to the MT, or operational unit, central directorate?

Do you feel involved with what happens in the MT?

Is the job role you expect in the MT, the job role you can execute? Why, Why not?

\section{Perception about the future}

According to you, what does the team need to function effectively?

How would you adapt your own behavior?

Can you describe a situation in which the MT functioned well?

What was different in those situations in comparison to situations the team functioned worse?

Why do you believe it is important to have a good functioning team?

What behavior should you have to change?

\section{Coding Scheme MT Meetings Chapter 4:}

Behavioral Integration Scale (Hambrick, 1994; Simsek et al., 2005)

Information Exchange (Simsek et al., 2005): the quality and quantity of the exchanged information;

\section{Table 1: Measure for Information Exchange}

( $1=$ Totally Disagree, $5=$ Totally Agree $)$

In the complete agenda item team members predominantly share information with each other

Joint Decision Making (based on Simsek et al., 2005): Team members make decisions based on a mutually based understanding of each other's problems and needs;

2. The decision has been made "outside" the team and is only communicated to the other team members. Team members are not aware of each other's range of duties (e.g. responsibilities and activities), nor have a clear understanding of the universal needs and problems of other team members.

3. The decision has been made "outside" the team and is only communicated to the other team members. Team members show clearly what they think about the decision and what consequences the decision will have for their personal responsibilities. The team does not have a clear understanding of the universal needs and problems of other team members. 
4. The decision has not yet been made and team members share their ideas, expertise and or expectations with each other. The team creates no clear understanding of the universal needs and problems of other team members and does not incorporate the different viewpoints in a (possible) decision.

5. The decision has not yet been made and team members share their ideas, expertise and or expectations with each other. The team creates an understanding of the universal needs and problems of other team members, but fails to incorporate the different viewpoints in a (possible) decision.

6. The decision has not yet been made and team members share their ideas, expertise and or expectations with each other. The team creates a clear understanding of the universal needs and problems of other team members and incorporates the different viewpoints in a (possible) decision.

Collaborative Behavior (Simsek et al., 2005): Mutual influence of persons via open and direct communication, solving conflicts and support of each other;

\section{Table 2: Measure for Collaborative Behavior}

(1= Totally Disagree, $5=$ Totally Agree $)$

Discussions are characterized by listening to each other

(react to what someone says; nodding; looking to someone)

Discussions are characterized by helping each other ("We can look at it together; We need to join forces!')



Team members help each other spontaneously (without asking)

Team members ask for help

Discussions are characterized by showing understanding for each other's ("I understand your passivity"; I understand your discontent (also non-verbal behavior)

Discussions are characterized by mutual support ("It's going great"; "Good Luck!"; "We can accomplish this together!)

Discussions are characterized by mutual misunderstandings

("You misunderstood me"; "That's not what I meant"; be at crosspurposes; repetition of answers or questions)

Discussions are characterized by defensive behavior ("No, you misunderstand me, because"; You're right, but ..."; non-verbal behavior)

Discussions are characterized by judging each other ("That's a wrong conclusion"; "you're wrong about this"; you're incorrect")

Discussions are characterized by criticizing each other ("I disagree"; " I would do this differently")

Discussions are characterized by interrupting each other 



\section{Dankwoord}




\section{DANKWOORD}

"Het schrijven van een wetenschappelijk artikel is net als tennis: je slaat de bal zo vaak op en neer totdat de tegenstander de bal niet meer terugslaat". In mijn eerste jaar als promovendus gebruikte Stewart Clegg deze beeldspraak om te beschrijven hoe hij de professie van wetenschappelijk onderzoek zag. Ruim vier jaar later kan ik hieraan toevoegen dat een dosis zelfdiscipline en een lange adem, net zoals in een echt potje tennis, erg goed van pas komen. Maar natuurlijk zijn ook de benodigde trainingsuurtjes, de begeleidende coaches, het team en ondersteunende fans tijdens het spelen van dit spel onmisbaar.

Mariëlle en Ursula, jullie hebben mij de kans gegeven om het proefschrift onder jullie begeleiding te mogen schrijven. Afgelopen jaren is er een mooie wisselwerking ontstaan en met jullie scherpe en kritische blik tijdens onze regelmatige bijeenkomsten heeft het project zich steeds verder ontwikkeld met als uiteindelijk resultaat deze pennenvrucht. Bedankt hiervoor!

Natuurlijk ook een woord van dank aan alle collega's van de afdeling Organisatie en Strategie. De vele lunchgesprekken, koffiepraat en onderzoeksseminars hebben zeker bijgedragen aan de motivatie om iedere dag met (meer of mindere) inspiratie de schuifdeuren van de Tongersestraat 53 binnen te gaan. Adela, Anita Mieke en Kitty, jullie ook bedankt; voor het regelen van de vele administratieve zaken betreffende het aio-schap, zeker in de laatste fase, maar ook voor de vele kortere of langere praatjes waarna ik weer helemaal op de hoogte was van het reilen en zeilen op de afdeling. Anita en Hetty dank voor de mooie mogelijkheid om mijn academische carrière in Maastricht voort te zetten.

Het schrijven van een proefschrift is vele malen gemakkelijker met een aangenaam team. Andrea, Anneloes, Antonio, Daniela, Hans, Li Jia ,Omar en Sarah, bedankt voor alle proefschrift en niet-proefschrift gerelateerde adviezen en het kunnen stoomafblazen wanneer dat nodig was. Anant, my Indian friend, thanks for the introduction to delicious vegetarian Indian food. Though the preparation time of the food is beyond any Dutch kitchen norms your company surely compensated for this.

Bovendien was er niet alleen aandacht voor de wetenschappelijke en intellectuele ontwikkeling, maar zeker ook voor de sociale en sportieve bezigheden. Anneloes, Myrthe, Charlotte, Sjir en Hannes dank voor de "peer-pressure" om iedere dinsdagavond in hardloopmodus de Sint-Pietersberg te beklimmen! Een gezonde geest in een gezond lichaam!

Evenzeer, hebben vele tennisuurtjes bijgedragen aan een gezonde dosis ontspanning door inspanning! Peter, Rob, Bart en Jan het was telkens weer een groot plezier om deel uit te mogen maken van een prachtteam. Elke training of competitiedag zorgde ervoor 
dat ik mij met een opgeladen batterij en mentaal fris (maar meestal met spierpijn), weer op mijn onderzoek kon storten.

Verder was dit proefschrift niet mogelijk geweest zonder de medewerking van Tanno Bregonje die deuren heeft geopend om, met videocamera, de gebeurtenissen binnen de bestuurskamer te kunnen documenteren. Natuurlijk ook dank aan alle leidinggevenden die bereid waren hieraan mee te werken en tijd vrij te maken om met mij van gedachten te wisselen over het onderzoeksonderwerp.

Goede voorbeelden zijn natuurlijk ook nodig voor vooruitgang tijdens het schrijven van een proefschrift. Hannes, Katrin bedankt voor het van dichtbij mogen ervaren hoe je, door intensief samenwerken en veel plezier, efficiënt en effectief een boeiend artikel kunt schrijven. Een prachtvoorbeeld van hoe een idee onder het genot van een "zingende blondine" en een "echte kerel" tot een publicatie kan leiden.

Zoals in tennis een vaste trainingspartner van onschatbare waarde is, is dat niet anders als promovendus. Sjir, zoals je zelf al aangaf is een buddysysteem ideaal om ideeën en vaardigheden te kunnen ontwikkelen en verwezenlijken. Een betere buddy had ik de afgelopen jaren niet kunnen wensen. Als kamergenoten hebben we vele uren op het werk, maar ook daarbuiten doorgebracht. Jouw scherpe en weldoordachte opmerkingen wanneer de inspiratie- of ideeënbron weer eens dreigde op te drogen, heb ik altijd zeer gewaardeerd.

Hannes en Sjir, als partners in onderzoek, shenanigans, schwarzwalder kirschtorten, en lekker eten (zonder kaarslicht maar met whisky en whiskey), hebben we de afgelopen jaren een bijzondere band opgebouwd op zowel professioneel als persoonlijk vlak. Hopelijk houdt deze op beide vlakken nog lang stand!

Lieve vrienden en familie, bedankt voor jullie altijd oprechte belangstelling in mijn bezigheden in Maastricht. Nu ben ik echt klaar met mijn "studie".

Papa en mama, jullie speciaal bedankt voor de ongelimiteerde steun en liefde, en het creëren van de randvoorwaarden en alle mogelijkheden die onder andere hebben geleid tot dit proefschrift. Merel, ook jii bedankt voor de onveranderlijke interesse en steun de afgelopen jaren.

Tot slot, lieve Lieveke, wat is het leven leuk geworden sinds wij elkaar weer ontmoet hebben! Dank je wel voor het mij wijzen op de schoonheid van de kleine dingen in het leven en het organiseren van de vele gezellige uitjes die zorgen voor de nodige ontspanning en relativering. Ik ben me er terdege van bewust dat het samenleven met iemand die zijn proefschrift schrijft niet altijd even gemakkelijk is. Ik heb er echter alle vertrouwen in dat wij de duale loyaliteiten waar wij mee geconfronteerd worden, perfect weten te managen! 

Curriculum Vitae 


\section{CURRICULUM VITAE}

Maarten Cuijpers was born on February 25, 1979 in Geleen, The Netherlands. He attended Scholengemeenschap Sint Michiel in Geleen, where he graduated in 1997. Subsequently, he started his study in International Business at Maastricht University. During his studies he was a visiting undergraduate student at the Universidad del Pacifico de Lima in Peru. He graduated and obtained his M.Sc. in International Business in 2003. From 2003 till 2007 he was employed as a junior lecturer at the department of Organization and Strategy at the Maastricht School of Business and Economics. In the meantime, he studied Social Psychology at the Radboud University in Nijmegen where he obtained his B.Sc. in Social Psychology in 2006. In January 2007, Maarten started his dissertation research at the department of Organization and Strategy at the Maastricht University School of Business and Economics. Currently, Maarten works as a post-doctorate researcher at the same department.

\section{PUBLICATION}

Cuijpers, M., Günter, H. \& Hussinger, K. 2011. Costs and Benefits of Interdepartmental Innovation Collaboration, Research Policy, 40 (4): 565-575 